\title{
Field Observations and Numerical Model Simulations of a Migrating Inlet System
}

\author{
by \\ Julia A. Hopkins \\ B.S. Massachusetts Institute of Technology (2012) \\ Submitted to the Joint Program in Applied Ocean Science \& Engineering \\ in partial fulfillment of the requirements for the degree of \\ Doctor of Philosophy \\ at the \\ MASSACHUSETTS INSTITUTE OF TECHNOLOGY \\ and the \\ WOODS HOLE OCEANOGRAPHIC INSTITUTION
}

September 2017

C2017 Julia A. Hopkins. All rights reserved.

The author hereby grants to MIT and WHOI permission to reproduce and to distribute publicly paper and electronic copies of this thesis document in whole or in part in any medium now known or hereafter created

Author

Joint Program in Oceanography/Applied Ocean Science \& Engineering Massachusetts Institute of Technology \& Woods Hole Oceanographic Institution August 18, 2017

Certified by

Steve Elgar Senior Scientist, Applied Ocean Physics and Engineering Woods Hole Oceanographic Institution Thesis Supervisor

Accepted by

Jesse Kroll Professor of Civil and Environmental Engineering Chair, Graduate Program Committee

Accepted by

Henrik Schmidt

Chairman, Joint Committee for Applied Ocean Science \& Engineering Massachusetts Institute of Technology Woods Hole Oceanographic Institution 


\title{
Field Observations and Numerical Model Simulations of a Migrating Inlet System
}

\author{
by \\ Julia A. Hopkins \\ Submitted to the Joint Program in Oceanography/Applied Ocean Science \& Engineering \\ Massachusetts Institute of Technology \& Woods Hole Oceanographic Institution on August 18, \\ 2017, in partial fulfillment of the requirements for the degree of Doctor of Philosophy
}

\begin{abstract}
Waves, currents, and bathymetric change observed along $11 \mathrm{~km}$ of the southern shoreline of Martha's Vineyard include storm events, strong tidal flows $(>2 \mathrm{~m} / \mathrm{s})$, and an inlet migrating 2.5 $\mathrm{km}$ in $\sim 7$ years. A field-verified Delft3D numerical model developed for this system is used to examine the hydrodynamics in the nearshore and their effect on the migrating inlet. An initial numerical experiment showed that the observed $70^{\circ}$ tidal modulation of wave direction in the nearshore was owing to interactions with tidal currents, and not to depth-induced refraction as waves propagated over complex shallow bathymetry. A second set of simulations focused on the separation of tidal currents from the southeast corner of Martha's Vineyard, showing the positive correlation between flow separation and sediment transport around a curved shoreline.

Observations of waves, currents, and bathymetric change during hurricanes were reproduced in a third numerical experiment examining the competition between storm waves, which enhance inlet migration, and strong tidal currents, which scour the inlet and reduce migration rates. The combined field observations and simulations examined here demonstrate the importance of wave and tidal current forcings on morphological evolution at timescales of days to months.

Thesis Supervisor: Steve Elgar

Title: Senior Scientist, Applied Ocean Physics and Engineering

Woods Hole Oceanographic Institution
\end{abstract}




\section{Acknowledgements}

First and foremost, I give sincere thanks to Steve Elgar and Britt Raubenheimer. Steve, I had every intention of leaving Boston for graduate school until you contacted me in the spring of 2012 and convinced me to be a part of the PVLAB. For the past five years, your guidance made my graduate school experience one of the best I can imagine. Thank you for being one of the easiest advisors I know to get in touch with and talk to about work and life. Thank you for your encouragement and for helping me see this work to fruition. Britt, thank you for being a constant support, a wealth of good ideas, and much-needed voice of reason in the murky waters of numerical simulations.

Without the encouragement and help from the rest of the PVLAB, the field work of this thesis would not have been possible. In particular, Mara, thank you for being my field site buddy and for taking the journey to understand Katama Bay with me. Anna, thank you for being an amazing travel buddy (I will miss our coffee/chocolate/bookstore forays!). Levi, without you absolutely none of the field observations would be as helpful as they were to this project. Thank you so much; you have convinced me you are a magician. Thank you to the rest of the field crew, past and present, for data collection around Katama Bay over numerous years. Thank you to Jeff Hansen and everyone who helped me figure out how to get Delft3D running properly.

Thank you to my committee, which included Heidi Nepf, Eric Adams, and Tom Hsu. You always had open doors for my questions and pushed me to dig deeper and made sure this thesis became the best possible.

Thank you to my family, who provided unceasing support all the years I have been in Boston. Mom and Dad, you have helped me keep a healthy perspective during the grad process and were always present to help as I struggled with physical injuries during an already intensive $\mathrm{PhD}$ process. I cannot thank you enough. Jim and Meg, thank you for putting up with your middle sibling (hi) and for showing me all the wonderful things about the world outside of academia. It has been wonderful to see all of us grow in our own passions, and I have you to thank for my appreciation of the beauty and music outside of this academic bubble. I love you all and look forward to returning to NYC with a way to help combat rising sea levels outside the New York harbor.

I give sincere thanks to the friends who have been here throughout my journey in Boston, those who stayed with me after undergraduate at MIT (especially Charles, Cynthia, Julian, Michael) and those who I met and grew with during this grad process (Adam, Dane, Jay, Maha, Al, among many others). You all matched my insanity with your own, and without you I would not have stayed grounded enough or happy enough to see this process through.

I give special thanks to the students of D Entry, my home for the last bit of my graduate career. I have found that I perform at my best when I can give back to some greater community, and the MIT undergrads in D Entry taught me more than I could have imagined. I wish you all only the best in your budding careers of discovery. 
Thank you to my funding sources who made this work possible, including the Office of Naval Research, the National Science Foundation, the National Defense Science and Engineering Grant, the MIT Presidential Fellowship, and Sea Grant. 


\section{Contents}

$\begin{array}{lr}\text { Introduction } & 8\end{array}$

1. Motivation: Inlets and Coastal Management.................................... 8

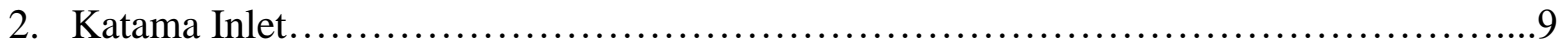

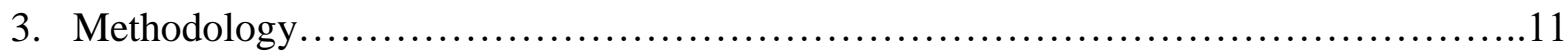

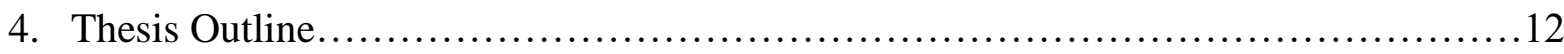

Chapter 1: Observations and model simulations of wave-current interaction on the inner

$\begin{array}{ll}\text { shelf } & 15\end{array}$

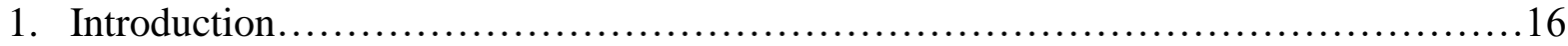

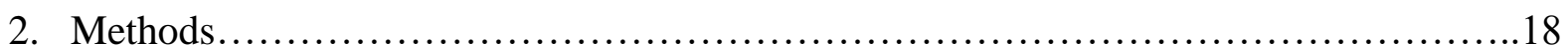

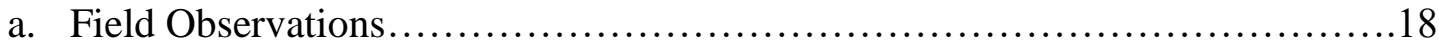

b. Numerical Model............................................................

3. Results............................................................... 25

a. Model-Data Comparison.............................................. 25

b. Simulations of Wave-Current Interaction................................ 31

c. Wave Direction in Shallow Water.......................................... 33

4. Conclusions .................................................................. 37

Chapter 2: Flow separation effects on shoreline sediment transport 43

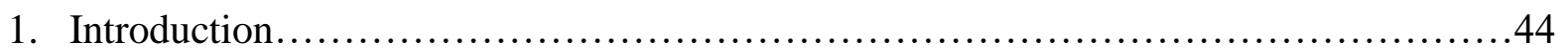

2. Numerical Simulations..................................................... 47

3. Results and Discussion.................................................. 49

Chapter 3: Storm Impact on Morphological Evolution of a Sandy Beach 60

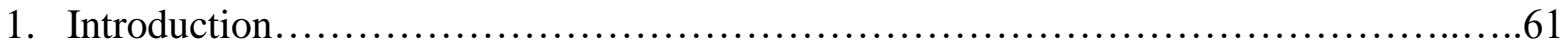




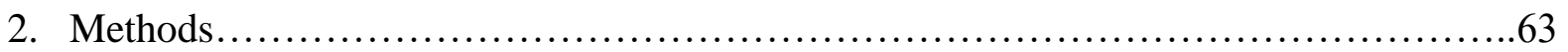

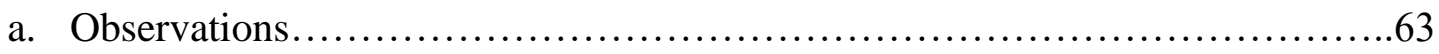

b. Numerical Simulations of Sediment Transport.................................64

c. Calibration of Model Sediment Transport..................................68

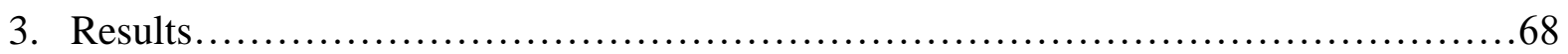

a. Validation of Hydrodynamics...............................................6

b. Validation of Morphodynamics.......................................... 70

c. Storm Impact on Morphology on Day to Week Timescales.......................72

d. Storm Impact on Morphology on Monthly Timescales.........................77

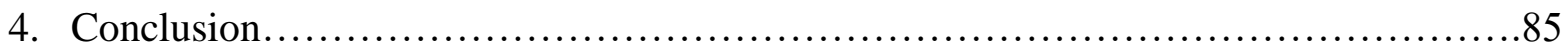

$\begin{array}{lr}\text { Conclusions and Future Work } & 92\end{array}$

Appendix 1: Sediment Transport Implementation in Delft3D 96

$\begin{array}{lr}\text { Appendix 2: Delft3D Morphodynamic Validation } & 104\end{array}$

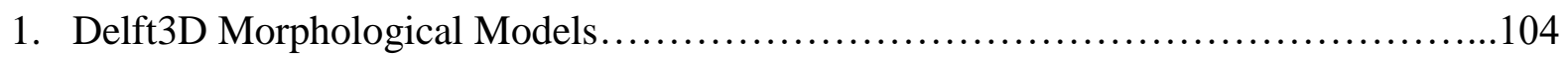

2. Metrics for Validation........................................................ 105

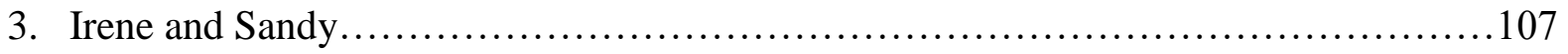

4. Coefficient Calibration........................................................... 108

5. Boundary Condition Calibration................................................. 109

6. Calibration to Full Observation Period.................................................110

$\begin{array}{lr}\text { Appendix 3: Wave Reduction Method } & 114\end{array}$ 


\section{Introduction}

\section{Motivation: Inlets and Coastal Management}

The livelihoods of the millions of people living within $100 \mathrm{~km}$ of a coastline (over $30 \%$ of the population in the U.S.A alone) [Ache et al., 2015] depend on the ability of coastal managers to plan for shoreline response to big waves and strong currents, especially as sea levels rise and storms intensify. At present, there is no systematic method to predict shoreline evolution given nearshore hydrodynamic conditions. State-of-the-art equations used to calculate sediment transport owing to waves and currents include several "tuning" parameters to match predicted with observed sediment transport [Amoudry and Souza, 2011]. Tuning allows for reasonable transport forecasts at individual sites with field observations, but has limited universal applicability, especially in regions lacking observations. More field observations, coupled with numerical sediment transport predictions, are needed to understand the nature of shoreline evolution and to develop more universal transport equations.

Dynamic coastal environments such as inlets can be studied over relatively short timescales (months to years) to investigate sediment transport in the field. Inlets are ubiquitous around the world on sandy beaches [Mcninch and Luettich, 2000; Fitzgerald and Pendleton, 2002; Bertin et al., 2009; Chaumillon et al., 2014], and often are associated with harbors, estuaries, aquaculture, recreation, and a range of ecosystem services and associated societal benefits. Maintaining an inlet for human use often requires expensive dredging of the inlet channel or nourishment of neighboring beaches [Galgano, 2009], costing millions of dollars per year [Parsons and Powell, 2001; Williams and Micallef, 2009]. With better knowledge of sediment transport, these 
activities could be targeted to maximize the desired impact on the inlet system, while minimizing cost.

This thesis seeks to improve the understanding of nearshore sediment transport by focusing on a sandy beach system along the southern shoreline of Martha's Vineyard, Massachusetts, U.S.A.

(Figure 1), which is characterized by a migrating inlet. Field data and a numerical model of this dynamic coastal environment allow for detailed study of the interaction between waves, currents, and sediment transport in the nearshore.

\section{Katama Inlet}

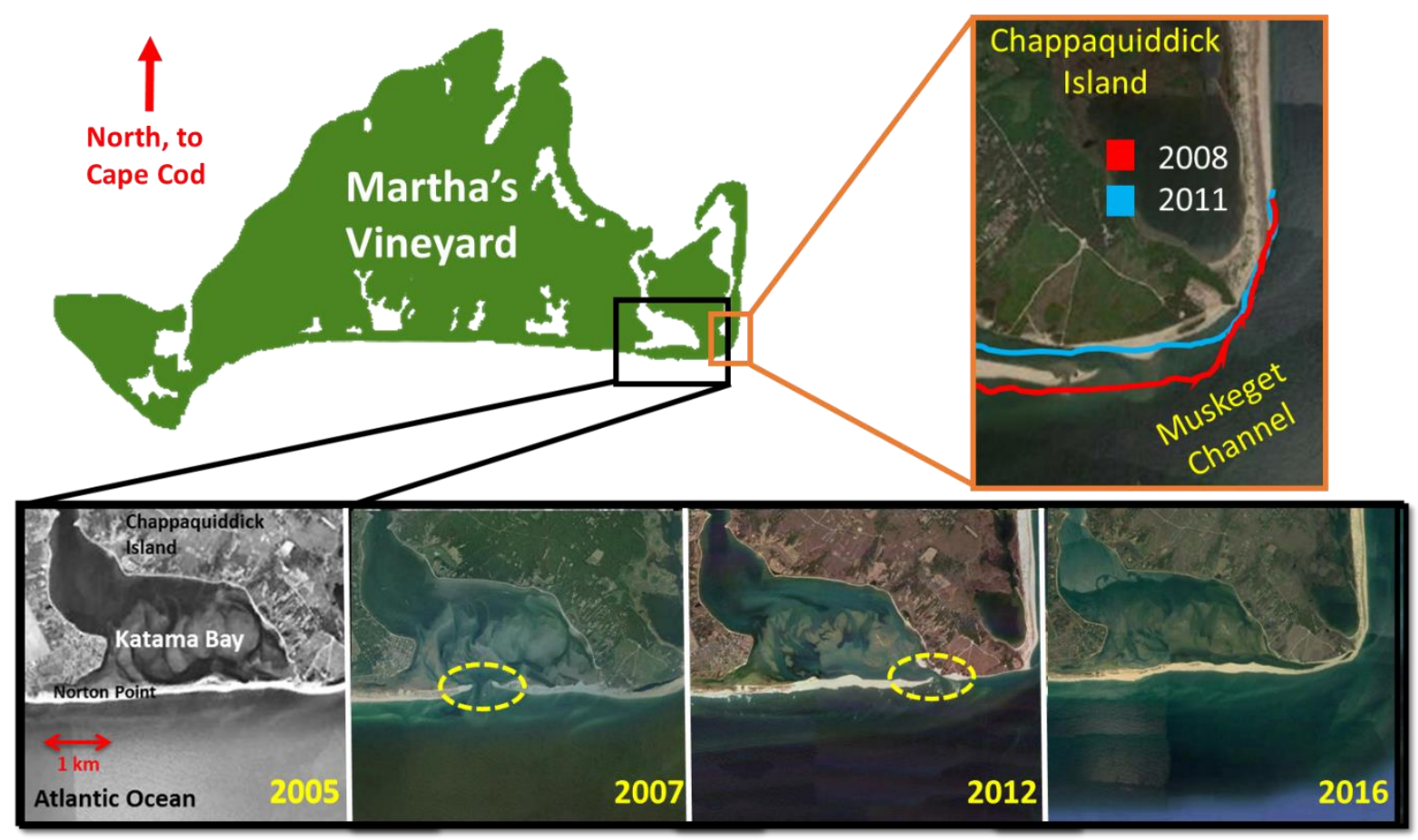

Figure 1: Martha's Vineyard, MA (green island) highlighting (black box) Katama Bay and (orange box) Chappaquiddick Island. Satellite images outlined in black show the progression of Katama Inlet (yellow circle) from 2005 to 2016 (years in lower right). Colored curves within the orange box (upper right) show the rapid erosion of the corner of the island from (red curve) 2008, (blue curve) 2011, and (satellite image in the background) 2014. 
The transient southern inlet of Katama Bay in Martha's Vineyard, MA provides an ideal case study of wave-current interaction and sediment transport. In a decadal cycle, the inlet opens during a large storm, migrates to the east, and closes upon reaching Chappaquiddick Island (Figure 1) [Ogden, 1974; Dunlop, 2013]. When the inlet is present it turns the Bay, which always is open to the north via Edgartown Channel, into a passage for tidal flow between Vineyard Sound and the Atlantic Ocean. Although the resulting tidal currents through the Bay strain moorings at Edgartown Marina, they also improve navigation to the Atlantic and water quality for the Bay shellfish farms [Arpin, 1970]. When the inlet is closed (sometimes for decades), the Bay becomes stagnant, and engineered attempts to improve Bay water quality have been unreliable. The 1937 artificial inlet lasted for more than a year, but most others $(1873,1919$, 1932) closed in less time [Dunlop, 2013].

The Katama system is an example of how a coastal environment responds to regular oceanic forcing, such as tides and waves, as well as to more powerful, but irregular forcing, such as strong flows and big waves that occur during storms. Previous studies in the Martha's Vineyard area have focused on inner shelf dynamics south of the island, using numerical model simulations ([Ganju and Sherwood, 2010; Ganju et al., 2011] and many others) to explain tidal controls on tidally rectified recirculation. Extensive field measurements within Katama Bay have been used to study the impact of storm-force waves on flows out of the Bay [Orescanin et al., 2014]. This thesis adds to the understanding of Katama and other coastal sandy systems by focusing on the nearshore region in and offshore of Katama Inlet, using field observations of waves, currents, and bathymetry in addition to numerical simulations to study the hydro- and morphodynamics of the system. 


\section{Methodology}

Field experiments conducted by the WHOI PVLAB in the summers of 2011-2016 used a suite of techniques to observe hydro- and morphodynamics around Katama Inlet. Acoustic Doppler current profilers (ADCPs) were used in water depths $>2 \mathrm{~m}$ to measure waves and profiles of currents, whereas Acoustic Doppler Velocimeters (ADVs, wave and current meters) were used in water depths $<2 \mathrm{~m}$ to measure wave properties and currents. The pressure gages deployed with the ADCP and ADV sensors also measured water level for tidal analysis. These sensor suites were augmented with small boat-mounted ADCP transects to obtain measurements of the vertical distribution of velocity along the ship track. To supplement the temporary deployments, waves and currents were measured nearly continuously at the Martha's Vineyard Coastal Observatory (MVCO), just offshore of the Katama study site.

Small boats with GPS and an acoustic altimeter were used to measure the nearshore bathymetry, and a hand pushed dolly was used to measure subaerial topography. Bathymetry measurements of the larger MV and Nantucket system were collected by the USGS. In addition, satellite images of Katama Inlet were used to supplement the approximately twice yearly nearshore bathymetric surveys.

A Delft3D FLOW-WAVE model was used to expand the spatial and temporal scales of the field data. Delft3D was designed to simulate surfzone hydrodynamics and sediment transport, and thus is an appropriate choice for the work presented here. The model has skill predicting nearshore hydrodynamics ([Elias et al., 2000; Treffers, 2008], and many others), the bulk 
properties of sediment transport around San Francisco Bay [Erikson et al., 2013], the evolution of beach bathymetry [Aarninkhof et al., 2006], and to study inlet migration [Tung et al., 2009], tidal channel evolution [Xie et al., 2009], and beach nourishment [Grunnet et al., 2004]. The extensive observations of tides, winds, waves, currents, and bathymetry near Katama Bay provide a unique opportunity to implement, test, and calibrate the model to learn more about shoreline response to oceanic forcing.

\section{Thesis Outline}

This thesis is divided into three chapters investigating nearshore hydrodynamics and sediment transport owing to wave-current interaction, large-scale flow separation, and storm intensity. Chapter 1 studies the impact of tidal currents on wave direction and details the field observations that are used to validate model hydrodynamics. It describes how wave interactions with strong inner shelf tidal flows result in large modulations to the directions of the wave field. Chapter 2 describes observations and model simulations of currents and sediment transport around the curved shoreline of the island. The combination of observations and numerical experiments suggest the importance of flow separation to nearshore sediment transport. Chapter 3 focuses on the impact of storms on inlet migration on timescales of days and of months, investigating the competing effects of waves and currents and the impact of storm clusters. In all chapters, field observations provide the foundation for simulations of both realistic and idealized inlet systems used to investigate the interdependence of waves, currents, and morphological evolution at this dynamic coastal environment. 


\section{References}

Aarninkhof, S., K. Wijnberg, D. Roelvink, and A. Reniers (2006), 2DH-Quantification of Surf Zone Bathymetry from Video, Coast. Dyn. 2005, 1-14, doi:10.1061/40855(214)64.

Ache, B. W., K. M. Crossett, P. A. Pacheco, J. E. Adkins, and P. C. Wiley (2015), "The Coast" is Complicated: A Model to Consistently Describe the Nation's Coastal Population, Estuaries and Coasts, 38(S1), 151-155, doi:10.1007/s12237-013-9629-9.

Amoudry, L. O., and A. J. Souza (2011), Deterministic Coastal Morphological and Sediment Transport Modeling: a Review and Discussion, Rev. Geophys., 49, 1-21, doi:10.1029/2010RG000341.1.INTRODUCTION.

Arpin, O. E. (1970), Tidal Inlet Problems Along the New England Coast, in Coastal Engineering 1970, pp. 1171-1185, American Society of Civil Engineers, New York, NY.

Bertin, X., A. B. Fortunato, and A. Oliveira (2009), A modeling-based analysis of processes driving wave-dominated inlets, Cont. Shelf Res., 29(5-6), 819-834, doi:10.1016/j.csr.2008.12.019.

Chaumillon, E., F. Ozenne, X. Bertin, N. Long, and F. Ganthy (2014), Wave climate and inlet channel meander bend control spit breaching and migration of a new inlet: La Coubre Sandspit, France., J. Coast. Res., (special issue), doi:10.2112/SI65-xxx.1.

Dunlop, T. (2013), Revised: A History of the Openings (and Closings) Through Norton Point, Pers. Commun.

Elias, E. P. L., D. R. Walstra, J. A. Roelvink, M. J. F. Stive, and M. D. Klein (2000), Hydrodynamic validation of Delft3D with field measurements at Egmond, Coast. Eng. 2000, 2714-2727.

Erikson, L. H., S. a. Wright, E. Elias, D. M. Hanes, D. H. Schoellhamer, and J. Largier (2013), The use of modeling and suspended sediment concentration measurements for quantifying net suspended sediment transport through a large tidally dominated inlet, Mar. Geol., 345, 96-112, doi:10.1016/j.margeo.2013.06.001.

Fitzgerald, D. M., and E. Pendleton (2002), Inlet Formation and Evolution of the Sediment Bypassing System : New Inlet, Cape Cod, Massachusetts, J. Coast. Res., 299(36), 290299.

Galgano, F. a (2009), Beach Erosion Adjacent To Stabilized Microtidal Inlets, Middle States Geogr., 42(1977), 18-32.

Ganju, N. K., and C. R. Sherwood (2010), Effect of roughness formulation on the performance of a coupled wave, hydrodynamic, and sediment transport model, Ocean Model., 33(3-4), 299-313, doi:10.1016/j.ocemod.2010.03.003.

Ganju, N. K., S. J. Lentz, A. R. Kirincich, and J. T. Farrar (2011), Complex mean circulation 
over the inner shelf south of Martha's Vineyard revealed by observations and a highresolution model, J. Geophys. Res., 116(C10), C10036, doi:10.1029/2011JC007035.

Grunnet, N. M., D.-J. R. Walstra, and B. G. Ruessink (2004), Process-based modelling of a shoreface nourishment, Coast. Eng., 51(7), 581-607, doi:10.1016/j.coastaleng.2004.07.016.

Mcninch, J. E., and R. A. Luettich (2000), Physical processes around a cuspate foreland : implications to the evolution and long-term maintenance of a cape-associated shoal, Cont. Shelf Res., 20, 2367-2389.

Ogden, G. (1974), Shoreline Changes Along the Southeastern Coast of Martha's Vineyard, Massachusetts for the Past 200 Years, Quat. Res., 4, 496-508.

Orescanin, M., B. Raubenheimer, and S. Elgar (2014), Observations of wave effects on inlet circulation, Cont. Shelf Res., 82, 37-42, doi:10.1016/j.csr.2014.04.010.

Parsons, G. R., and M. Powell (2001), Measuring the Cost of Beach Retreat, Coast. Manag., 29(2), 91-103, doi:10.1080/089207501750069597.

Treffers, R. (2008), Wave-Driven Longshore Currents in the Surf Zone.

Tung, T. T., D. R. Walstra, J. Van De Graaff, and M. J. F. Stive (2009), Morphological Modeling of Tidal Inlet Migration and Closure, in Journal of Coastal Research, vol. Special Is, pp. $1080-1084$.

Williams, A., and A. Micallef (2009), Beach Management: Principles and Practice, Earthscan, London.

Xie, D., Z. Wang, S. Gao, and H. J. De Vriend (2009), Modeling the tidal channel morphodynamics in a macro-tidal embayment, Hangzhou Bay, China, Cont. Shelf Res., 29(15), 1757-1767, doi:10.1016/j.csr.2009.03.009. 


\title{
Chapter 1:
}

\section{Observations and model simulations of wave-current interaction on the inner shelf ${ }^{1}$}

\begin{abstract}
Wave directions and mean currents observed for two 1-month-long periods in 7- and 2-m water depths along $11 \mathrm{~km}$ of the southern shoreline of Martha's Vineyard, MA have strong tidal modulations. Wave directions are modulated by as much as $70^{\circ}$ over a tidal cycle. The magnitude of the tidal modulations to the wave field decreases alongshore to the west, consistent with the observed decrease in tidal currents from 2.1 to $0.2 \mathrm{~m} / \mathrm{s}$ along the shoreline. A numerical model (SWAN and Deflt3D-FLOW) simulating waves and currents reproduces the observations accurately. Model simulations with and without wave-current interaction and tidal depth changes demonstrate that the observed tidal modulations of the wave field primarily are caused by wavecurrent interaction and not by tidal changes to water depths over the nearby complex shoals. Simulations further show that the direction of tidally averaged wave-driven alongshore transport in the surfzone primarily is owing to complex nearshore bathymetry and not wave-current interaction.
\end{abstract}

${ }^{1}$ Parts of this chapter have been published as: Hopkins, J., S. Elgar, and B. Raubenheimer (2016), Observations and model simulations of wave-current interaction on the inner shelf, J. Geophys. Res. Ocean., 121(1), doi:10.1002/2015JC010788.Used with permission as granted in the original copyright agreement. 


\section{Introduction}

Understanding wave propagation across the continental shelf to the shore is critical to predicting forces on shoreline structures, increases in wave-driven water levels, wave overtopping and flooding, dangerous wave-driven surfzone currents, wave-driven sediment transport, and beach erosion and accretion. As waves propagate (shoal) over increasingly shallow bathymetry, conservation of energy flux causes wave heights to become larger before breaking. Breaking waves dissipate energy while transferring momentum flux to the water column. In the surf zone, the time-averaged wave-driven forcing raises water levels near the shoreline [Longuet-Higgins and Stewart, 1964], producing alongshore varying sea levels and currents [Apotsos et al., 2008; Shi et al., 2011; Hansen et al., 2015] and, in the case of obliquely incident waves, driving alongshore currents in the direction of wave propagation [Longuet-Higgins, 1970; Thornton and Guza, 1986; Guza et al., 1986; Feddersen et al., 1998; and many others]. The wave-orbital velocities and wave-generated mean currents can transport sediment and act as a mechanism for shoreline evolution [Fredsoe and Deigaard, 1992; van Rijn, 1993; Amoudry and Souza, 2011; references therein; and many others].

The energy and direction of waves propagating across the continental shelf to the shore are affected by the bathymetry and by currents, both of which cause shoaling and refraction. Wave energy can be increased by shoaling and decreased by dissipative processes, including bottom friction, whitecapping, and depth-limited breaking. Depth-induced refraction increases with decreasing wave frequency and redirects wave crests to align with bathymetry in shallow water (potentially resulting in areas with wave focusing and shadowing), although breaking waves are 
not necessarily normally incident. Similarly, currents change wave height and direction by altering the wavenumber $k$, given by the linear dispersion relationship

$$
\sigma=\sqrt{g k \tanh (k h)}
$$

where $\sigma$ is the intrinsic wave frequency, $g$ is the gravitational acceleration, and $h$ is the water depth. A current $\boldsymbol{U}$ interacting with the wave field causes the intrinsic frequency to be Doppler shifted such that the apparent (e.g., observed) frequency $\omega$ becomes [Longuet-Higgins and Stewart, 1961; Wolf and Prandle, 1999]

$$
\omega=\sigma+\boldsymbol{k} \cdot \boldsymbol{U}
$$

which, by re-application of (1) to the Doppler-shifted frequency $\omega$ in place of $\sigma$, gives a new wavenumber. Changes in wavenumber cause changes to energy flux, $E C_{g}$, where $E$ is energy and $C_{g}=F(\omega, k)$ is the group velocity. Changes in wavenumber likewise affect wave direction, $\theta$. Similar to depth-induced changes, current-induced changes in $\theta$ (relative to the current direction) between two locations (A and B) are given by Snell's Law

$$
k_{A} \sin \left(\theta_{A}\right)=k_{B} \sin \left(\theta_{B}\right)
$$

There have been many investigations of current-induced wave height growth or decay, usually for the case of currents flowing in the same or opposite direction of the waves [Gonzales, 1984; Jonsson, 1990; Wolf and Prandle, 1999; Olabarrieta et al., 2011, 2014; Elias et al., 2012; and many others]. There are fewer observational studies of the current-induced changes in wave direction, partially because waves propagating into an opposing or following current $(\theta=$ $0^{\circ}$ or $180^{\circ}$ ), such as commonly occurs near strong jets from inlets, river mouths, and estuaries, do not change direction (Eq 3 ). The change in direction is maximum for angles near $\theta=45^{\circ}$, and increases with current speed and wave frequency (Eqs 1-3) [Wolf and Prandle, 1999]. 
Previously, tidal modulations of $+/-10^{\circ}$ have been observed in 12 - to $18-\mathrm{m}$ water depth for relatively high-frequency $(0.5 \mathrm{~Hz})$ waves [Wolf and Prandle, 1999] and in $11 \mathrm{~m}$ depth for swelldominated $(0.05-0.30 \mathrm{~Hz})$ wave fields [Hansen et al., 2013]. It was hypothesized that the modulation of the high-frequency wave direction was owing to tidal currents [Wolf and Prandle, 1999], and numerical simulations of one tidal cycle suggest the directional changes in the observed swell wave field likewise were owing to currents, not to tidal changes in water depth [Hansen et al., 2013]. Here, tidally modulated changes to wave heights and directions in 7- and 2-m water depths along an Atlantic Ocean shoreline are investigated with both observations from two 1-month long periods and numerical model simulations. Simulations with idealized timeinvariant wave boundary conditions are then used to determine the impact of the observed wavecurrent interaction on wave-driven sediment transport in the surf zone.

\section{Methods}

\section{a. Field Observations}

Water levels, waves, and currents were measured for approximately one month along $11 \mathrm{~km}$ of the southern shoreline of Martha's Vineyard, MA (Figure 1) in both August 2013 and JulyAugust 2014. In 2013 and 2014 along the 7-m depth isobath, 1-min mean current profiles in 0.5$\mathrm{m}$ high vertical bins between $0.5 \mathrm{~m}$ above the sea floor and the sea surface were obtained with Nortek $1 \mathrm{MHz}$ AWAC acoustic Doppler current profilers for 12 minutes every half hour, followed by $1024 \mathrm{~s}$ of $2 \mathrm{~Hz}$ samples of bottom pressure, sea-surface elevation (from a $1 \mathrm{MHz}$ vertical acoustic beam), and near-surface velocities to estimate wave characteristics. In 2013 an additional sensor was deployed in $12 \mathrm{~m}$ depth (Figure 1b), $8.8 \mathrm{~km}$ west of the eastern-most sensor located at $x=0 \mathrm{~km}$. In 2014, $2 \mathrm{~Hz}$ observations of currents ( $0.8 \mathrm{~m}$ above the seafloor) and 
near-bottom pressure were measured with $10 \mathrm{MHz}$ Sontek Triton acoustic Doppler velocimeters at 5 locations along the $2-\mathrm{m}$ depth isobath from $x=0$ to $x=3.3 \mathrm{~km}$ (Figure $1 \mathrm{c}$ ).

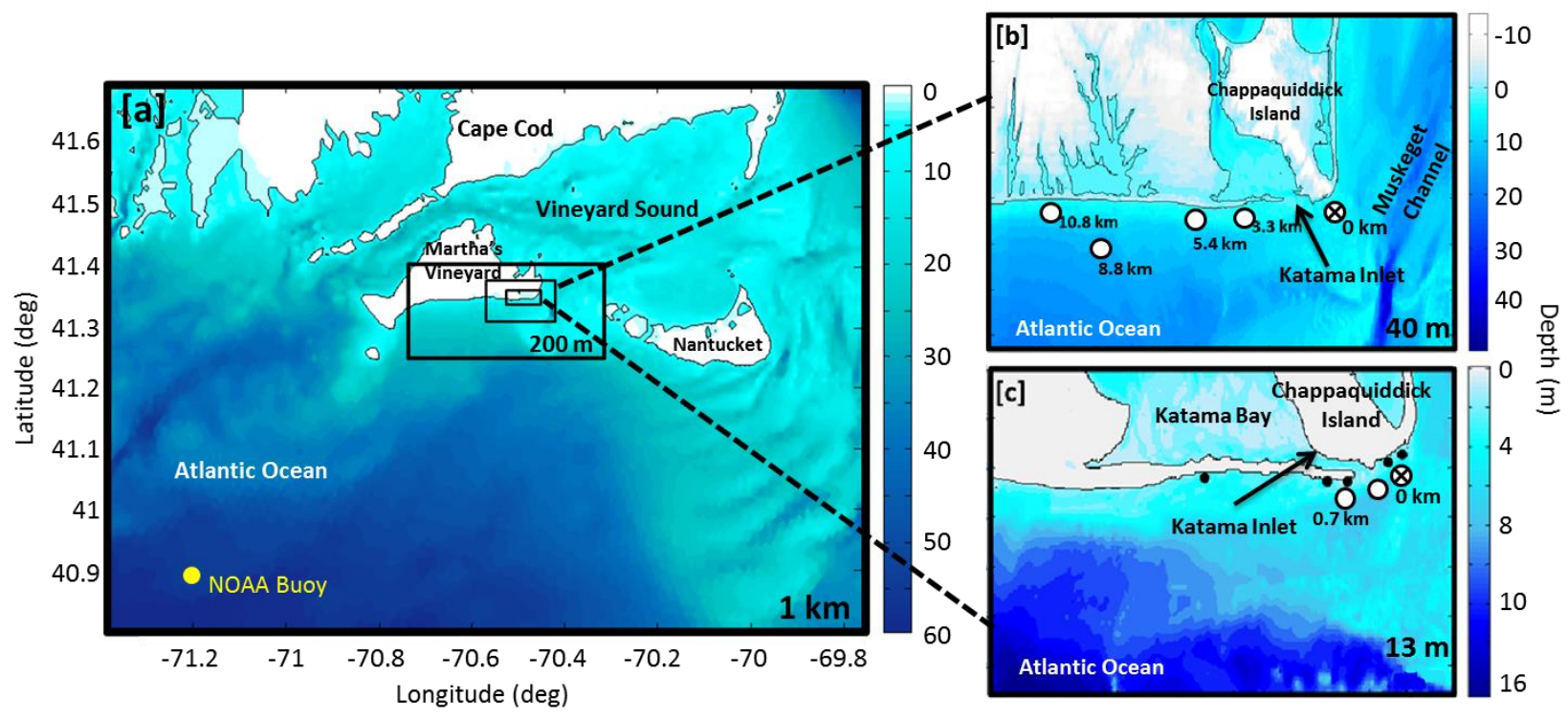

Figure 1: Bathymetry (color contours, scales on the right) and nested grids (black rectangular outlines) for (a) the full model domain, (b) the region near the shoreline of Martha's Vineyard, and (c) the inner grid near the shoreline. Open ( $7 \mathrm{~m}$ depth) and filled ( $2 \mathrm{~m} \mathrm{depth})$ circles are locations of colocated wave and current sensors. The 7-m depth sensors are labeled with their distance $(\mathrm{km})$ from the eastern-most sensor located at $x=0 \mathrm{~km}$ (open circle with " $X$ "). The sensor at $x=8.8 \mathrm{~km}$ was in $12 \mathrm{~m}$ depth. The yellow circle in (a) is NOAA buoy $44097(\sim 50 \mathrm{~m}$ depth). Spatial resolutions $(1000,200,40$, and $13 \mathrm{~m})$ are shown in the lower right-hand corner of each grid. The sensors in (b) were deployed in 2013, and the sensors in (c) were deployed in 2014. Bathymetric contours near the shoreline of the two inner-most grids are shown in Figure 6.

There was little vertical structure to the mean currents in 7 and $12 \mathrm{~m}$ depth except in the bottom and top $0.5 \mathrm{~m}$ high bins, so the interior bins were used to estimate depth-averaged flows. The two 12-min profiling periods every hour were combined to provide estimates of 1 -hr means of the depth-averaged currents. One-hr averages of the alongshore component of the single-point velocity measurements in $2 \mathrm{~m}$ depth are assumed to be representative of depth-averaged alongshore flows. The $2 \mathrm{~Hz}$ time series were used to estimate significant wave heights $\left(H_{\text {sig }}, 4\right.$ times the standard deviation of sea-surface fluctuations) and wave directions [Kuik et al., 1988] 
in the frequency $(f)$ band $0.05<f<0.30 \mathrm{~Hz}$. Bottom pressures were converted to sea-surface elevation using linear wave theory.

The bathymetry in the region is complex (Figure 1), including islands, shoals, and the rapidly migrating Katama Inlet [Ogden, 1974] that separates Katama Bay from the Atlantic Ocean. Bathymetric surveys of the shoreline, inlet channel, and ebb shoal near Katama Inlet were performed in summer 2013 and 2014 with a GPS and an acoustic altimeter mounted on a jetski. The horizontal resolution of the jetski surveys is on the order of $10 \mathrm{~m}$, with finer resolution near steep features. Additional bathymetry was obtained during 1998 and 2008 USGS surveys (Northeast Atlantic 3 arc second map [National Geophysical Data Center, 1999] and Nantucket 1/3 arc second map [Eakins et al., 2009]), and has horizontal resolution of 10 to $90 \mathrm{~m}$. The southern shoreline of Martha's Vineyard is oriented east-west (Figure 1). West of Katama Inlet, bathymetry contours, especially in depths less than $\sim 10 \mathrm{~m}$ are roughly parallel to the shoreline (Figure 1b). However, south and east of Katama Inlet and Bay, the bathymetry is cross- and alongshore inhomogeneous.

Offshore waves were measured in approximately $50 \mathrm{~m}$ depth with a Waverider buoy (Figure 1a, NOAA buoy 44097). Offshore waves were small to moderate $\left(H_{s i g}<2 \mathrm{~m}\right)$, usually coming from the south, southwest, or southeast (Figure 2). Tidal currents were more than $2.0 \mathrm{~m} / \mathrm{s}$ at the eastern-most 7-m depth sensor ( $x=0 \mathrm{~km}$, Figure 1$)$, and decreased to less than $0.2 \mathrm{~m} / \mathrm{s} 11 \mathrm{~km}$ to the west ( $x=10.8 \mathrm{~km}$, Figure 1b) (discussed below). Maximum tidal currents in $2 \mathrm{~m}$ depth also decreased from east $(0.8 \mathrm{~m} / \mathrm{s}$ at $x \sim 0 \mathrm{~km}$, Figure $1 \mathrm{c})$ to west $(0.2 \mathrm{~m} / \mathrm{s}$ at $x \sim 3.3 \mathrm{~km}$, Figure $1 \mathrm{~b})$. These observations are consistent with prior studies of tidal propagation in the region [Chen et 
al., 2011], including the phase difference between the $0.5 \mathrm{~m}$ amplitude tides in Vineyard Sound and the Atlantic Ocean, which drive tidal currents greater than $2 \mathrm{~m} / \mathrm{s}$ through Muskeget Channel (Figure 1). To the west of Muskeget Channel, tidal currents weaken and become east-west oriented [Chen et al., 2011]. The measured (and modeled) alongshore changes in the tidal modulation of currents, wave heights, and directions (discussed below) in 2- and 7-m water depths in 2014 are consistent with those in $7 \mathrm{~m}$ depth in 2013, suggesting that the westward decrease in tidal modulation is owing to a temporally constant spatial structure, not a change in behavior from 2013 to 2014.
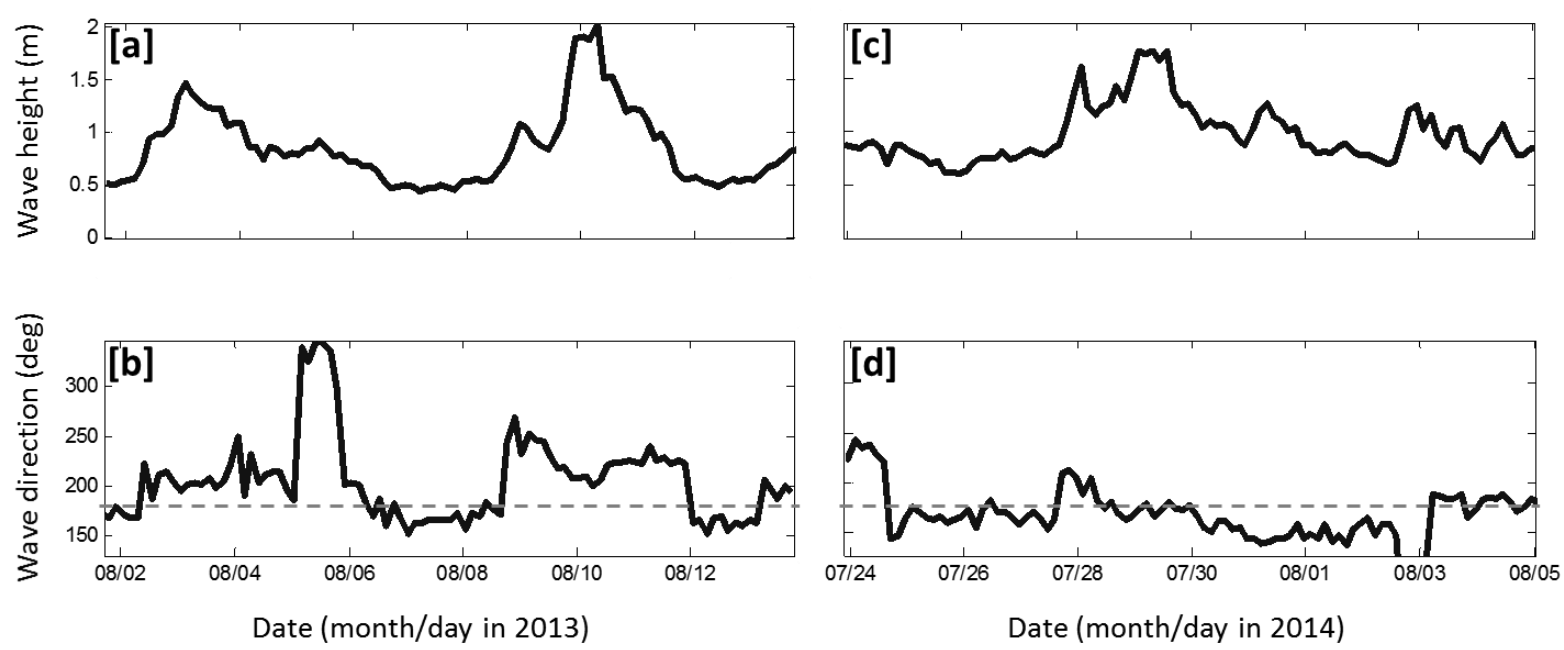

Figure 2: Offshore $(a, c)$ significant wave height and $(b, d)$ wave direction (in nautical coordinates, so that waves coming from the south have direction $=180^{\circ}$ ) estimated with measurements from the NOAA Waverider buoy in 50-m water depth (Figure 1) in (a, b) 2013 and (c, d) 2014 versus time. The dashed lines at $180^{\circ}$ are approximately shore normal in $7-\mathrm{m}$ water depth.

\section{b. Numerical Model}

A coupled wave and flow numerical model was used to investigate the processes leading to the spatial and temporal structure of the waves and currents observed south of Martha's Vineyard. Waves were modeled with SWAN [Booij et al., 1999] by solving the wave action conservation equation, and currents were modeled with Delft3D-FLOW [Lesser et al., 2004] by solving the 
nonlinear shallow water equations. The wave model includes depth- and current-induced refraction, and dissipation owing to whitecapping, depth-induced breaking, and bottom friction. Wind was not implemented because observed winds usually were less than $5 \mathrm{~m} / \mathrm{s}$ [mean (standard deviation) were $2.8(1.6)$ and $3.4(2.0) \mathrm{m} / \mathrm{s}$ in 2013 and 2014, respectively]. For the conditions observed here, model results with wind were not significantly different than results without wind. Quartet and triad nonlinear interactions were turned off owing to the lack of wind forcing, the relatively short propagation distances in deep water, and the focus on observations seaward of the region of strong quadratic nonlinearities (where $k h \ll<1$ ). Although quadratic nonlinear interactions are important to many aspects of wave evolution in shallow water [Freilich and Guza, 1984], their effects on bulk (energy weighted) statistics of the wave field (e.g., wave height, average direction, centroidal frequency) are relatively small [Gorrell et al., 2011]. The circulation model includes the effects of waves on currents through wave radiationstress gradients, combined wave and current bed shear stress, and Stokes drift. The wave and flow models were coupled, such that FLOW passes water levels and Eulerian depth-averaged velocities to SWAN, and SWAN passes wave parameters to FLOW, which is run continuously for $\leq 0.25 \mathrm{~s}$ time intervals. Similar combined wave and circulation models have been used to investigate wave-current interactions on the inner shelf [8-15 m depth Hansen et al., 2013], in the surf zone [Hansen et al., 2014, 2015; Chen et al., 2015], near river mouths [Elias et al., 2012], and in coastal bays [Mulligan et al., 2010].

SWAN and Delft3D-FLOW (in depth-averaged mode) were run over 3 (2013) and 4 (2014) nested grids (Figure 1a) with both two-way (FLOW) and one-way nesting (SWAN). The outermost grid, with $1 \mathrm{~km}$ resolution, spans about $150 \mathrm{~km}$ along the north and south boundaries 
and $100 \mathrm{~km}$ along the east and west boundaries. Nested in this coarse grid are finer grids of 200 and $40 \mathrm{~m}$ resolution in 2013, and a third grid with $13 \mathrm{~m}$ resolution in 2014 to compare with the closely spaced observations $(0 \leq x \leq 0.7 \mathrm{~km}$, Figure $1 \mathrm{c})$ obtained in 2014 . Nesting allows calculations on the coarser grids to serve as boundary conditions for the finer grids, enhancing the resolution of the model near the shoreline with minimal computational cost. The combined USGS large-scale and either the 2013 or the 2014 high-resolution shoreline bathymetry were interpolated onto each of the nested grids.

SWAN has skill in a range of environments, including the inner shelf south of Martha's Vineyard [12 to 27 m depth, Ganju and Sherwood, 2010; Ganju et al., 2011] and many shallow water areas [Magne et al., 2007; Mulligan et al., 2010], whether forced with observations [Gorrell et al., 2011; Chen et al., 2015; Hansen et al., 2013, 2014, 2015] or with output from global wave models [van der Westhuysen, 2010; Kumar et al., 2012]. Here, SWAN was run in stationary mode, with wave-field boundary conditions supplied every $3 \mathrm{hrs}$. Stationary mode solves for equilibrium wave conditions for a given set of boundary conditions and is less computationally expensive than non-stationary mode. For the 3-hr periods and for the wind and wave conditions used here, the assumption of stationarity is not violated even for the largest grid. For the 2013 bathymetry, boundary conditions were a JONSWAP frequency-directional $\left(\cos ^{N}(\theta)\right.$, where the default value of $\mathrm{N}=20$ was used) spectrum based on the mean wave direction $\theta, H_{\text {sig }}$, and average wave period provided by the model WaveWatchIII [WWIII, Tolman, 2002] every 3 $\mathrm{km}$ along the open (water) boundaries of the outer grid. The wave model also was run using the frequency-directional spectrum estimated with observations at the buoy in $50 \mathrm{~m}$ water depth (Figure 1a) applied uniformly at each point on the boundaries of the outer grid. For southerly 
waves (which are the most common) model skill was similar for the spatially variable WWIII wave forcing and the spatially uniform buoy forcing. However, model skill was significantly higher with the spatially varying WWIII boundary conditions than with the spatially constant buoy conditions when waves at the buoy came from the north or northeast, in which case the spatially varying wave field is not represented well by the measurements near the southwest corner of the domain (Figure 1a). WWIII simulations were not available in 2014, so buoy observations were used on the boundaries (wave conditions were southerly). In all cases, SWAN solves the spectral action balance using 36 directional bins $\left(10^{\circ} / \mathrm{bin}\right)$ and 37 frequency bands logarithmically spaced between 0.03 and $1.00 \mathrm{~Hz}$. The wave model used a depth-limited wave breaking formulation without rollers [Battjes and Janssen, 1978] with the default value $\gamma=H_{\text {sig }} / h$ $=0.73$, and a JONSWAP bottom friction coefficient associated with wave orbital motions set higher $\left(0.100 \mathrm{~m}^{2} / \mathrm{s}^{3}\right)$ than the default $\left(0.067 \mathrm{~m}^{2} / \mathrm{s}^{3}\right)$ [Hasselmann et al., 1973]. The higher coefficient resulted in more accurate modeled wave heights. Using default coefficients, observed wave heights were under predicted using some friction formulations [Madsen et al., 1988] and over predicted using other approaches [Collins, 1972]. Model wave directions were insensitive to the friction formulation.

The circulation model Deflt3D-FLOW solves the time-varying nonlinear shallow water equations on a staggered Arakawa-C grid using an alternating-direction-implicit solver [Lesser et al., 2004] to compute currents throughout the modal domain. The model was run using the 13 most energetic satellite-generated tidal constituents [Egbert and Erofeeva, 2002] along open boundaries, which were dominated by the M2 ( $~ 80 \%$ of the variance, with small changes depending on location along the boundary) and N2 ( 10\% of the variance) constituents. In 
addition, the model used a free slip condition at closed (land) side boundaries, a spatially uniform Chezy roughness of $65 \mathrm{~m}^{0.5} / \mathrm{s}$ (roughly equivalent to a drag coefficient of $C_{d}=0.0023$ ) at bottom boundaries, and default Delft3D parameters for coupling the FLOW and WAVE models [Deltares, 2014]. Second-order differences were used with a time step of 0.25 s for 2013 (40 $\mathrm{m}$ spacing in the highest resolution grid) and $0.15 \mathrm{~s}$ for 2014 (13 m spacing) for numerical stability.

Model parameters (e.g., time steps, grid resolution) were chosen to accommodate future studies of shoreline evolution in the Katama region on time scales varying from that of individual storms to seasons to years. Spatial and temporal resolutions are fine enough for numerical stability and verification with observations. Using higher resolution does not change simulation results significantly and requires more computational effort.

\section{Results}

\section{a. Model-Data Comparisons}

Model predictions of the sea levels, waves, and currents are comparable with observations in 7and 2-m water depths in the area south of Martha's Vineyard. The model simulates the observed 3-hr sea-level fluctuations (primarily the M2 tide) fairly well (within a few cm), although occasionally it under predicts the minima and maxima by as much as 0.10 to $0.15 \mathrm{~m}$ (Figure 3 ). These model-data differences could be owing to imperfect tidal boundary conditions, inaccurate model bathymetry, or unmodeled physical processes. Similar to previous results [van der Westhuysen, 2010; Mulligan et al., 2010; Gorrell et al., 2011; Hansen et al., 2015; and many others], the model skillfully predicts the wave heights observed in 7 (Figure 4a-c) and $2 \mathrm{~m}$ 
(Figure 5a,b) depth. Model-data wave height discrepancies in shallow water (e.g., Figure 5b) could be caused by inaccurate model bottom friction, incorrect model simulations of sea level, or inaccurate model bathymetry. The small errors in wave height (which typically are over estimated at all tide levels) are more likely owing to inaccurate bathymetry than to the under estimation of the range of sea level fluctuations. The model also skillfully predicts the wave directions (Figures 4d-f, 5c,d), including the large tidal modulations observed near the eastern edge of the domain $(x=0.3 \mathrm{~km}$, Figure $4 \mathrm{f})$.

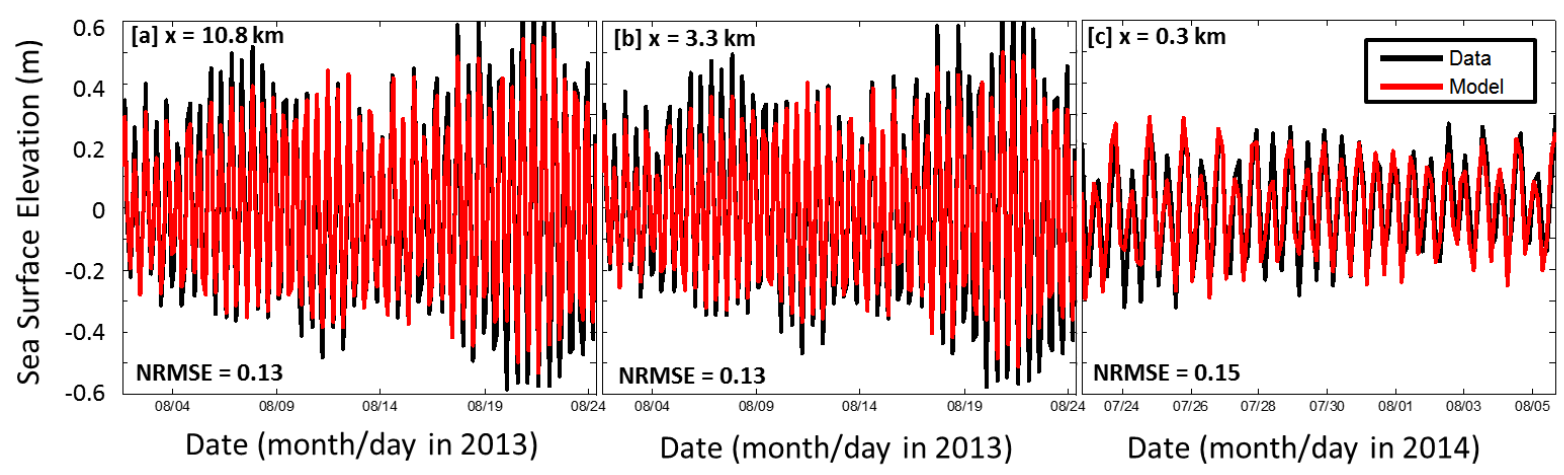

Figure 3. Observed (black curves) and modeled (red curves) 3-hr average sea-surface elevations (relative to mean sea level) versus time at locations (Figure 1b) $x=$ (a) 10.8, (b) 3.3, and (c) 0.3 $\mathrm{km}$ (distances are relative to the sensor at $x=0 \mathrm{~km}$ ). RMSE values (normalized by the data range) are given in the lower left-hand corners. 

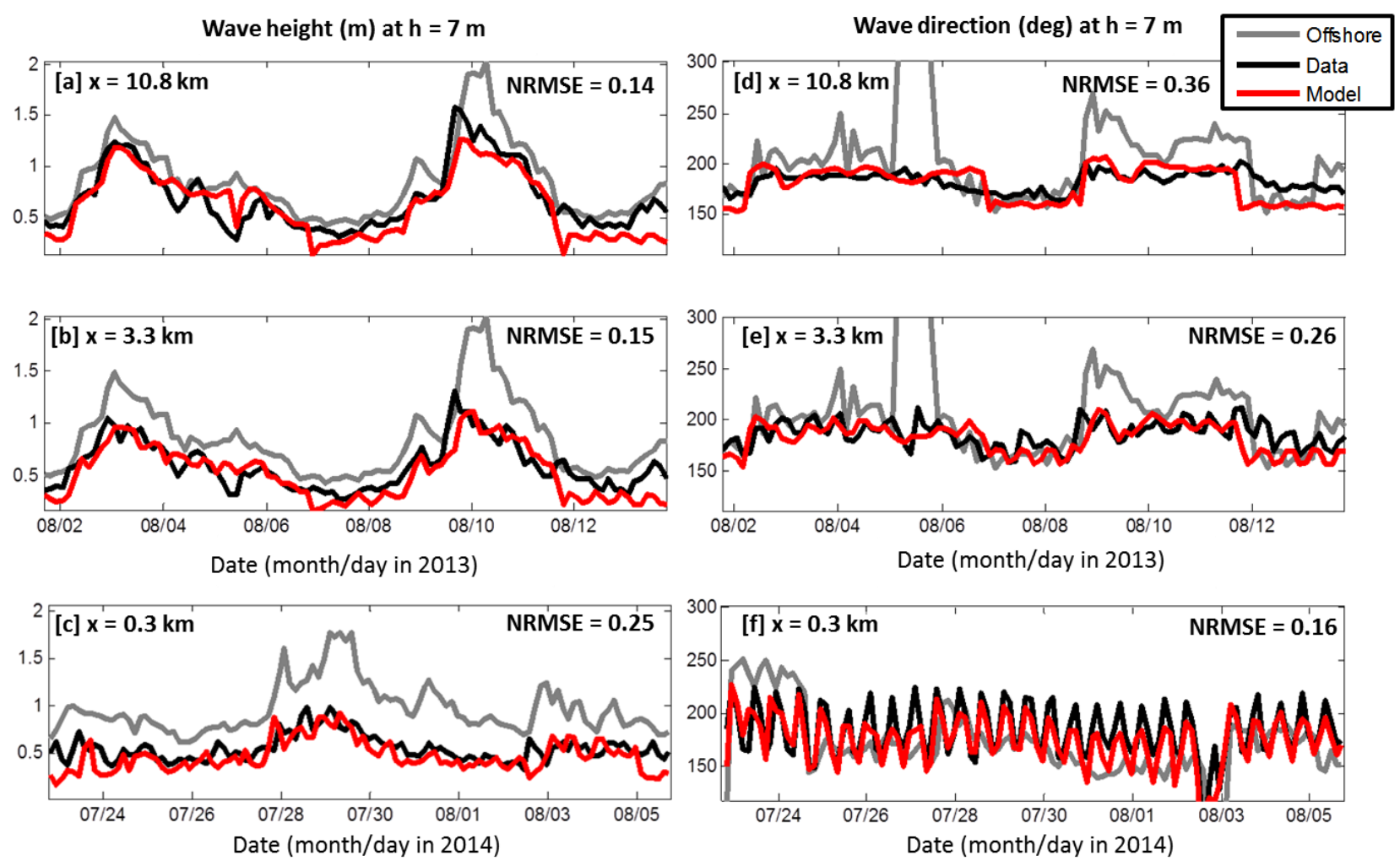

Figure 4: Observed (black curves) and modeled (red curves) 3-hr (a-c) significant wave height and (d-f) wave direction in 7-m water depth versus time at locations (Figure 1) $x=(\mathrm{a}, \mathrm{d}) 10.8$, (b, e) 3.3 , and (c, f) $0.3 \mathrm{~km}$ (distances are relative to the sensor at $x=0 \mathrm{~km}$ ). Grey curves are the observed offshore (50 m depth) wave heights and directions. RMSE values (normalized by the data range) are given in the upper right-hand corners.
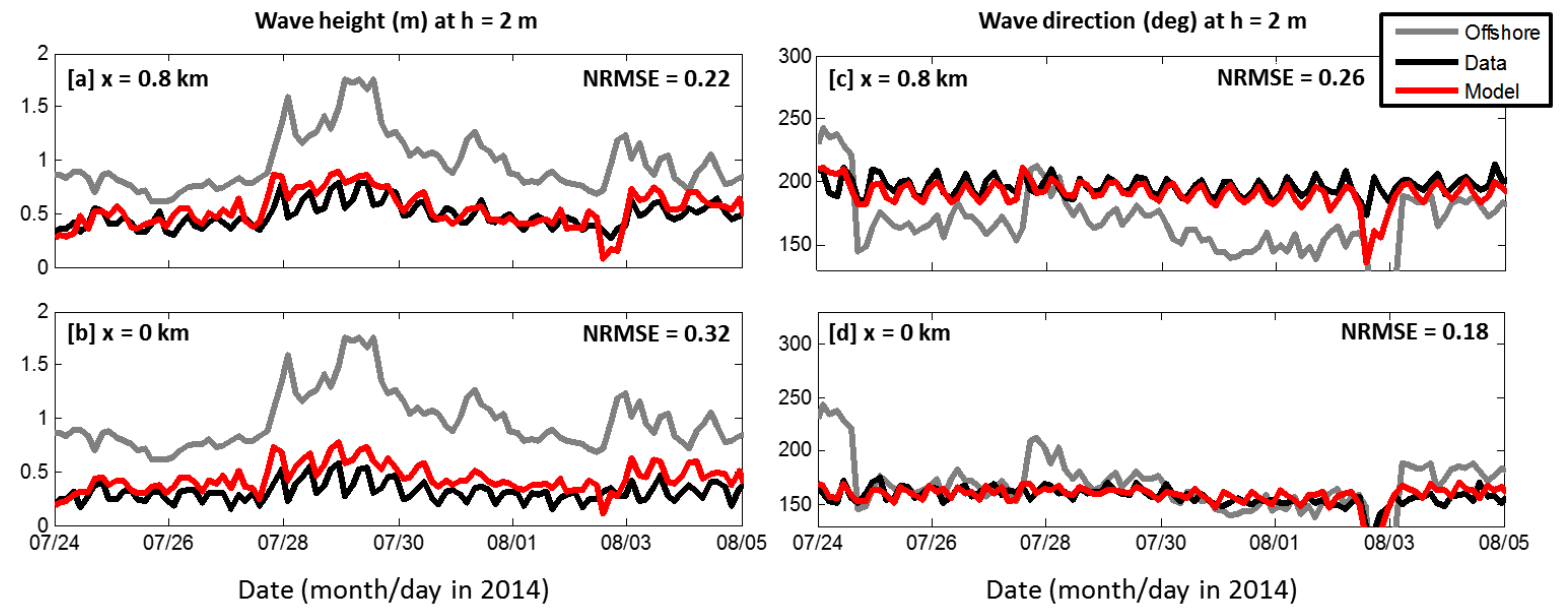

Figure 5: Observed (black curves) and modeled (red curves) 3-hr (a, b) significant wave height and $(\mathrm{b}, \mathrm{d})$ wave direction $(\mathrm{c}, \mathrm{d})$ in 2-m water depth versus time at locations (Figure 1) $x=(\mathrm{a}, \mathrm{c})$ 0.8 and $0 \mathrm{~km}$ (distances are relative to the sensor at $x=0 \mathrm{~km}$ ). Grey curves are the observed offshore (50 $\mathrm{m}$ depth) wave heights and directions. RMSE values (normalized by the data range) are given in the upper right-hand corners. 
Model simulations suggest strong spatial inhomogeneity in wave heights (Figure 6a) and directions (Figure 6b) onshore of the complex bathymetry, similar to nearshore waves in other locations [Apotsos et al., 2008; Hansen et al., 2013; Chen et al., 2015; and others], and consistent with the observations (colored circles in Figure 6). The tidal modulation of wave heights (Figures 4 and 5) varied along the shoreline, resulting in a tidally varying alongshore change in wave height (e.g., Figure 6a) in $7 \mathrm{~m}$ depth from 0 to as much as $35 \%$ of the offshore wave height (Figure 7). The model simulates both the magnitude (Figure 6a) and the tidal modulation (Figure 7b) of the observed alongshore gradient in wave height fairly well.

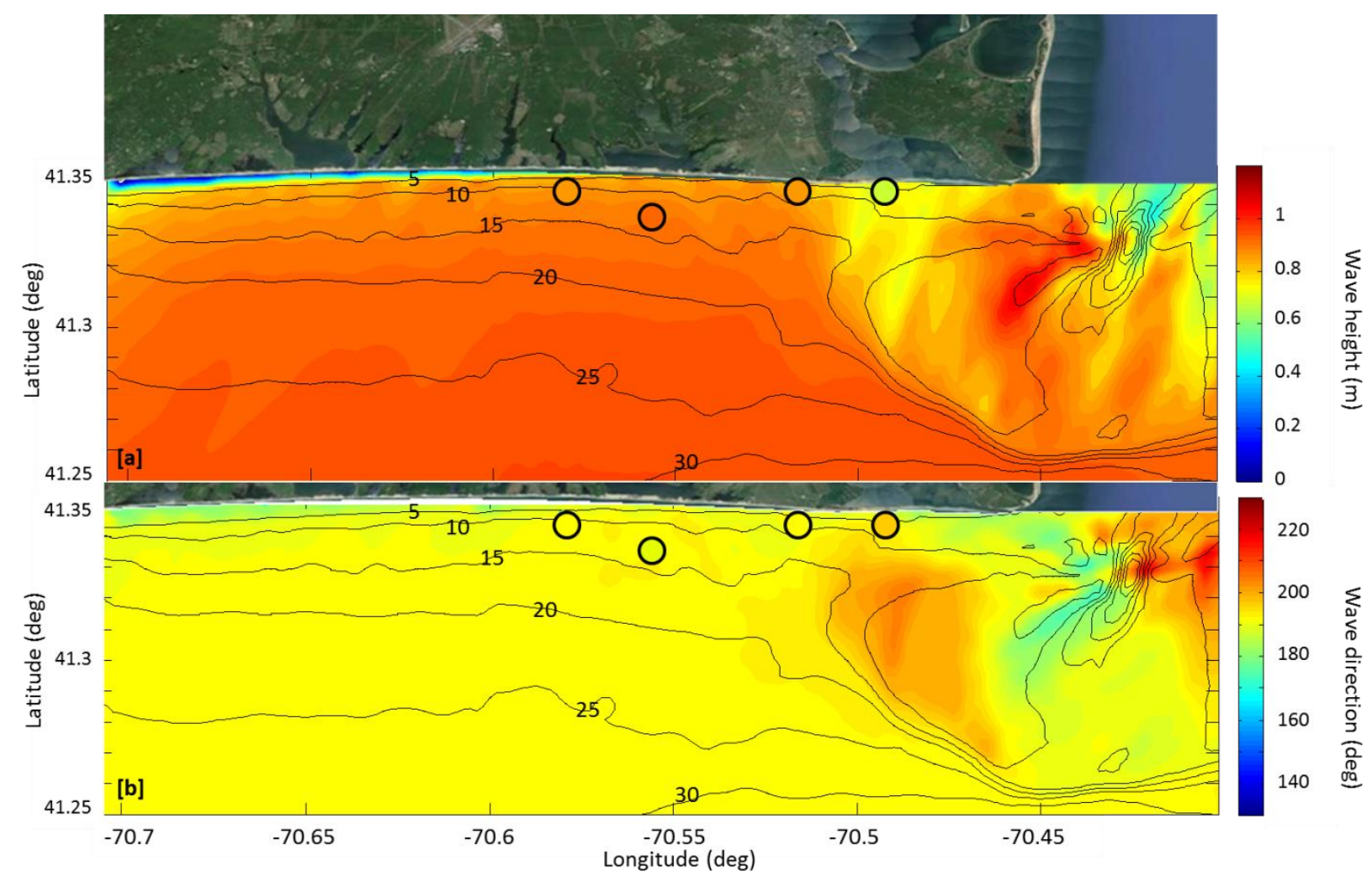

Figure 6: Spatial distribution (color contours, scales on the right) of modeled (a) significant wave height and (b) wave direction on 3 August 2013 09:00 hrs EDT during flood tide (flow from west to east into Muskeget Channel). Black curves are depth contours every $5 \mathrm{~m}$, and the black circles are filled with the color of the observed values at those locations. If model and data agree, the color inside the circle matches the color of the surrounding model contours. 

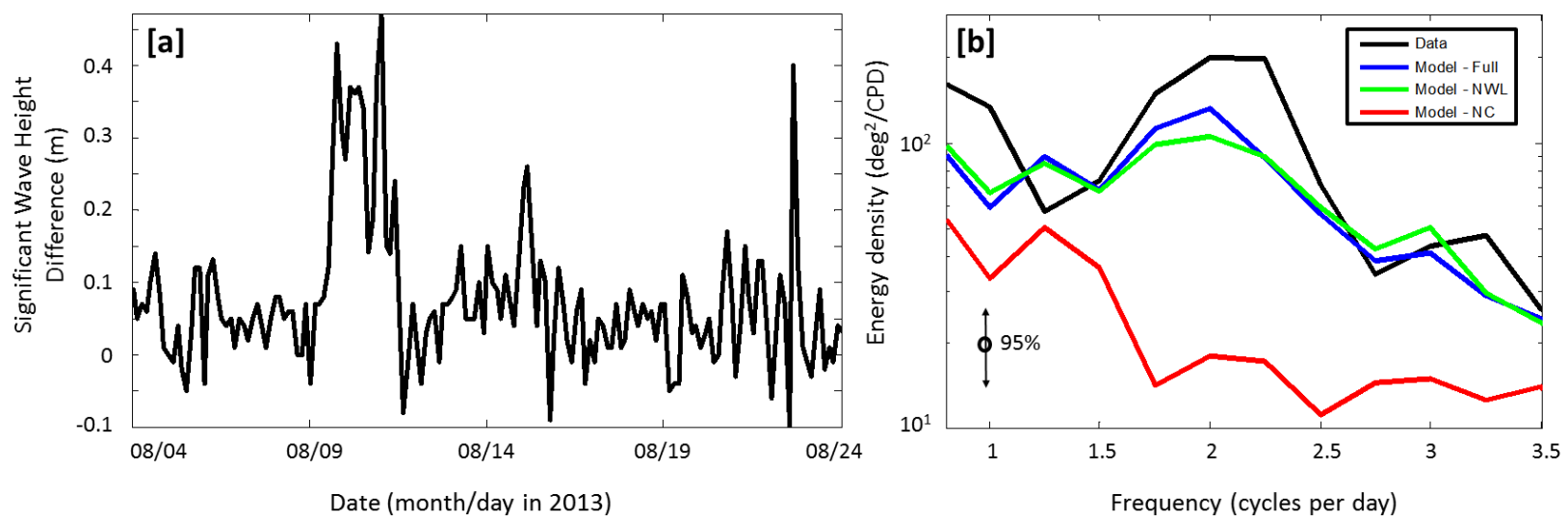

Figure 7: (a) Difference between the significant wave height observed in $7 \mathrm{~m}$ depth at $x=3.3$ and $x=10.8 \mathrm{~km}$ versus time. (b) Energy density of the time series of alongshore difference in wave height versus frequency for observations (black curve) and simulated by the model including tidal currents and water depth changes (blue curve), currents, but no depth changes (green curve), and depth changes, but no currents (red curve). The spectra have 36 degrees of freedom, and the $95 \%$ confidence levels are shown.

The amplitude of the observed mean currents (primarily M2) decreases from east (Figure 8c,f, black curves) to west (Figure 8b,e and Figure 8a,d, black curves) by an order of magnitude, and is modeled well (red curves in Figure 8$)$. At the eastern edge of the domain $(x=0.3 \mathrm{~km})$, near the strong tidal flows in Muskeget Channel (Figure 1), the model underestimates the western component of the flow (Figure 8c), possibly owing to incorrect modeling of flow separation near the southeast corner of Chappaquiddick Island (Figure 1). Model simulations (see Chapter 2) suggest that the size and location of the region of flow separation are sensitive to bathymetry and shoreline shape, which may not be accurate near the separation region. Model skill is higher a few $\mathrm{km}$ to the west (e.g., $x=3.3 \mathrm{~km}$, Figure $8 \mathrm{~b}$ ), away from the separation region. Model-data discrepancies in the relatively small cross-shore (north-south) flows (Figure 8d-f) may be owing to neglect of cross-shore winds, Stokes-Coriolis currents [Lentz et al., 2008], three-dimensional effects, or incorrect bathymetry in the model. 

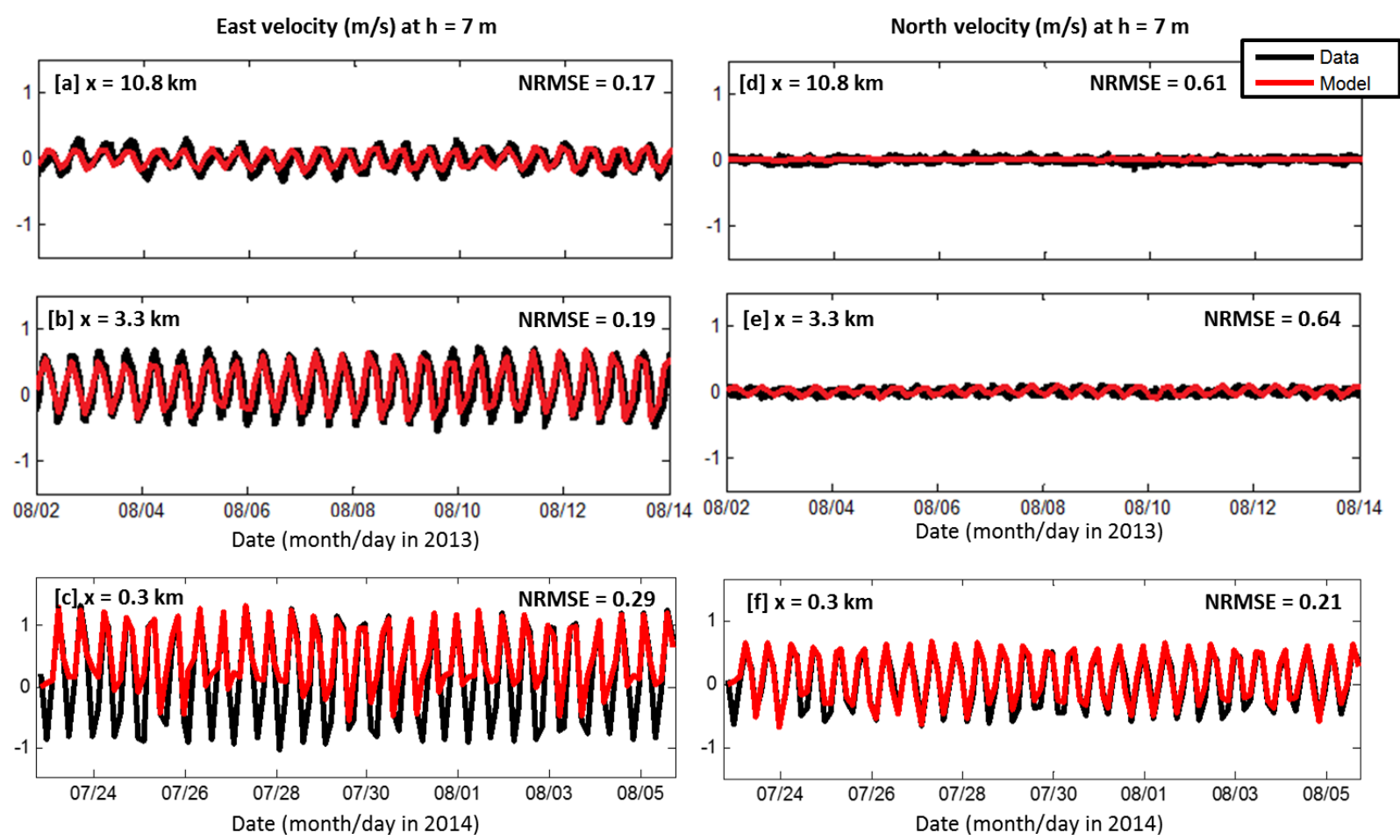

Figure 8: Observed (black curves) and modeled (red curves) 1-hr mean depth-averaged (a-c) east and (d-f) north velocity in 7-m water depth versus time at locations (Figure 1) $x=(\mathrm{a}, \mathrm{b}) 10.8$, (c,d) 3.3 , and (e,f) $0.3 \mathrm{~km}$. RMSE values (normalized by the data range) are given in the upper right-hand corners.

The relatively strong tidal flows and the tidal changes in water depth can result in refraction and tidal modulation of the wave field (including heights and directions), especially at the eastern edge of the domain where currents are strongest (Figure 8c,f) and the offshore bathymetry is most inhomogeneous (Figures 1 and 6). For example, the amplitudes of the M2 component of the observed and modeled tidal currents and wave directions are largest in the east $(x=0 \mathrm{~km})$ and decrease to the west $(x=10.8 \mathrm{~km})$ (Figure 9). Near the eastern edge of the domain $(x<0.5 \mathrm{~km}$, Figure 9) the model under predicts the M2 amplitudes of the mean currents (Figures 8c and 9) and the wave directions, possibly because horizontal flow separation around Chappaquiddick Island becomes important in this region. Additionally, small errors in the amplitude of tidal 
boundary conditions could contribute to mismatch between simulated and observed current and wave direction M2 amplitudes.

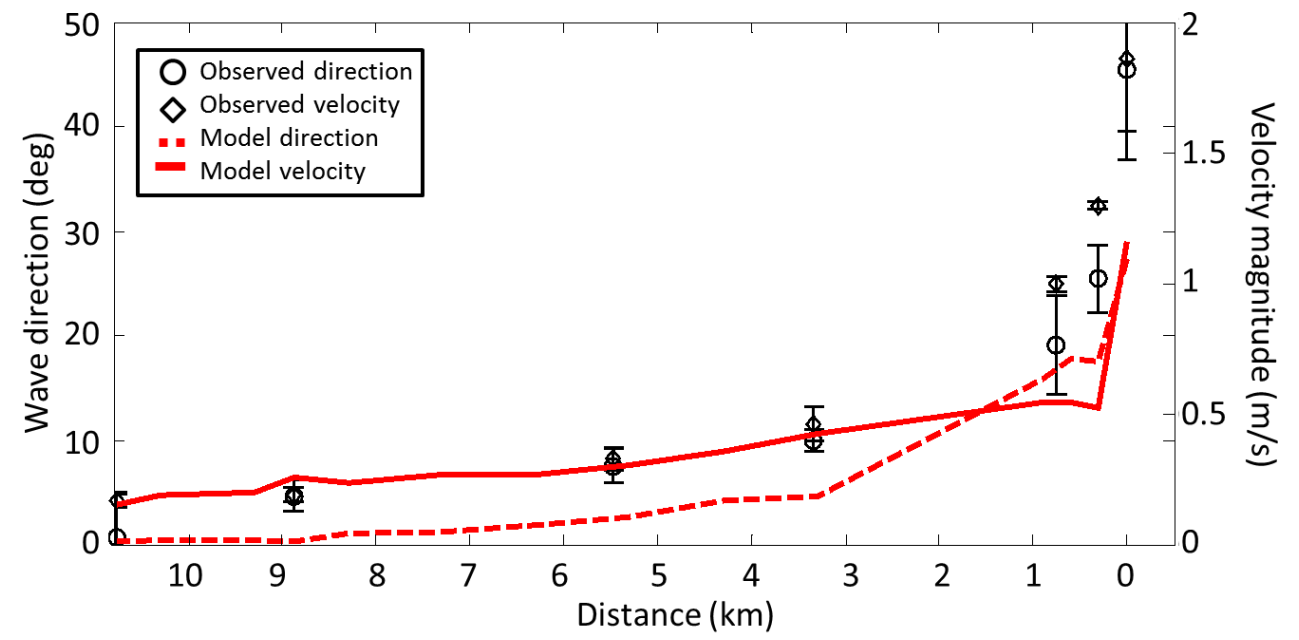

Figure 9: Amplitude of the observed (black symbols) and modeled (red curves) tidal (M2) modulation of wave direction (open circles, dashed curve) and velocity magnitude (open diamonds, solid curve) in $7 \mathrm{~m}$ depth versus distance from the eastern-most sensor $(x=0 \mathrm{~km}$, Figure 1). 95\% confidence intervals of the M2 amplitude estimates, calculated using a tidal frequency analysis of the time series ("T_TIDE," Pawlowicz et al., 2002) are shown for the observations. Some of the error bars for the observed velocity magnitude are smaller than the diamond symbols. The errors in estimating model amplitudes (not shown) are similar to those from the observations.

\section{b. Simulations of Wave-Current Interaction}

To determine if the M2 fluctuations in the wave field are caused by depth- or current-induced refraction or both, the model was run with both currents and tidal depth oscillations, with tidal depth oscillations, but no currents, and with currents, but no tidal depth oscillations. The observed tidal fluctuations in the alongshore gradient of wave heights are simulated better by the model with currents and depth changes (compare the blue with the black curve in Figure 7b) than by the model with depth changes only (red curve, Figure 7b). The modeled gradients with currents, but no depth changes (green curve, Figure 7b) are similar to those using the full model (currents and depth changes, blue curve, Figure 7b), suggesting the modulations of the alongshore gradients in wave heights primarily are caused by current-induced refraction. 
Model tests and Eqs (1-3) suggest that the observed tidal modulation in wave direction also is owing to currents and not depth changes. For $0.1 \mathrm{~Hz}$ waves propagating from 50 to $7 \mathrm{~m}$ depth across tidally varying currents with similar magnitudes to flows observed in Muskeget Channel, Eqs (1-3) predict large $\left( \pm \sim 35^{\circ}\right)$ modulations to the wave direction, comparable with the observations (Figures 4e,f, 5c,d, and 9) and with the model simulations that account for a frequency-directional spectrum and spatially varying currents and bathymetry (blue curves in Figure 10). In contrast, the observed tidal modulations of wave direction are not reproduced by the model when currents are not included (red curves, Figure 10), but are reproduced for the model with currents, but no tidal depth changes (green curves, Figure 10). Similar to previous model runs for one tidal cycle [Hansen et al., 2013], the simulations suggest that the observed tidal modulations of wave direction are caused primarily by current-induced refraction. As waves refract over the bathymetry between 7 and $2 \mathrm{~m}$ depth, the tidal modulation of direction is reduced to about $\pm 10^{\circ}$ relative to shore normal (Figure $5 \mathrm{c}, \mathrm{d}$ ). Consequently, alongshore currents (and associated sediment flux) driven by breaking waves may change direction (or strengthen and weaken) with the tide, even when offshore wave conditions are constant.
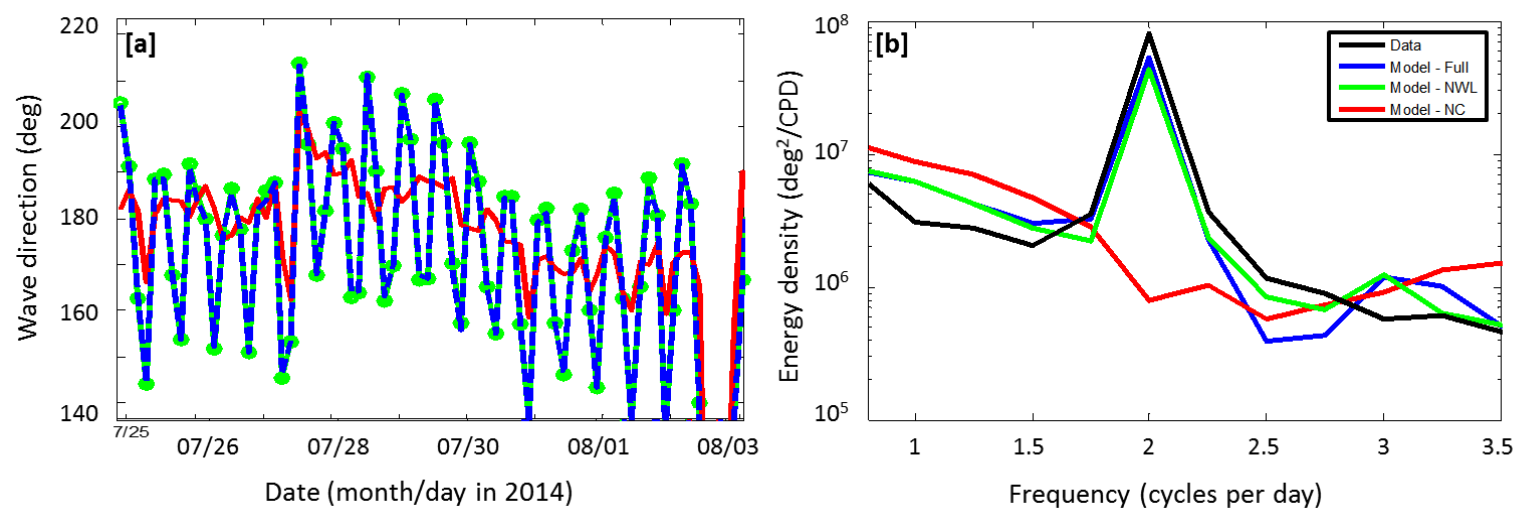

Figure 10: (a) Wave direction versus time at $x=0.3 \mathrm{~km}$ and (b) energy density of the time series of wave direction versus frequency for observations [black curve, (b) only] and simulated by the model including tidal currents and water depth changes (blue curves), currents, but no depth 
changes (green curves), and depth changes, but no tidal currents (red curves). The spectra have 36 degrees of freedom, and the $95 \%$ confidence levels are shown. Model-data time series comparisons are given in Figure 4f.

\section{c. Wave Directions in Shallow Water}

The impact of strong current-induced wave direction modulations on tidally-averaged wavedriven sediment transport was tested using simulations with idealized, time-invariant wave boundary conditions and nearshore bathymetry featuring a closed inlet (to eliminate effects of inlet flows on nearshore transport). Specifically, wave conditions with three significant wave heights $(1,3$, and $5 \mathrm{~m})$ and from three directions (south, southwest, southeast) were simulated with and without tidal currents using both measured bathymetry (when the inlet was closed, 2015, Figure 11a,b) and an idealized version of the 2015 bathymetry with plane parallel depth contours (Figure 11c). The resulting wave directions were averaged over several tidal cycles to determine spatial variation in wave direction and direction modulation at 2 and $5 \mathrm{~m}$ depth. The simulations suggest that as offshore wave heights increase for normally incident waves, mean direction in $5 \mathrm{~m}$ depth increases (Figure 12a) and the tidal modulation of the wave direction decreases (Figure 12b). Larger offshore waves have different energy-weighted directions and smaller directional modulation because depth-induced breaking on the shallow bathymetry farther offshore results in energy loss at higher frequencies in the wave spectrum (Eq 1-3). 


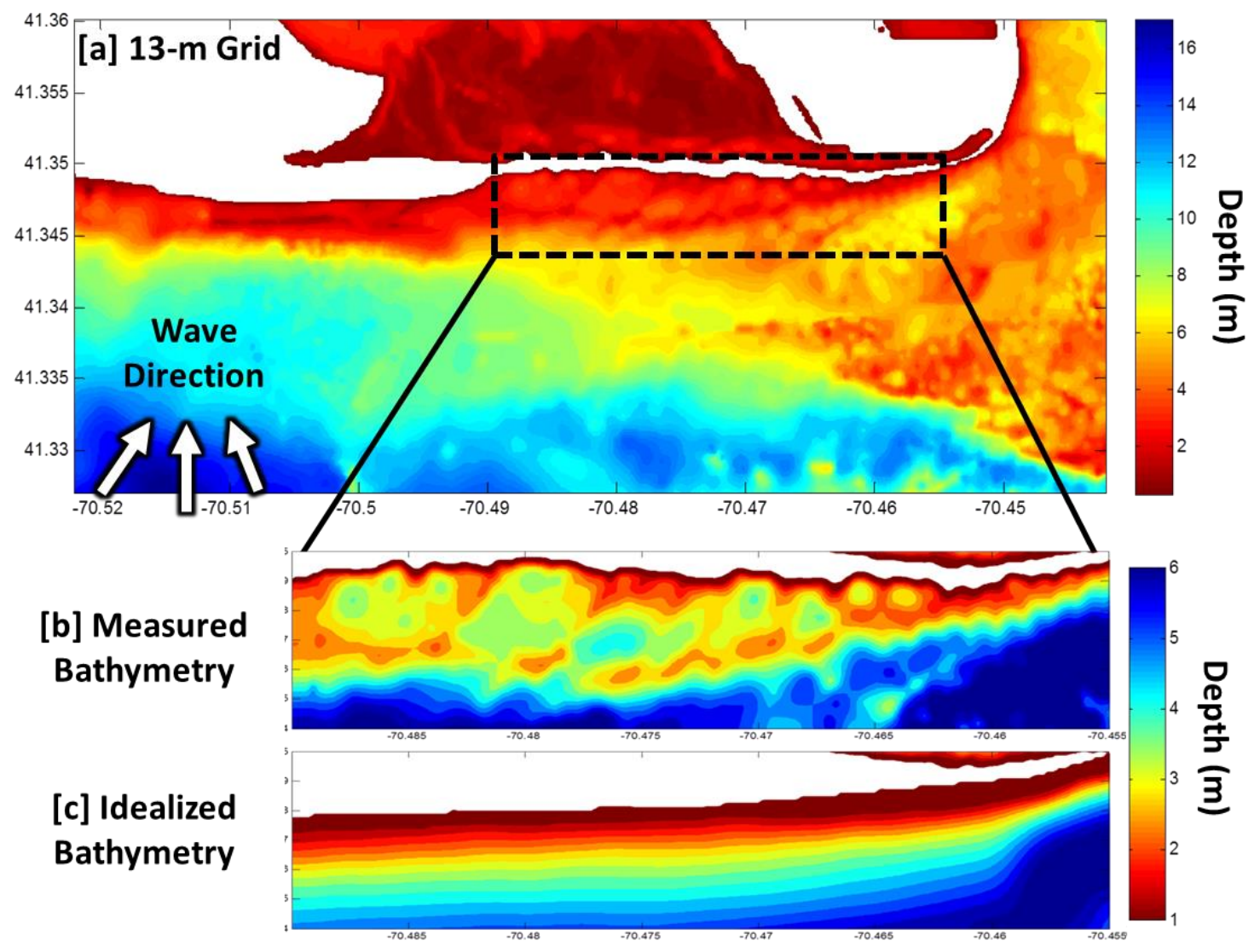

Figure 11: Color contours of water depth (2015 observations, red is shallow, blue is deep, scale on the right) for idealized wave-current interaction model simulations with (a) three offshore wave directions (normal, $-30^{\circ}$ from normal, $+30^{\circ}$ from normal) (white arrows) using (b) measured and (c) idealized planar-parallel nearshore bathymetry.

Offshore wave direction also impacts the orientation of waves as they propagate over the shoals south of the inlet (Figure 1). Waves from the south refract to the southwest, and waves from the southeast refract to be more shore-normal. These changes in direction offshore of the inlet (Figure 12) suggest the importance of inhomogeneous offshore bathymetry on tidally-averaged wave direction in the nearshore. 

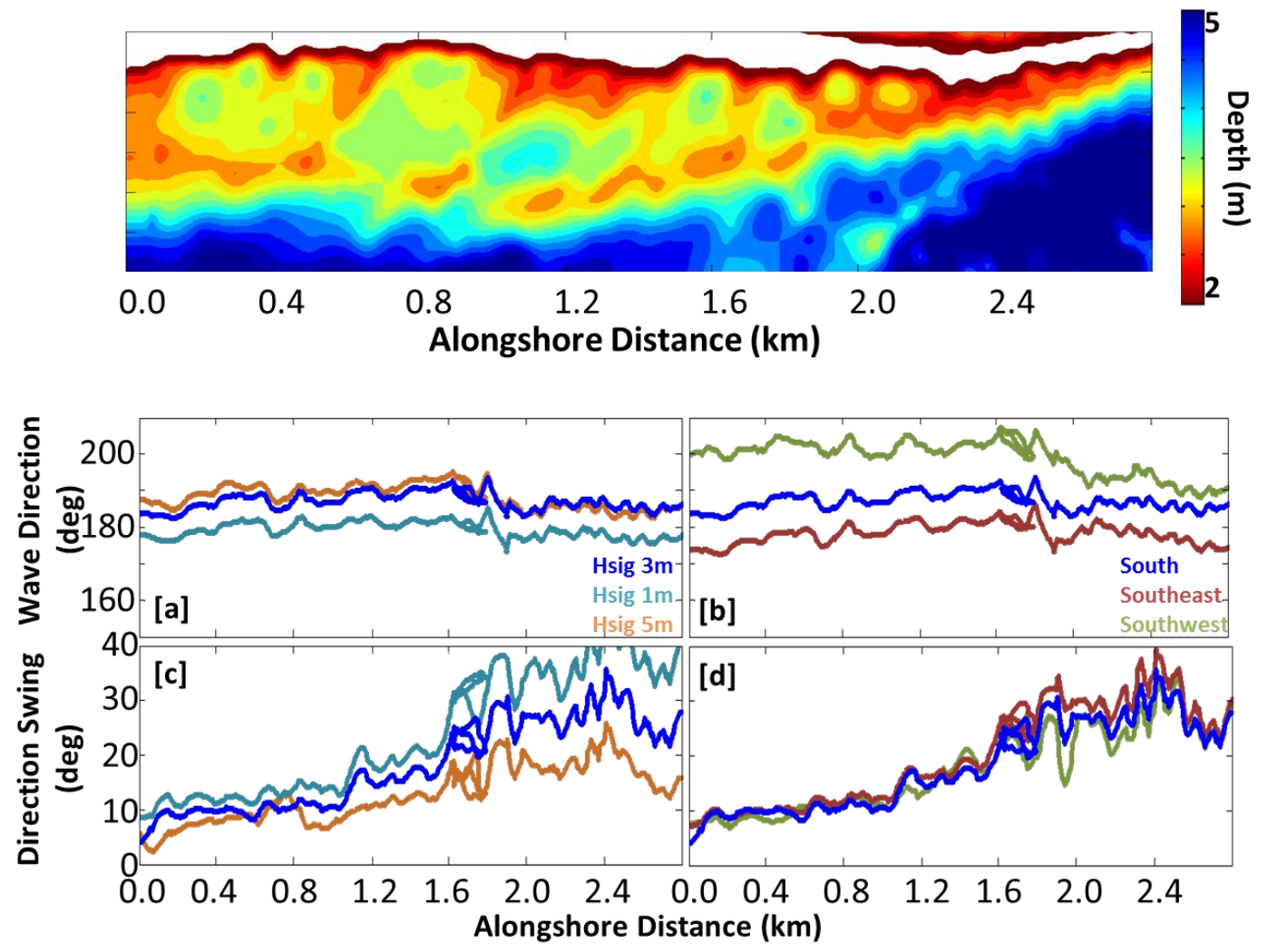

Figure 12: Tidally-averaged $(a, b)$ wave direction and $(c, d)$ wave direction modulation versus alongshore distance owing to tidal currents in 5-m water depth for (a,c) offshore significant wave heights of 3 (dark blue), 1 (teal), and $5 \mathrm{~m}$ (orange) and (b,d) offshore wave directions with offshore wave height set to $3 \mathrm{~m}$ from south (shore normal, dark blue), southeast ( $-30 \mathrm{deg}$ from shore normal, red), and southwest (+30 deg from shore normal, green). The color contour plot on top indicates depth (red is shallow, blue is deep, scale on the right) for the alongshore extent shown in (a-d).

As waves approach the point of breaking, the relative importance of bathymetry and currents to the tidally averaged wave direction changes. In 5-m water depth, the difference in wave direction between model simulations with and without tidal currents is greater (about $10 \mathrm{deg}$, compare dark blue with purple curves in Figure 13a)) than the difference between simulations with and without inhomogeneous bathymetry (compare dark blue with teal in Figure 13a). The 10-degree difference between simulations with and without tidal currents is owing to strong tidal asymmetry in the alongshore currents (Figure 14). In contrast, wave directions in $2 \mathrm{~m}$ depth for simulations with and without tidal currents showed similar alongshore mean directions, whereas 
the mean wave directions from simulations with inhomogeneous bathymetry (dark blue and purples curves in Figure 13b) vary significantly relative to the directions of waves propagating over plane parallel contours (light blue or teal curve in Figure 13b). The pattern in the mean direction with inhomogeneous bathymetry matches the undulations in the shallow bathymetry (Figure 13). The simulations suggest that, despite the impact of tidal currents on wave directions on the inner continental shelf, the direction of waves at breaking (and subsequently the direction of wave-driven surfzone sediment transport) at Katama primarily is owing to inhomogeneous shallow water bathymetry.

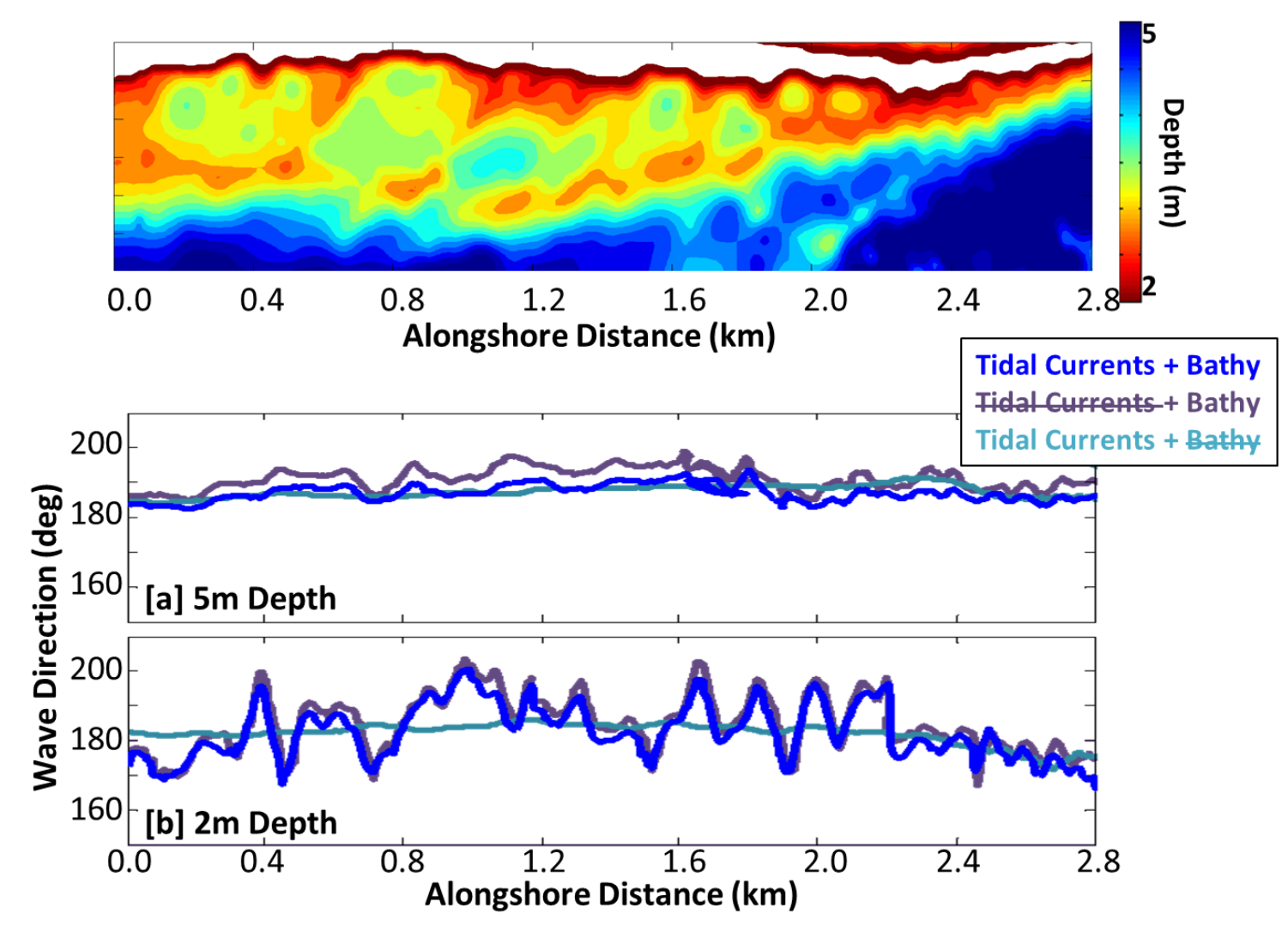

Figure 13: Tidally averaged wave direction simulated at (a) 5- and (b) 2-m depth versus alongshore distance for (dark blue) model runs with both tidal currents and inhomogeneous bathymetry impacting wave direction, (purple) model runs with inhomogeneous bathymetry, but no tidal current effect on waves, and (teal) model runs with tidal currents and planar parallel bathymetry impacting wave direction. The color contour plot on top indicates depth (red is shallow, blue is deep, scale on the right) for the alongshore extent shown in (a-d). 


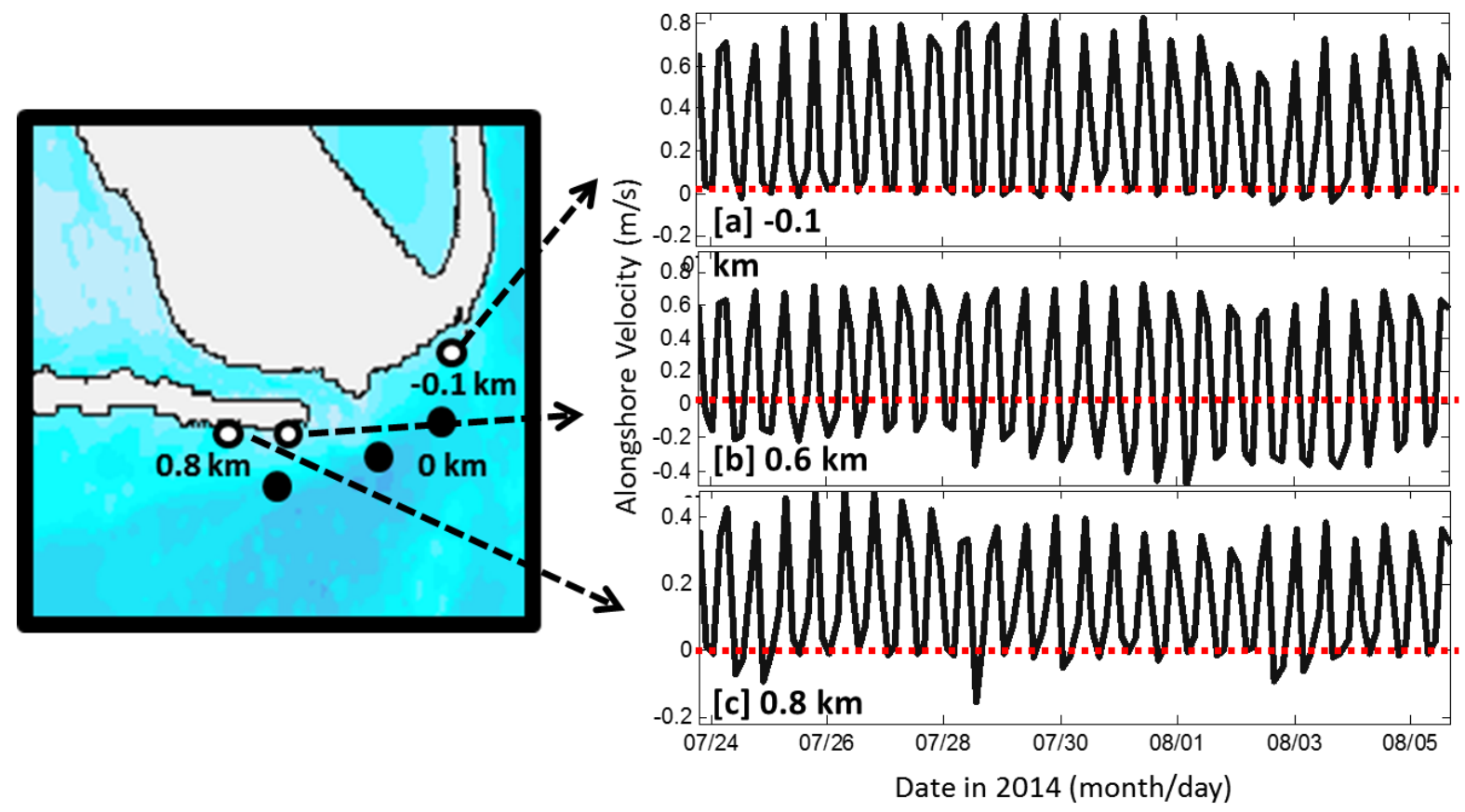

Figure 14: Observed alongshore velocity in 2-m water depth (a) -0.1 (b) 0.6 , and (c) $0.8 \mathrm{~km}$ west of the inlet (see map inset). Dashed red lines mark zero velocity to highlight tidal asymmetry.

\section{Conclusions}

A combined wave (SWAN) and circulation (Delft3D-FLOW) numerical model accurately simulates waves and currents observed in 7- and 2-m water depths near Katama Bay and Inlet, on the southern shoreline of Martha's Vineyard, MA in the presence of strong $(>2 \mathrm{~m} / \mathrm{s})$ tidal currents and complex bathymetry. The model reproduces the alongshore gradients in waves and mean currents, as well as the large $\left( \pm 35^{\circ}\right)$ tidal modulation of wave directions observed for two 1-month-long periods. Model simulations with and without wave-current interactions demonstrate that the modulations of the wave field in $7 \mathrm{~m}$ depth primarily are owing to currentinduced refraction, and not to tidal changes in water levels. In contrast, wave directions in $\sim 2 \mathrm{~m}$ depth at this location are strongly affected by depth-induced refraction over inhomogeneous shallow water bathymetry, rather than the result of interactions with the strong tidal currents in deeper water. The comparisons with observations suggest that the model with wave-current 
interaction and with the parameters used here simulates waves and currents accurately in regions with complex bathymetry and strong currents. These results further suggest that tidal modulations in wave direction in other coastal environments with complex bathymetry and strong currents also could be owing to wave-current interaction.

\section{Acknowledgements}

The data used in this study are available by contacting the authors, hychenj@mit.edu or elgar@whoi.edu

Support was provided by ONR, NSF, Sea Grant, NDSEG, an MIT Presidential Graduate Fellowship, and the Office of the Assistant Secretary of Defense (Research and Engineering) via National Security Science and Engineering and Vannevar Bush Faculty Fellowships. Mumen Alzubi, Kohl Brinkman, Danik Forsman, Janet Fredericks, Levi Gorrell, Liliana Montoya, Mara Orescanin, Maddie Smith, Anna Wargula, and Billy Wells helped obtain the observations, and Jeff Hansen provided valuable help with modeling 


\section{References}

Amoudry, L.O., and A.J. Souza (2011). Deterministic coastal morphological and sediment transport modeling: a review and discussion. Rev. Geophys., 49, 1-21. doi:10.1029/2010RG000341

Apotsos, A., B. Raubenheimer, S. Elgar, and R.T. Guza (2008). Wave-driven setup and alongshore flows observed onshore of a submarine canyon. J. Geophys. Res., 113(C7), C07025. doi:10.1029/2007JC004514

Battjes, J.A., and J.P..M. Janssen (1978). Energy loss and set-up due to breaking of random waves, paper presented at $16^{\text {th }}$ Conference on Coastal Engineering, ASCE, Hamburg, Germany.

Booij, N., R.C. Ris, and L.H. Holthuijsen (1999). A third-generation wave model for coastal regions: 1. Model description and validation. J. Geophys. Res., 104(C4), 7649. doi:10.1029/98JC02622

Chen, C., H. Huang, R.C. Beardsley, Q. Xu, R. Limeburner, G.W. Cowles, and H. Lin (2011). Tidal dynamics in the Gulf of Maine and New England Shelf: An application of FVCOM. $J$. Geophys. Res., 116(C12), C12010. doi:10.1029/2011JC007054

Chen, J.-L., T.J. Hsu, F. Shi, B. Raubenheimer, and S. Elgar (2015). Hydrodynamics and sediment transport modeling of New River Inlet (NC) under the interaction of tides and waves, J. Geophys. Res., 118(10), 5054-5073. doi:10.1002/jgrc.20397

Collins, J.I. (1972), Prediction of shallow-water spectra, J. Geophys. Res., 77(15), 2693-2707, doi:10.1029/JC077i015p02693.

Deltares, 2014. Delft3D-Wave. Simulation of short crested waves with SWAN. User manual. Deltares, Rotterdamseweg 185, The Netherlands.

Eakins, B.W., L.A. Taylor, K.S. Carignan, R.R. Warnken, E. Lim, and P.R. Medley (2009). Digital Elevation Model of Nantucket, Massachusetts: Procedures, Data Sources and Analysis, NOAA Technical Memorandum NESDIS NGDC-26, Dept. of Commerce, Boulder, CO, pp. 29

Egbert, G.D. and S.Y. Erofeeva (2002). Efficient Inverse Modeling of Barotropic Ocean Tides. J. Atmos. Ocean. Technol., 19, 183-204.

Elias, E.P.L., G. Gelfenbaum and A.J. Van der Westhuysen (2012). Validation of a coupled wave-flow model in a high-energy setting: The mouth of the Columbia River. J. Geophys. Res. Ocean., 117(C9). doi:10.1029/2012JC008105

Feddersen, F., R.T. Guza, S. Elgar and T.H.C. Herbers (1998). Alongshore momentum balances in the nearshore. J. Geophys. Res., 103(C8), 15667-15676. doi:10.1029/98JC01270 
Fredsoe, J. and R. Deigaard (1992). Mechanics of Coastal Sediment Transport. World Scientific Publishing, Singapore.

Freilich, M.H. and R.T. Guza (1984). Nonlinear effects on shoaling surface gravity waves, Philos. Trans. R. Soc. London Ser. A, 311, 1-41.

Ganju, N.K. and C.R. Sherwood (2010). Effect of roughness formulation on the performance of a coupled wave, hydrodynamic, and sediment transport model. Ocean Model., 33(3-4), 299313. doi:10.1016/j.ocemod.2010.03.003

Ganju, N.K., S.J. Lentz, A.R. Kirincich and J.T. Farrar (2011). Complex mean circulation over the inner shelf south of Martha's Vineyard revealed by observations and a high-resolution model. J. Geophys. Res., 116(C10), C10036. doi:10.1029/2011JC007035

Gonzalez, F.I. (1984). A Case Study of Wave-Current-Bathymetry Interactions at the Columbia River Entrance. J. Phys. Ocean., 1065-1078.

Gorrell, L., B. Raubenheimer, S. Elgar and R.T. Guza (2011). SWAN predictions of waves observed in shallow water onshore of complex bathymetry. Coast. Eng., 58(6), 510-516. doi:10.1016/j.coastaleng.2011.01.013

Guza, R.T., E.B. Thornton and N. Christensen Jr (1986). Observations of Steady Longshore Currents in the Surf Zone. J. Phys. Ocean., 16, 1959-1969.

Hansen, J. E., E. Elias, J.H. List, L.H. Erikson and P.L. Barnard (2013). Tidally influenced alongshore circulation at an inlet-adjacent shoreline. Cont. Shelf Res., 56, 26-38. doi:10.1016/j.csr.2013.01.017

Hansen, J. E., T.T. Janssen, B. Raubenheimer, F. Shi, P.L. Barnard, and I.S. Jones (2014). Observations of surfzone alongshore pressure gradients onshore of an ebb-tidal delta. Coast. Eng., 91, 251-260. doi:10.1016/j.coastaleng.2014.05.010

Hansen, J., B. Raubenheimer, J. List, and S. Elgar (2015) Modeled alongshore circulation and force balances onshore of a submarine canyon, J. Geophys. Res.,120, 1887-1903. doi: 10.1002/2014JC010555

Hasselmann K., T.P. Barnett, E. Bouws, H. Carlson, D.E. Cartwright, K. Enke, J.A. Ewing, H. Gienapp, D.E. Hasselmann, P. Kruseman, A. Meerburg, P. Mller, D.J. Olbers, K. Richter, W. Sell, and H. Walden (1973). Measurements of wind-wave growth and swell decay during the Joint North Sea Wave Project (JONSWAP), Ergnzungsh. zur Dtsch. Hydrogr. Zeitschrift R., A(8):12, 95

Jonsson, I.G. (1990), "Wave-current interactions", in Ocean Engineering Science: The Sea, 9A edited by B. Le Méhauté and D. M. Hanes, pp. 65-120, Harvard University Press, Massachusetts. 
Kuik, A.J., G.P. van Vledder and L.H. Holthuijsen (1988). A method for the routine analysis of pitch-and-roll buoy wave data. J. Phys. Ocean., 18, 1020-1034.

Kumar, N., G. Voulgaris, J.C. Warner and M. Olabarrieta (2012). Implementation of the vortex force formalism in the coupled ocean-atmosphere-wave-sediment transport (COAWST) modeling system for inner shelf and surf zone applications. Ocean Model., 47, 65-95. doi:10.1016/j.ocemod.2012.01.003

Lesser, G.R., J.A. Roelvink, J.A.T.M. van Kester and G.S. Stelling (2004). Development and validation of a three-dimensional morphological model. Coast. Eng., 51, 883-915. doi:10.1016/j.coastaleng.2004.07.014

Lentz, S., M. Fewings, P. Howd, J. Fredericks and Kent Hathaway (2008). Observations and a model of undertow over the inner continental shelf. J. Phys. Ocean., 38(11), 2341-2357. doi: 10.1175/2008JPO3986.1

Longuet-Higgins, M.S. (1970). Longshore currents generated by obliquely incident sea waves: 1. J. Geophys. Res., 75(33), 6778-6789. doi:10.1029/JC075i033p06778

Longuet-Higgins, M.S. and R.W. Stewart (1961). The changes in amplitude of short gravity waves on steady non-uniform currents, J. Fluid Mech., 10(4), 529-549. doi:10.1017/S0022112061000342

Longuet-Higgins, M.S. and R.W. Stewart (1964). Radiation stresses in water waves; a physical discussion, with applications. Deep Sea Res., 11(4), 529-562. doi:10.1016/00117471(64)90001-4

Madsen, O., Y.-K. Poon and H. Graber (1988). Spectral wave attenuation by bottom friction: Theory. in Proceedings 21th International Conference Coastal Engineering, ASCE, pages 492-504.

Magne, R., K. Belibassakis, F. Herbers, T. Ardhuin, W. O’Reilly, and V. Rey (2007). Evolution of surface gravity waves over a submarine canyon. J. Geophys. Res. 112, C01002. doi:10.1029/2005JC003035.

Mulligan, R.P., A.E. Hay and A.J. Bowen (2010). A wave-driven jet over a rocky shoal. J. Geophys. Res., 115(C10), C10038. doi:10.1029/2009JC006027

National Geophysical Data Center (1999). U.S. Coastal Relief Model - Northeast Atlantic, Natl. Oceanic and Atmos. Admin., Boulder, Colo. doi:10.7289/V5MS3QNZ

Ogden, G. (1974). Shoreline Changes Along the Southeastern Coast of Martha's Vineyard, Massachusetts for the Past 200 Years. Quat. Res., 4, 496-508.

Olabarrieta, M., J.C. Warner and N. Kumar (2011). Wave-current interaction in Willapa Bay. J. Geophys. Res., 116(C12), C12014. doi:10.1029/2011JC007387 
Olabarrieta, M., W.R. Geyer and N. Kumar (2014). The role of morphology and wave-current interaction at tidal inlets: an idealized modeling analysis. J. Geophys. Res. 119, doi:10.1002/2014JC010191.

Pawlowicz, R., B. Beardsley, and S. Lentz (2002). Classical tidal harmonic analysis including error estimates in MATLAB using T_TIDE. Computers and Geosci., 28, 929-937.

Shi, F., D.M. Hanes, J.T. Kirby, L. Erikson, P. Barnard and J. Eshleman (2011). Pressuregradient-driven nearshore circulation on a beach influenced by a large inlet-tidal shoal system. J. Geophys. Res., 116(C4), C04020. doi:10.1029/2010JC006788

Thornton, E.B. and R.T. Guza (1986). Surf zone longshore currents and random waves: Field data and models. J. Phys. Ocean., 16, 1165-1178.

Tolman, H.L. (2002), User manual and system documentation of WAVEWATCH-III version 2.22, Tech. Rep. 222, Natl. Weather Serv./Natl. Cent. for Environ. Prediction/Mar. Model. and Anal. Branch, NOAA, Silver Spring, Md.

van der Westhuysen, A.J. (2010). Modeling of depth-induced wave breaking under finite depth wave growth conditions. J. Geophys. Res., 115(C1), C01008. doi:10.1029/2009JC005433

van Rijn, L. (1993). Principles of Sediment Transport in Rivers, Estuaries and Coastal Seas. Blokzijl, Aqua Publishing, Netherlands.

Wolf, J. and D. Prandle (1999). Some observations of wave-current interaction. Coast. Eng., 37(3-4), 471-485. doi:10.1016/S0378-3839(99)00039-3 


\title{
Chapter 2:
}

\section{Flow separation effects on shoreline sediment $\operatorname{transport}^{1}$}

\begin{abstract}
Field-tested numerical model simulations are used to estimate the effects of an inlet, ebb shoal, wave height, wave direction, and shoreline geometry on the variability of bathymetric change on a curved coast with a migrating inlet and strong nearshore currents. The model uses bathymetry measured along the southern shoreline of Martha's Vineyard, MA, and was validated with waves and currents observed from the shoreline to 10-m water depth. Between 2007 and 2014, the inlet was open and the shoreline along the southeast corner of the island eroded $\sim 200 \mathrm{~m}$ and became sharper. Between 2014 and 2016, the corner accreted and became smoother as the inlet closed. Numerical simulations indicate that the variability of sediment transport near the corner shoreline depends more strongly on its radius of curvature (a proxy for the separation of tidal flows from the coast) than on the presence of the inlet, the ebb shoal, or wave height and direction. As the radius of curvature decreases (as the corner sharpens), tidal asymmetry of nearshore currents is enhanced, leading to more sediment transport near the shoreline over several tidal cycles. The results suggest that feedbacks between shoreline geometry and innershelf flows can be important to coastal erosion and accretion along curved coastlines, even in the vicinity of an inlet.
\end{abstract}

${ }^{1}$ Parts of this chapter have been published as: Hopkins, J., S. Elgar, and B. Raubenheimer (2017), Flow separation effects on shoreline sediment transport, Coast. Eng., 125, doi:10.1016/j.coastaleng.2017.04.007. Used with permission as granted in the original copyright agreement. 


\section{Introduction}

Sediment transport on shorelines is affected by wave-orbital velocities, breaking-wave-driven currents, tidal currents, and inlet flows. In particular, inlet flows can interrupt alongshore sediment transport, resulting in sediment deposition inside the bay (flood tide delta), in the ocean near the inlet mouth (ebb-tide delta or shoal) or farther offshore [Escoffier, 1940; Komar and Inman, 1970; Slingerland, 1983; Adams et al., 2015, references therein and many others]. Erosion downstream of the inlet is possible owing to inlet-induced reduction in alongshore sediment supply. The inlet influence can extend for more than $10 \mathrm{~km}$ along the coast [Fenster and Dolan, 1996], although it often extends less than 4 km [Fenster and Dolan, 1996; Hicks et al., 1999; Castelle et al., 2007; Adams et al., 2015]. The inlet region of influence depends on many factors, including the geometry of the ebb shoal and main inlet channel [Fitzgerald, 1984], the offshore bathymetry [Shi et al., 2011; Hansen et al., 2013], wave climate [Bertin et al., 2009; Robin et al., 2009], tidal prism [Powell et al., 2006; Adams et al., 2015], and the presence of headlands [Hume and Herdendorf, 1992; O'Connor et al., 2007].

Traditional knowledge associates increased sediment transport around the shoreline at Wasque Point on the southeast corner of Martha's Vineyard, MA, USA (Figure 1) with the opening of the nearby Katama Inlet [Ogden, 1974]. Katama Inlet breached in 2007 near the middle of Norton Point (Figure 1c) and migrated east until it closed in 2015 (Figure 1d). While the inlet was open, the shoreline near the corner of Wasque Point eroded 200 m [Figure 1d, compare the purple curve (2014) with the blue curve (2008, similar to 2007)]. Once Norton Point extended eastward 
and wrapped around Wasque Point, closing the inlet, the corner reverted toward its 2007 position [Figure 1d, compare the yellow curve (2015) with the blue curve (2008)]. Here, it is shown that although the erosion and subsequent accretion of the southeast corner of Martha's Vineyard is consistent with a potential reduction (increase) in alongshore transport when the inlet is open (closed), the variability of transport (magnitude of erosion plus magnitude of deposition) depends strongly on the radius of curvature of the corner, a proxy for flow separation.

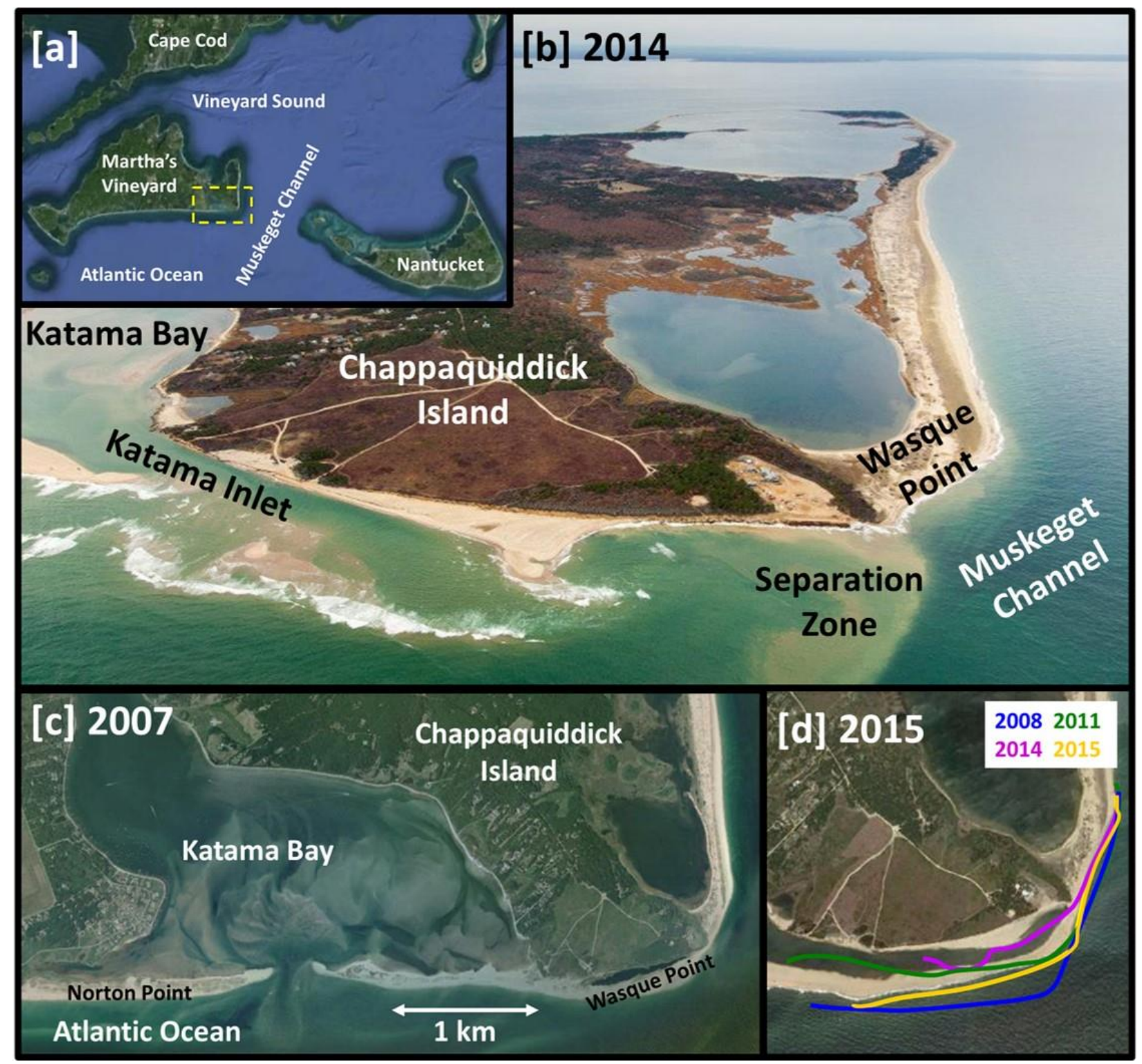

Figure 1: (a) Location of Martha's Vineyard, MA, (b) photograph of Chappaquiddick Island, Katama Bay and Inlet, and Wasque Point in 2014 [within the yellow box in (a)], (c) Google Earth image of the Katama area 2 months after Norton Point was breached in Apr 2007, and (d) 
close up image of Wasque Point in 2015, with shorelines from 2008 (blue curve, similar to 2007), 2011 (green), 2014 (purple), and 2015 (yellow). Photograph in (b) by Bill Brine.

Similar to the Martha's Vineyard coastline, many shorelines with inlets also have complex larger-scale bathymetry and strong inner-shelf currents, including inlets throughout New England [Fitzgerald et al., 2002], along the U.S. Atlantic Coast [Mcninch and Luettich, 2000], and on sandy coasts around the world [Bertin et al., 2009; Chaumillon et al., 2014]. Strong currents near headlands or sharp shoreline transitions such as Wasque Point (Figure 1) can impact sediment transport significantly. In particular, the separation of currents flowing around headlands or sharp corners can generate eddies that suspend, transport, and deposit sediment [McNinch and Luettich, 2009; Best, 1987; Signell and Geyer, 1991; White and Wolanski, 2008; Spiers et al., 2009; and many others]. Sediment transport in this case scales as a cube of the velocity [Bagnold, 1966] which becomes tidally asymmetric within the region of flow separation, possibly generating a tidally-averaged transport in the nearshore.

Flow separation and the generation of eddies depend on the radius of curvature of the corner (or aspect ratio of a headland) [Best and Reid, 1984], the balance of bottom friction and current strength, and the ratio of flow strength to local acceleration [Signell and Geyer, 1991]. Near Wasque Point, the strong ebb jet through Muskeget Channel separates from the shoreline, resulting in a quiescent zone at the southeastern corner of Chappaquiddick Island (Figure 1a,b). The evolution of the radius of curvature of Wasque Point, a primary control of flow separation, over the lifetime of Katama Inlet (Figure 1d) suggests that flow separation, in addition to the inlet, could impact sediment transport at nearby shorelines. Here, field-tested numerical model simulations are used to estimate the effects of an inlet, the ebb shoal, wave height, wave 
direction, and shoreline geometry on erosion and deposition along a curved coast with a migrating inlet.

\section{Numerical Simulations}

Waves and currents were simulated with the numerical models SWAN (waves [Booij et al., 1999]) and Delft3D-FLOW (currents [Lesser et al., 2004]) using hydrodynamic settings detailed in Chapter 1. Similar to previous studies at this location [Hopkins et al., 2015], for the no-wind cases and relatively short evolution distances here, wind and nonlinear interactions were not included.

Sediment transport [Van Rijn, 1993] was simulated using the modeled waves and currents. Most model parameters were set to default values with a grain size of $500 \mu \mathrm{m}$ based on sediment samples acquired around Katama Bay in 2013, except for the reference height $(0.5 \mathrm{~m})$, the current-related reference concentration factor (0.25), and the wave-related suspended and bedload transport factors $(0.1)$, which were reduced from the default values (1) that smoothed all bedforms and produced unrealistic transport around the island. Reduction in the wave-related transport factors has become standard practice for studies using Delft3D (Daly et al., 2014; among others). Transport was averaged over several tidal cycles to remove variability within ebb or flood flows. The divergence (convergence) of the transport vectors was used as a proxy for erosion (deposition), and the morphology was not updated during the model run. These proxies primarily are a function of the simulated hydrodynamics, which have been verified with field observations at this [Hopkins et al., 2015] and other [Mulligan et al., 2010; Elias et al., 2012; Hansen et al., 2013, 2014, 2015] shallow-water locations. 
Similarly to the model in Chapter 1, large-scale bathymetry within the model domain was obtained during 1998 and 2008 USGS surveys (Northeast Atlantic 3 arc second map National Geophysical Data Center, 1999] and Nantucket 1/3 arc second map [Eakins et al., 2009]), and has horizontal resolution of 10 to $90 \mathrm{~m}$. The bathymetry near the shoreline, inlet channel, bay, and ebb shoal near Katama Inlet was obtained each summer between 2011 and 2015 with a GPS and an acoustic altimeter mounted on a jetski. The horizontal resolution of the jetski surveys is on the order of $10 \mathrm{~m}$, with finer resolution near steep features. For 2008 (similar to 2007 immediately after the inlet was breached), the location of the inlet and the geometry of the southeastern corner of Chappaquiddick Island (Figure 1) were estimated from satellite images.

When initialized with frequency-directional spectra from WaveWatchIII [Tolman, 2002] along the offshore boundary of the model domain, and run over the bathymetry observed in 2015 , the model simulates the currents observed near the southeastern shoreline of Chappaquiddick Island, including the sharp gradient from the strong ebb flows in Muskeget Channel (red in Figure 2) to the quiescent zone of weak flows near the shoreline (blue in Figure 2). The observed currents were estimated with an acoustic Doppler current profiler (ADCP) mounted on a small boat. Each suite of six transects (Figure 2a and $2 \mathrm{~b}$ ) took about $2 \mathrm{~h}$, during which time the tidal flows changed (increasing ebb currents flowing from Vineyard Sound to the Atlantic), explaining some of the discrepancies with the 1-h flow simulations. 


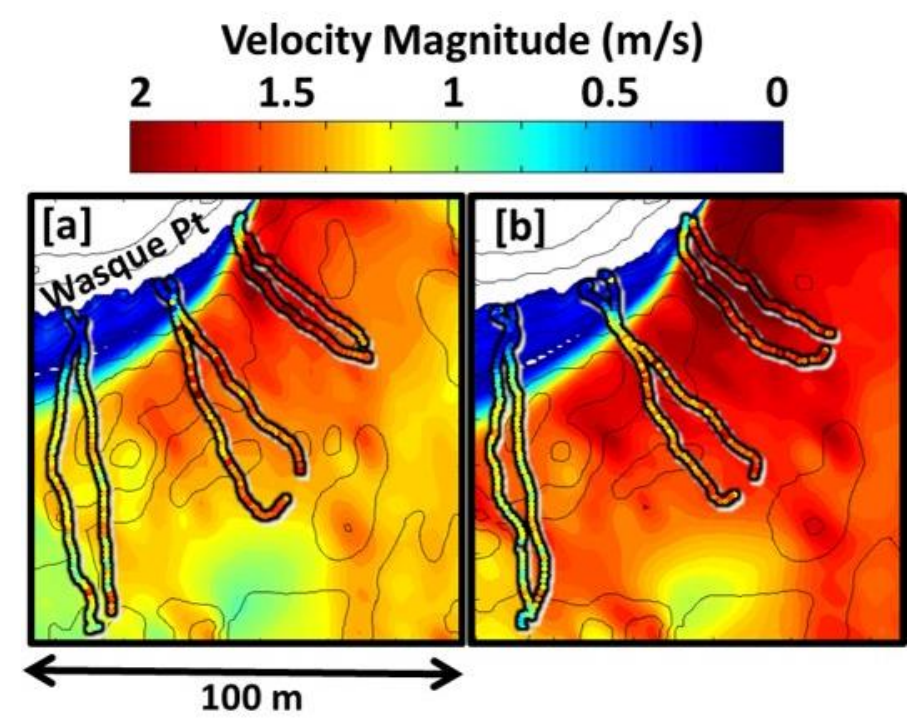

Figure 2. Observed (colored symbols within black outlines of the boat transects) and simulated (color contours, scale above) currents near Wasque Point during approximately (a) mid- and (b) maximum-ebb tide. If model and data agree, the colors along the transect lines match the colors of the surrounding simulation contours. The observations (13 Jul 2015) from the ADCP transects are averaged over depth and over $\sim 10 \mathrm{~m}$ along the track (boat speed $\sim 1 \mathrm{~m} / \mathrm{s}$ ). The simulated currents are from 1-h model runs initialized with wave and tidal conditions corresponding approximately to those observed during the middle of each $\sim 2$-h long suite of transects.

\section{Results and Discussion}

Model simulations were used to investigate the effects of the inlet, the ebb shoal, incident wave height, incident wave direction, and the shape of the southeast corner of Chappaquiddick Island (a proxy for flow separation) on erosion and deposition of sediment near Wasque Point. Along the offshore boundaries the model wave field had a JONSWAP spectral shape with $H_{\text {sig }}=1$ (representative of typical conditions in this area occurring $\sim 70 \%$ of the time in the last decade) or $3 \mathrm{~m}$ (representative of storm events that occur $\sim 5 \%$ of the time) and $8 \mathrm{~s}$ waves with a $\cos ^{20}$ directional distribution centered either on shore-normal or $30^{\circ}$ west of normal. Tides on the boundaries were set to values between spring and neap. Model simulations were averaged over three tidal cycles for each year with observed nearshore bathymetry (2008, 2011-2015). 
The radius of curvature of the southeast corner of Chappaquiddick Island is used as a proxy for flow separation [Best and Reid, 1984]. The center of the curve is at a point closest to where ebb flows begin to separate from the shoreline, estimated as the location with the largest simulated cross-shore velocity gradient near the corner (green circle in Figure 3a). The angles of tangents to the shoreline (relative to the tangent at the center point) are calculated every $13 \mathrm{~m}$ on either side of the center, and the slope of a least squares fit of distance as a function of angle is used as the estimate of the radius of curvature (Figure 3b). The sum of the absolute values of total erosion and total deposition within an area $+/-400 \mathrm{~m}$ from the center point extending from the shoreline to 2-m water depth (Figure 3c) is used as a proxy for sediment transport. The results are not significantly different for areas that extend between $+/-200$ to $+/-500 \mathrm{~m}$ tangential to the center and to 4-m water depth.
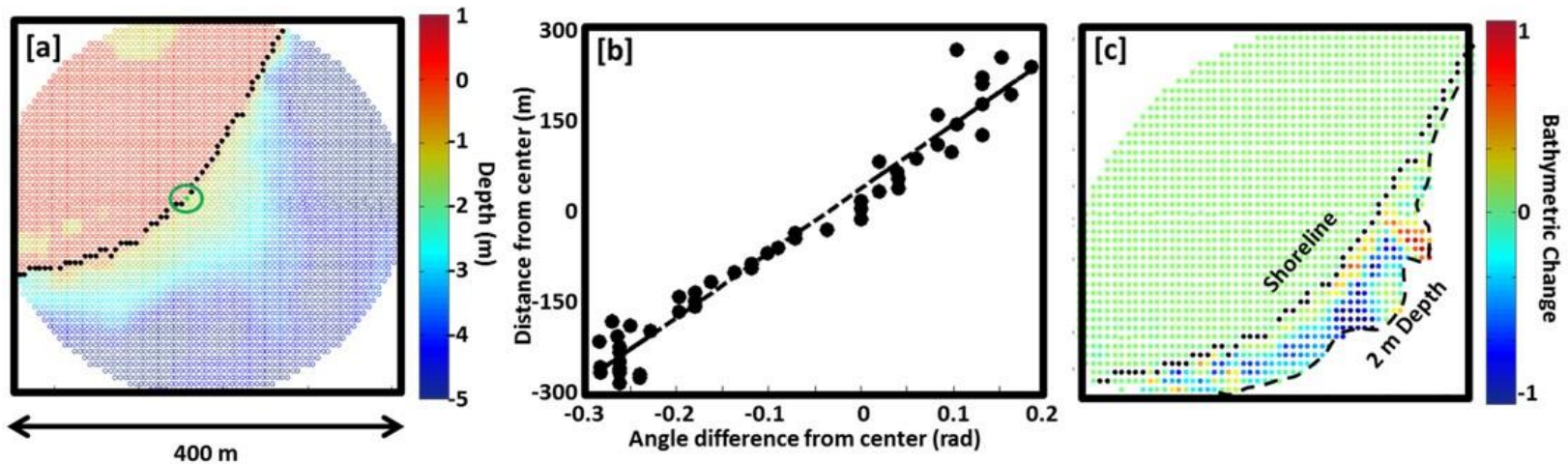

Figure 3: (a) Color contours of elevation (relative to mean sea level, scale on right) on the southeast corner of Chappaquiddick Island near Wasque Point in 2011. The black dots are the shoreline, and the green circle is the center of the radius of curvature. (b) Distance from the center point versus angle of tangents to the shoreline (relative to a tangent at the center). The slope of the least squares fit (dashed line) is the radius of curvature. (c) Color contours of erosion (blue) and deposition (red) (scale on right, arbitrary units) within a region between the shoreline (black dotted curve) and $2 \mathrm{~m}$ depth (black dashed curve).

Seven scenarios were simulated for each of the 6 years with measured bathymetry. Erosion and deposition were estimated for 1-m high normally incident waves using $i$ ) the measured bathymetry (dark open circles in Figure 4), ii) the same bathymetry with the inlet artificially 
closed (dark closed circles on Figure 4), and iii) with the inlet open, but the ebb-tidal delta (ebb shoal) replaced with alongshore uniform bathymetry similar to that on either side of the shoal (open squares in Figure 4). In addition, erosion and deposition were simulated for 3-m high incident waves for each year using $i v$ ) the measured bathymetry with normally incident waves (light open circles in Figure 4), v) the measured bathymetry with normally incident waves and the inlet artificially closed (light closed circles, Figure 4), vi) the measured bathymetry with waves from $30^{\circ}$ west of normal incidence (light open diamonds in Figure 4), and vii) the same bathymetry with the inlet artificially closed with waves from $30^{\circ}$ west of normal incidence (light closed diamonds in Figure 4).
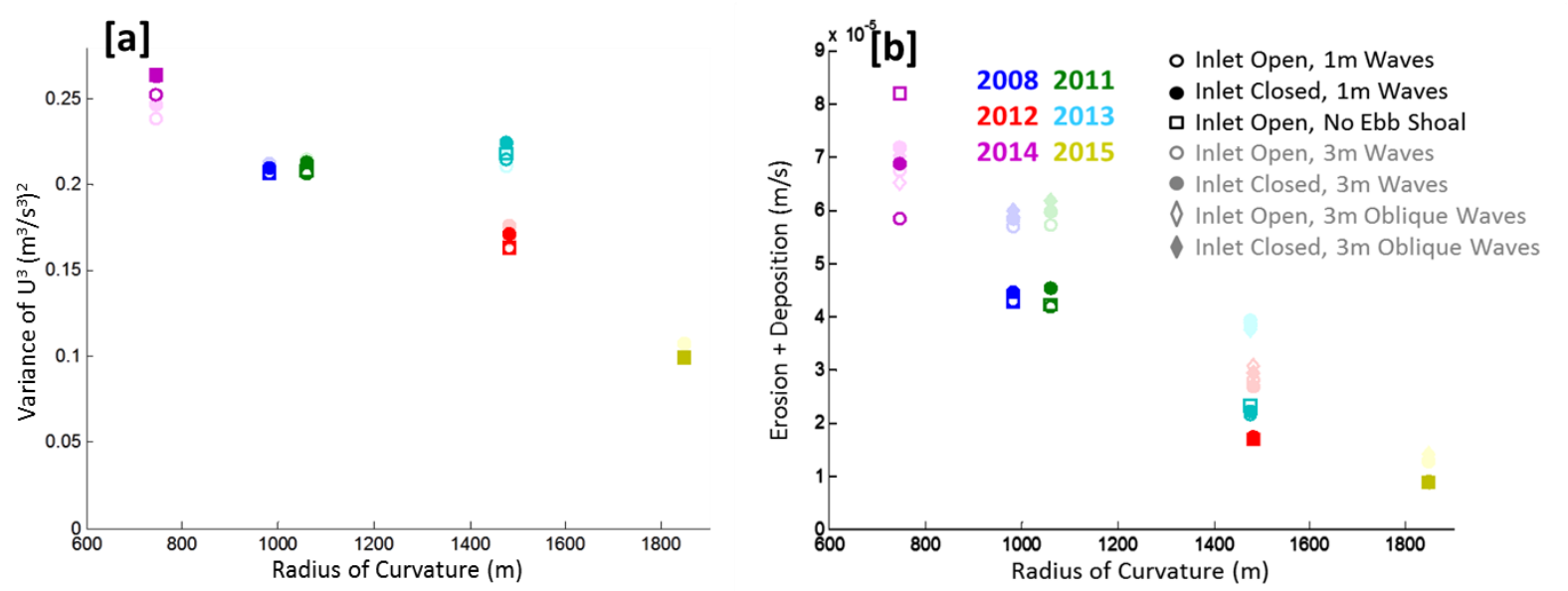

Figure 4. (a) The variance of velocity cubed (proxy for shear stress at the bed) and (b) the sum of the absolute values of simulated erosion and deposition along $400 \mathrm{~m}$ of the shoreline between 0 - and 2-m water depths (Figure 3c) versus the radius of curvature of the southeastern corner of Chappaquiddick Island in each of 6 years (colors, legend in upper right). Simulations used the bathymetry observed each year with the inlet open (open symbols), with the inlet artificially closed (closed symbols), with normally (circles) and obliquely (30 $0^{\circ}$ west of normal, diamonds) incident offshore wave directions, and with the ebb shoal removed artificially (open squares) for incident significant wave heights of 1 (dark colors) and $3 \mathrm{~m}$ (light colors). Inlet-open cases are not shown for 2015 because the inlet was closed.

Although momentum from the inlet flows during ebb tide tends to enlarge the separation region a few tens of meters (Figure 5), the simulated total erosion and deposition is not strongly affected by closing the inlet [compare open with closed circles for each year (colors) in Figure 4]. 
Similarly, removing the ebb shoal (Figure 4, open squares) does not have a significant effect on erosion and deposition, except in 2014 (Figure 4, purple symbols), when the inlet mouth and ebb shoal were $<0.5 \mathrm{~km}$ from Wasque Point (Figure 1b). As expected, there is more sediment motion with $3 \mathrm{~m}$ waves than with $1 \mathrm{~m}$ waves with the inlet open or closed (Figure 4, compare light with dark circles), and more transport with obliquely incident waves that drive more alongshore flow (Figure 4, compare light diamonds with light circles), the differences in erosion and deposition at the corner are relatively small. In contrast, the simulated erosion and deposition depends more on changes in the radius of curvature than on the different scenarios in any year (Figure 4), suggesting that sediment transport near the shoreline is influenced more by separation from the coast of the strong Muskeget Channel ebb-tidal flows than on the presence or absence of the inlet or the ebb shoal or on the details of the incident wave field. Sediment transport varies with the cube of velocity, and thus the correlation of the spatial variance of velocity cubed with radius of curvature (Figure 4a) suggests a direct link between radius of curvature and currentdriven sediment transport and morphological change around the curved coast.
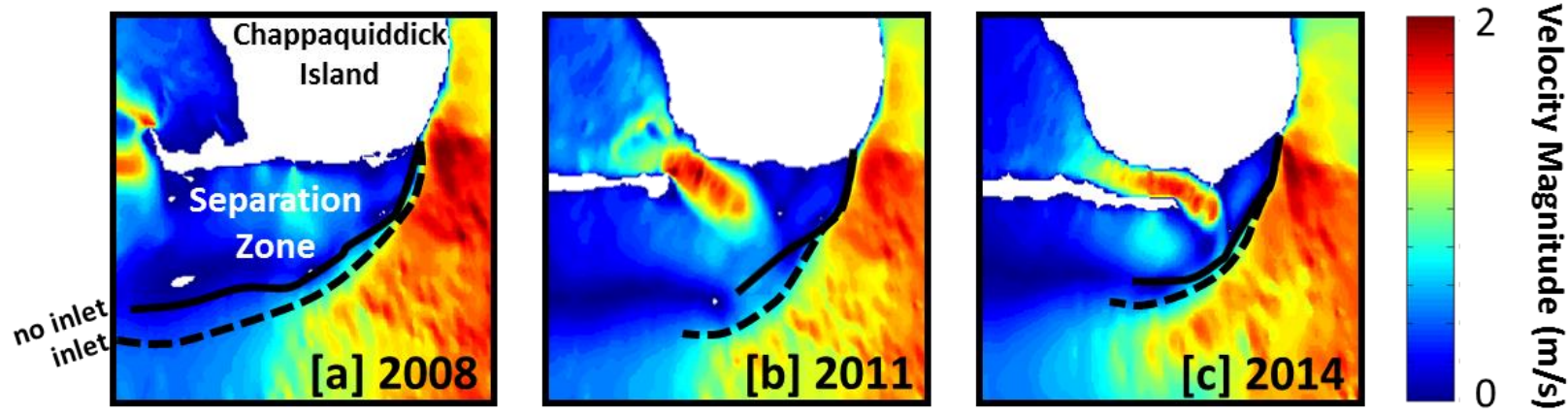

Figure 5: Contour maps of velocity magnitude (red $=2 \mathrm{~m} / \mathrm{s}$, blue $=0 \mathrm{~m} / \mathrm{s}$, color scale on the right) at peak ebb around the southeast corner of Chappaquiddick Island for the inlet location at (a) the middle of Katama Bay in 2008, (b) closer to the east of the Bay in 2011, and (c) south of Chappaquiddick Island in 2014. The size of the quiescent zone (black curves) is larger for simulations that include inlet flows (dashed) than simulations without inlet flows (solid). 
The simulations further suggest that the geometry of the separation region and the intensity of the separated jet combine to influence sediment transport at the southeast corner, while vorticity generated at the boundary of the quiescent zone does not correlate with radii of curvature or with erosion and deposition (not shown). Instead, tidally asymmetric transport is enhanced at the shoreline when the corner is sharper (smaller radius) and the ebb-tide quiescent zone is larger, because sediment is mobilized during the stronger flood flows and deposited during ebb when currents decrease. The strength of the ebb jet outside of the quiescent zone also increases when the corner is sharper, allowing for more sediment motion (Figure 4a). In 2008, 1 year after Katama Inlet formed, the radius of curvature was small and the simulations have relatively high erosion and deposition near the shoreline (dark blue symbols in Figure 4). As the shoreline eroded between 2011 and 2013, the radius of curvature increased, and although the shoreline continued to erode, satellite images suggest the rate slowed (Figure 1d), consistent with the reduction in simulated erosion and deposition (2011 through 2013 in Figure 4). In 2014 the inlet mouth was south (rather than west) of Chappaquiddick Island (compare Figure 1b with 1c), and Norton Point had extended eastward to within the separation region (Figure 1b), resulting in a greatly sharpened corner (Figure 1b, purple symbols in Figure 4), and increased erosion and deposition. Between summer 2014 (Figure 1b) and summer 2015 (Figure 1d) Norton Point extended rapidly (several $\mathrm{m} /$ day from satellite and visual observations) until the inlet closed. When the Norton Point sand spit reached the shoreline near Wasque Point in 2015, the corner was smooth (largest radius of curvature), and erosion and deposition was smallest (yellow symbols in Figure 4), consistent with visual observations that suggest the shoreline did not evolve significantly between 2015 and 2016 . 


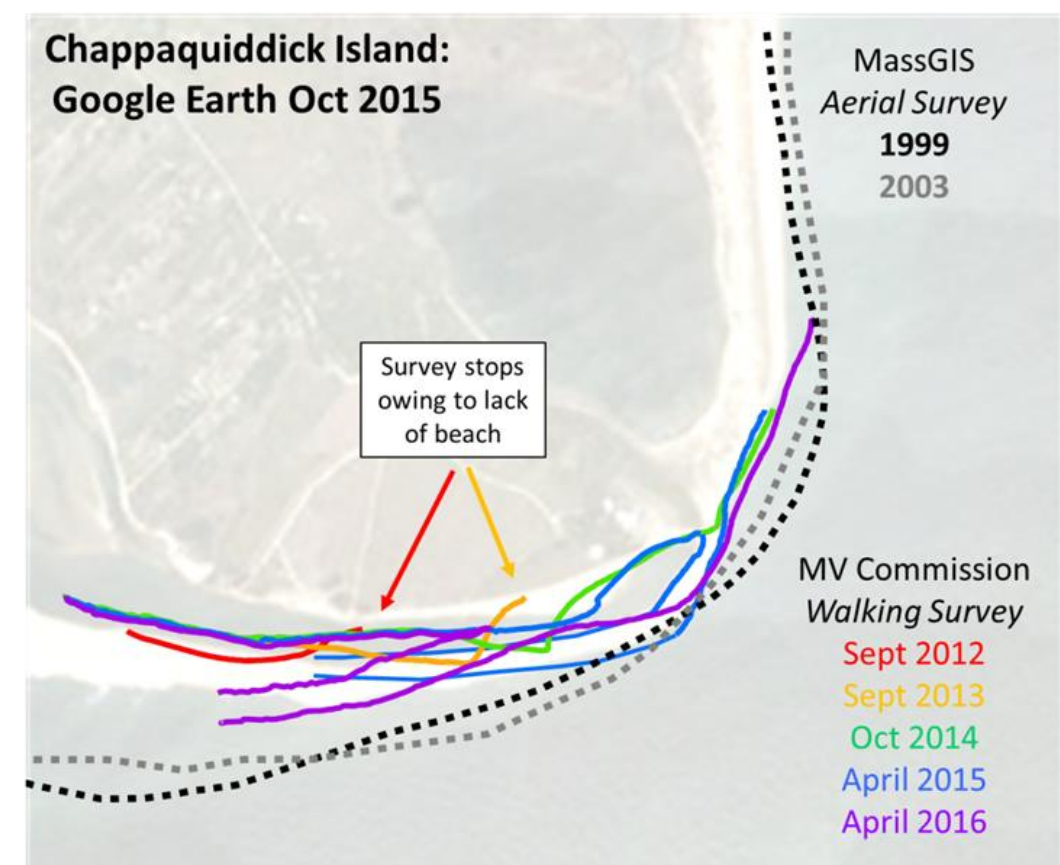

Figure 6: Aerial photograph of the southeast corner of Chappaquiddick Island in October 2015 (inlet closed) overlaid with (dotted) aerial surveys of the shoreline in (black) 1999 and (grey) 2003 and (solid) walking GPS surveys conducted by the Martha's Vineyard Commission in (red) Sept 2012, inlet open, (orange), Sept 2013, inlet open, (green) October 2014, inlet open, (blue) April 2015, inlet closed, and (purple) April 2016, inlet closed. The shoreline position changes more rapidly when the inlet is open (red - green) than when the inlet is closed (compare red and green curves with black and grey dotted curves and the seaward edges of the blue and purple curves). Data are courtesy of Chris Seidel at the Martha's Vineyard Commission (personal communication).

Although the simulations suggest erosion and deposition near the shoreline do not depend strongly on the presence or absence of the inlet, nor on wave-driven alongshore transport, there is increased erosion downstream after the inlet opens, in contrast with a relatively stable shoreline with the inlet closed (Figure 6). Disruption of alongshore transport or changes in circulation when the inlet opens (e.g., the simulated tidally averaged momentum of the currents near the southeast corner of Chappaquiddick Island decreases up to $10 \%$ when the inlet is open) may enhance corner erosion and impact the strength of flow separation around the corner. Fieldverified simulations with evolving morphology might help determine why the shoreline starts to erode when the inlet opens, and why the shoreline is stable when the inlet is closed. The 
simulations here do not include morphological evolution. However, they suggest that erosion and deposition decrease as the curvature of the southeast corner of Chappaquiddick Island increases and separation from the coast of the strong Muskeget Channel ebb flows decreases.

These results apply to any curved coastline with strong tidal flows, where flow separation can occur and either generate eddies or enhance the velocity variance in the nearshore (high flows increase, low flows decrease) to move sediment. The relationship between bathymetric change and radius of curvature (Figure 4) gives a broad indication of how the sharpness of a curved coastline can affect nearshore sediment transport and bathymetric change by altering the separation of currents from the shoreline. The strength of the tidal currents around the coastline also influence the impact of flow separation, a parameter space which has been previously explored (Signell and Geyer, 1991). The results presented here allow the impact of curvature on sediment transport to be combined with previous results about flow separation for a more complete picture of the impact of curved coastlines on both hydro- and morphodynamics in the nearshore. 


\section{Acknowledgements and data}

Data are available by e-mail to the authors. We thank Levi Gorrell and the PVLAB field crew for help obtaining the field observations, Jeff Hansen for help with numerical modeling, and Chris Seidel for performing walking surveys to track the evolution of the Chappaquiddick corner. Funding was provided by NSF, Sea Grant (NOAA), NDSEG, ASD(R\&E), and ONR. 


\section{References}

Adams, P. N., K. M. Keough, and M. Olabarrieta (2015), Beach Morphodynamics Influenced by an Ebb-Tidal Delta on the North Florida Atlantic Coast, Earth Surf. Process. Landforms, n/a-n/a, doi:10.1002/esp.3877.

Bagnold, R. A. (1966), An Approach to the Sediment Transport Problem from General Physics.

Bertin, X., A. B. Fortunato, and A. Oliveira (2009), A modeling-based analysis of processes driving wave-dominated inlets, Cont. Shelf Res., 29(5-6), 819-834, doi:10.1016/j.csr.2008.12.019.

Best, J. L., and I. Reid (1984), Separation Zone at Open-Channel Junctions, J. Hydraul. Eng., 110(11), 1588-1594, doi:10.1061/(ASCE)0733-9429(1984)110:11(1588).

Booij, N., R. C. Ris, and L. H. Holthuijsen (1999), A third-generation wave model for coastal regions: 1. Model description and validation, J. Geophys. Res., 104(C4), 7649, doi:10.1029/98JC02622.

Castelle, B., P. Bonneton, H. Dupuis, and N. Sénéchal (2007), Double bar beach dynamics on the high-energy meso-macrotidal French Aquitanian Coast: A review, Mar. Geol., 245(1-4), 141-159, doi:10.1016/j.margeo.2007.06.001.

Chaumillon, E., F. Ozenne, X. Bertin, N. Long, and F. Ganthy (2014), Wave climate and inlet channel meander bend control spit breaching and migration of a new inlet: La Coubre Sandspit, France., J. Coast. Res., (special issue), doi:10.2112/SI65-xxx.1.

Eakins, B.W., L.A. Taylor, K.S. Carignan, R.R. Warnken, E. Lim, and P.R. Medley (2009). Digital Elevation Model of Nantucket, Massachusetts: Procedures, Data Sources and Analysis, NOAA Technical Memorandum NESDIS NGDC-26, Dept. of Commerce, Boulder, CO, pp. 29

Elias, E. P. L., G. Gelfenbaum, and A. J. Van der Westhuysen (2012), Validation of a coupled wave-flow model in a high-energy setting: The mouth of the Columbia River, J. Geophys. Res. Ocean., 117(C9), doi:10.1029/2012JC008105.

Escoffier, F. F. (1940), The stability of tidal inlets, Shore and Beach, 8(4), 114-115.

Fenster, M., and R. Dolan (1996), Assessing the Impact of Tidal Inlets on Adjacent Barrier Island Shorelines, J. Coast. Res., 12(1), 294-310.

Fitzgerald, D. M. (1984), Interactions Between the Ebb-Tidal Delta and Landward Shoreline : Price Inlet, South Carolina, J. Sediment. Petrol., 54(4), 1303-1318.

Fitzgerald, D. M., I. V Buynevich, R. A. Davis Jr, and M. S. Fenster (2002), New England tidal inlets with special reference to riverine-associated inlet systems, Geomorphology, 48, 179208. 
Hansen, J. E., E. Elias, J. H. List, L. H. Erikson, and P. L. Barnard (2013), Tidally influenced alongshore circulation at an inlet-adjacent shoreline, Cont. Shelf Res., 56, 26-38, doi:10.1016/j.csr.2013.01.017.

Hansen, J. E., T. T. Janssen, B. Raubenheimer, F. Shi, P. L. Barnard, and I. S. Jones (2014), Observations of surfzone alongshore pressure gradients onshore of an ebb-tidal delta, Coast. Eng., 91, 251-260, doi:10.1016/j.coastaleng.2014.05.010.

Hansen, J. E., B. Raubenheimer, J. H. List, and S. Elgar (2015), Modeled alongshore circulation and force balances onshore of a submarine canyon, J. Geophys. Res. Ocean., 120(3), 18871903, doi:10.1002/2014JC010555.

Hicks, M. D., T. M. Hume, A. Swales, and M. O. Green (1999), Magnitudes, spacial extent, time scales and causes of shoreline change adjacent to an ebb tidal delta, Katikati Inlet, New Zealand, J. Coast. Res., 15(1), 220-240.

Hopkins, J. A., S. Elgar, and B. Raubenheimer (2015), Observations and model simulations of wave-current interaction on the inner shelf, J. Geophys. Res. Ocean., 120(1), 1-11, doi:10.1002/2015JC010788.Received.

Hume, T. M., and C. E. Herdendorf (1992), Factors Controlling Tidal Inlet Characteristics on Low Drift Coasts, , 8(2), 355-375.

Komar, P. D., and D. L. Inman (1970), Longshore Sand Transport on Beaches, J. Geophys. Res., 75(30), 5914-5927.

Lesser, G. R., J. A. Roelvink, J. a. T. M. van Kester, and G. S. Stelling (2004), Development and validation of a three-dimensional morphological model, Coast. Eng., 51, 883-915, doi:10.1016/j.coastaleng.2004.07.014.

Mcninch, J. E., and R. A. Luettich (2000), Physical processes around a cuspate foreland : implications to the evolution and long-term maintenance of a cape-associated shoal, Cont. Shelf Res., 20, 2367-2389.

Mulligan, R. P., A. E. Hay, and A. J. Bowen (2010), A wave-driven jet over a rocky shoal, $J$. Geophys. Res., 115(C10), C10038, doi:10.1029/2009JC006027.

National Geophysical Data Center (1999). U.S. Coastal Relief Model - Northeast Atlantic, Natl. Oceanic and Atmos. Admin., Boulder, Colo. doi:10.7289/V5MS3QNZ

O’Connor, M., J. A. G. Cooper, and D. W. T. Jackson (2007), Morphological Behaviour of Headland-Embayment and Inlet-Associated Beaches, Northwest Ireland, J. Coast. Res., SI 50, 626-630.

Ogden, G. (1974), Shoreline Changes Along the Southeastern Coast of Martha's Vineyard, Massachusetts for the Past 200 Years, Quat. Res., 4, 496-508. 
Powell, M. A., R. J. Thieke, and A. J. Mehta (2006), Morphodynamic relationships for ebb and flood delta volumes at Florida's tidal entrances, Ocean Dyn., 56(3-4), 295-307, doi:10.1007/s10236-006-0064-3.

Van Rijn, L. (1993), Principles of Sediment Transport in Rivers, Estuaries and Coastal Seas, Aqua Publishing, Blokzijl, Netherlands.

Robin, N., F. Levoy, O. Monfort, and E. Anthony (2009), Short-term to decadal-scale onshore bar migration and shoreline changes in the vicinity of a megatidal ebb delta, J. Geophys. Res. Earth Surf., 114(4), 1-13, doi:10.1029/2008JF001207.

Shi, F., D. M. Hanes, J. T. Kirby, L. Erikson, P. Barnard, and J. Eshleman (2011), Pressuregradient-driven nearshore circulation on a beach influenced by a large inlet-tidal shoal system, J. Geophys. Res., 116(C4), C04020, doi:10.1029/2010JC006788.

Signell, R. P., and W. R. Geyer (1991), Transient Eddy Formation Around Headlands, J. Geophys. Res., 96(C2), 2561-2575.

Slingerland, R. (1983), Systematic monthly morphologic variation of assawoman inlet: Nature and causes, Earth Surf. Process. Landforms, 8(2), 161-169, doi:10.1002/esp.3290080207.

Tolman, H. L. (2002), User manual and system documentation of WAVEWATCH-III version 2.22, NOAA / NWS / NCEP / MMAB Tech. Note, 222, 133. 


\title{
Chapter 3:
}

\section{Storm Impact on Morphological Evolution of a Sandy Beach}

\author{
Abstract \\ Observations of waves, currents, and bathymetric change in the nearshore owing to two \\ hurricanes at Katama Inlet, Martha's Vineyard show over $2.5 \mathrm{~m}$ of erosion and accretion after \\ each storm. A numerical model (Delft3D) simulating waves, currents, and morphological change \\ reproduces the observations with minimal tuning of the sediment transport parameters. Model \\ simulations of a week of storm activity show that increased storm intensity (total energy of the \\ storm divided by the duration of the storm) enhances sediment transport in this mixed wave-and- \\ tidal energy environment, similar to other wave-dominated environments. Simulations of months \\ of storm activity further suggest that the presence of storms enhances the morphological \\ evolution at this site, and in particular the migration of Katama Inlet. The rate of evolution \\ depends on both the balance of wave and tidal current energy and the distribution of storms over \\ time.
}




\section{Introduction}

Accurate predictions of changes in shoreline position are necessary for managing beaches, ports, and coastal infrastructure, as well as for planning resilient nearshore communities. These predictions rely in part on skillful numerical models of nearshore sediment transport and morphological change, which can help determine the efficacy and longevity of natural features such as barrier islands and marshes, as well as help predict the response of coastal environments to rising sea levels.

Changes in shoreline position are especially pronounced during storms, when high energy waves and storm surge can alter the shoreface of a beach in just days or even hours ([Miller, 1999; Lindemer et al., 2010; Herrling and Winter, 2014]; and many others). On decadal timescales, long term observations of shoreline changes along barrier islands in the Gulf of Mexico [Morton et al., 1995; Wahl and Plant, 2015] and the Outer Banks of the Carolinas [Moore et al., 2013] suggest that storm events (both waves and storm surge) correlate with the evolution of the coastline, with sea-level rise becoming more important on timescales of centuries. Additionally, the enhanced shoreline changes observed in 2013 at beaches in Europe, relative to changes observed during the previous decade, correlated with unusually energetic storm waves (rather than to storm surge) [Masselink et al., 2016].

Many models accurately predict nearshore hydrodynamics during storms, including waves, surge, setup, and, in some cases, overwash ([Hsu et al., 2006; Lindemer et al., 2010; Dietrich et al., 2011; Mulligan et al., 2015]; and many others). Ideally, these hydrodynamics can be used in numerical simulations to investigate the mechanisms of nearshore sediment transport and predict 
morphological evolution. However, at present sediment transport cannot be simulated accurately without tuning to observed transport [Amoudry and Souza, 2011], and there are few comparisons of simulations with observations of storm-induced sediment transport and morphological change. As a result, there are few studies of the relative importance of occasional storms and daily tides to shoreline evolution.

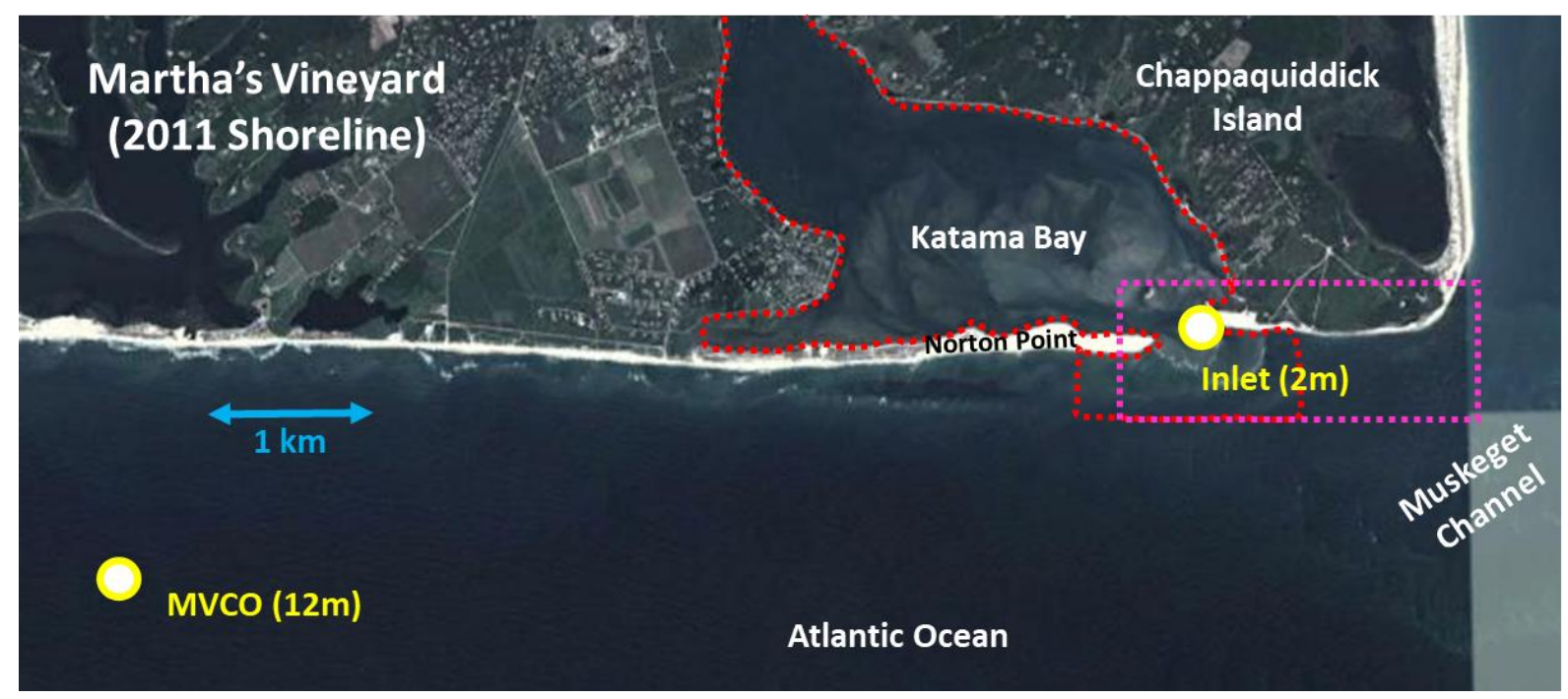

Figure 1: Satellite image of Martha's Vineyard in 2011. White circles with yellow outlines indicate locations of wave (MVCO, bottom left) and current (Inlet, middle right) sensors deployed during Hurricanes Irene and Sandy. The red dotted curve surrounds the area surveyed before and after Hurricane Irene (similar for Sandy). The pink dotted box encompasses the area used to calculate sediment transport variance owing to storm conditions.

Here, field observations are used to calibrate a numerical model that simulates nearshore hydrodynamics, sediment transport, and morphological change along the southern shoreline of Martha's Vineyard, MA (Figure 1). The observations include waves, currents, and bathymetry over several years (2011-2015) that contained hurricanes, nor'easter storms, and strong tidal currents. Before the observation period, Norton Point, the sand barrier separating Katama Bay from the Atlantic Ocean (Figure 1) breached during a strong nor'easter storm in April 2007. It then migrated $2.5 \mathrm{~km}$ eastward until it closed in 2015 [Orescanin et al., 2016; Hopkins et al., 2017]. Between 2011 and 2015 tidal currents observed in Katama Inlet (Figure 1) were as high 
as $2 \mathrm{~m} / \mathrm{s}$ [Orescanin et al., 2016] and tidal currents flowing through Muskeget Channel separating Vineyard Sound from the Atlantic (Figure 1) were as high as $3 \mathrm{~m} / \mathrm{s}$ [Hopkins et al., 2017]. The rapid morphological evolution and detailed hydrodynamic observations at this site are used in a field-calibrated Delft3D model to investigate the relative roles of wave- and tidallydriven sediment transport, the importance of storms in a mixed-energy wave and tide environment, and the differences between short, highly energetic (e.g., hurricanes) and longer, less energetic (e.g., nor'easters) storms.

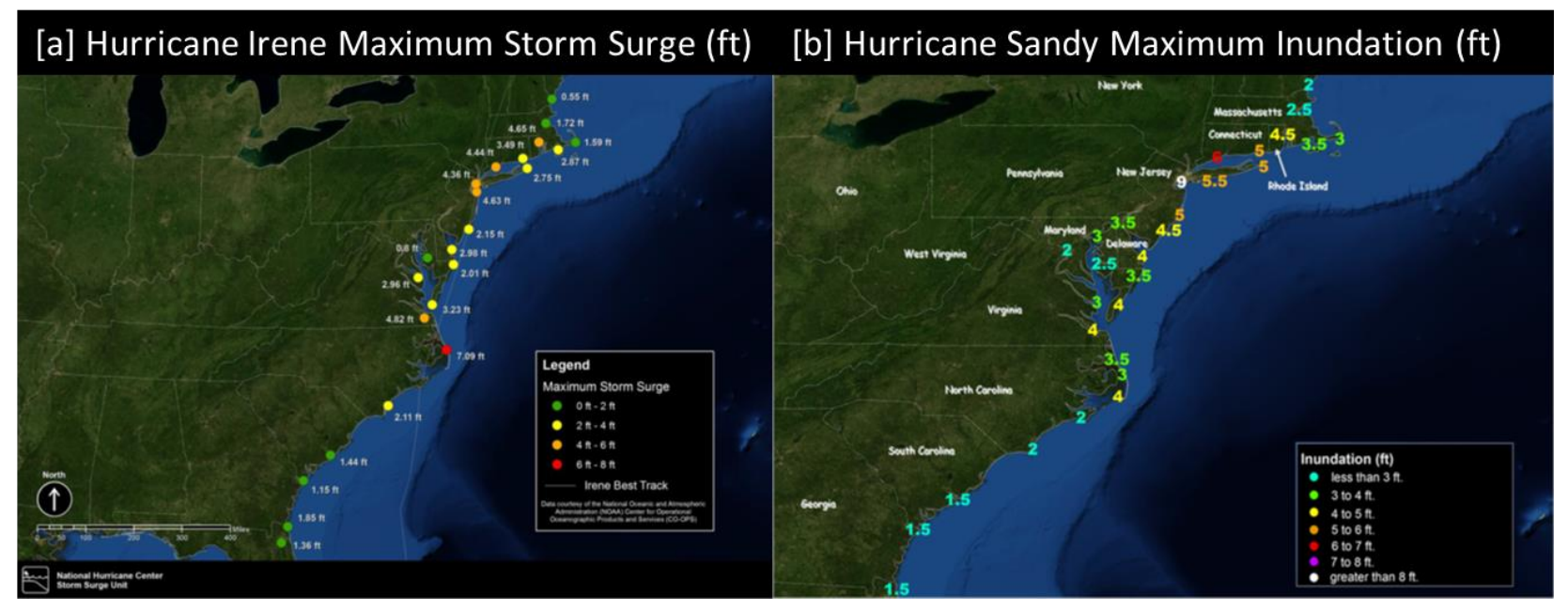

Figure 2: (a) Maximum storm surge owing to Hurricane Irene and (b) maximum inundation owing to Hurricane Sandy along the East Coast of the United States. Martha's Vineyard had $\sim 1$ $\mathrm{m}$ of storm surge from Irene and $\sim 1 \mathrm{~m}$ of inundation from Sandy.

\section{Methods}

\section{a) Observations}

Simulations of measured bathymetric change focus on Hurricanes Irene and Sandy, two of the most energetic storms to hit the East Coast of the United States in the last few decades. In 2011, Irene produced storm surge up to $1.2 \mathrm{~m}$ in the Northeast, and in 2012, Sandy caused inundation of over $1.8 \mathrm{~m}$ in similar areas (Figure 2). In total, both storms caused several billions worth of 
damage to coastal communities and infrastructure along the sandy coast of the United States [Avila and Cangialosi, 2011; Blake et al., 2013].

To track the impact of these storms on Katama, bathymetry from the northern end of Edgartown Channel through Katama Bay and Inlet and across the ebb shoal in the ocean to the south (Figure 1, red curve) was measured with a GPS- and acoustic-altimeter-equipped personal watercraft. The vertical resolution of the surveys is approximately $0.05 \mathrm{~m}$, and the horizontal resolution is $0.10 \mathrm{~m}$ along transects separated by 5 (near complex bathymetry) to $60 \mathrm{~m}$ (uniform bathymetry). Surveys were conducted before (August 6, 2011) and after (August 30, 2011) the passage of Hurricane Irene (28-29 August 2011) and before (October 2, 2012) and after (November 11, 2012) the passage of Hurricane Sandy (30 October, 2012) and a nor'easter (November 7-9, 2012). The bay surface area is approximately $7.5 \times 10^{6} \mathrm{~m}^{2}$, and water depths range from less than $1 \mathrm{~m}$ on the flood shoal to $10 \mathrm{~m}$ at the northern part of the Bay [Orescanin et al., 2016].

Offshore waves were measured in 50 m depth with NOAA buoy 44097 (Figure 1), waves in 12 m depth were measured at the Martha's Vineyard Coastal Observatory (MVCO, http://www.whoi.edu/mvco), and currents in Katama Inlet were measured with a pressure gage colocated with an acoustic Doppler velocimeter with sample volume about $0.8 \mathrm{~m}$ above the sandy seafloor in $\sim 2 \mathrm{~m}$ depth. Bottom pressures were corrected for atmospheric pressure fluctuations and converted to sea-surface elevation fluctuations assuming hydrostatic pressure and using linear theory.

\section{b) Numerical Simulations of Sediment Transport}


Observations of the hydrodynamics and morphodynamics during the hurricanes were used to calibrate and test the Delft3D numerical model (Chapter 1) on the southern coast of Martha's Vineyard. The default sediment transport formulation (TRANSMOR2000, based on Van Rijn, 1993) was used to approximate the nonlinear response of sand grains to forcing by waves and currents.

Sediment transport in the nearshore can be characterized as grains of noncohesive sediment at the bed and in the water column that move owing to a combination of forcing by waves, currents, and gravity. The motion depends on a balance between the weight of the grain (gravity), the force required to overcome friction, and the stress imparted by the surrounding fluid. In addition, grains interact with each other by colliding and bouncing, and by sheltering other grains from the ambient flow field. Some numerical models can simulate the motion of collections of individual sand grains by parameterizing grain-grain interactions [Drake and Calantoni, 2001; Calantoni et al., 2004; Hsu and Liu, 2004; Amoudry et al., 2008; Yeganeh-Bakhtiary et al., 2009], but modern computational resources are not sufficient to integrate the motion of billions of individual particles comprising a beach.

Instead, most models of shoreline morphological evolution parameterize the basic physics underlying grain motion. Often, transport is divided into bedload (grains move in the boundary layer near the bed) and suspended load (grains are lifted into the water column above the bed where they are advected by currents). Sediments can move both in the cross- and alongshore directions. Although both modes and directions of transport are important, models for alongshore 
sediment transport are more skillful than those for cross-shore transport when applied to large areas of coastline [Amoudry and Souza, 2011].

Early studies of alongshore transport solved for the total load using an approach that assumes a portion of the flow energy transports sediment at the bed and a portion of the energy suspends sediment that is then transported by currents in the water column [Bagnold, 1966; Bowen, 1980; Bailard, 1981]. This "energetics" approach scales sediment transport $q$ as wave energy $E \sim H s i g^{2}$, giving $q \sim H s i g^{2}$. While best used on wave-dominated coastlines over long timescales, energetics models driven with observations of waves and currents were used to show that cross-shore gradients in seaward-directed mean currents ("undertow") drive sediment offshore during storms, resulting in offshore migration of sand bars [Thornton et al., 1996; Gallagher et al., 1998; Hsu et al., 2006], and that asymmetrical waves drive sediment onshore during calmer conditions, resulting in onshore migration of sand bars [Hoefel and Elgar, 2003; Hsu and Raubenheimer, 2006; Hsu et al., 2006]. However, by parameterizing important processes, energetics models are limited [Van Wellen et al., 2000; Drake and Calantoni, 2001; Van Rijn, 2002].

Recently, three-dimensional numerical models such as Delft3D have implemented sediment transport formulations with parameterizations that approximate the force balance on grains [Van Rijn, 1985; Soulsby and Damgaard, 2005]. Bedload motion is initiated when the fluid-induced bed stress exceeds a critical value, with the bedload transport $q_{B}$ given by [Meyer-Peter and Muller, 1948; Fredsoe and Deigaard, 1992; Soulsby and Damgaard, 2005] 


$$
q_{B}=m \tau^{n}\left(\tau-\tau_{c r}\right)^{p}
$$

where $\tau$ is a non-dimensional bed shear stress (scaled as the cube of near-bed velocity) and $\tau_{c r}$ is the shear-stress threshold for motion. There are several expressions for $\tau$ and for the values of the constants $m, n, p$ that depend on currents, waves, and bedforms [Amoudry and Souza, 2011].

The stress-based models approximate the turbulence in the boundary layer and the mean flow field that lifts grains into the water column against the force of gravity. The suspended sediment is advected by wave-orbital velocities and mean currents. Denser grains do not travel as far as less dense grains because they are not suspended as high above the bed and because they fall back to the bed more rapidly [Van Rijn, 1993; Harris and Wiberg, 2001; Lesser et al., 2004]. The vertical distribution of sediment concentration usually is modeled by an advection-diffusion equation that balances particle fall velocity with an empirical particle mixing coefficient that depends on sediment properties and wave and current conditions [Amoudry and Souza, 2011].

Most parameterizations of the threshold of motion for bedload and of the vertical mixing of suspended load depend on a bottom boundary layer that is affected by bottom roughness, which is a function of sediment grain sizes and bedforms. Common bottom roughness formulations for turbulent conditions assume a logarithmic velocity profile near the bed [Grant and Madsen, 1982; Fredsoe, 1984; Madsen, 1994], an approach that has been verified in laboratory studies [van der A et al., 2011; Yuan and Madsen, 2014]. The calculations of bottom shear stress using the bottom roughness and near-bed velocities include wave-current formulations [Madsen, 1994; Soulsby and Clarke, 2005], as well as terms to account for a fixed rippled bed [Grant and 
Madsen, 1979] or a movable bed [Harris and Wiberg, 2001]. Although these formulations have been tested in the laboratory, there are few verifications with field data.

Here, a commonly used version of the shear stress models [Van Rijn, 1993] (see Appendix 1 for details) is applied to simulate the sediment transport and morphological change along the southern shoreline of Martha's Vineyard near Katama Inlet (Figure 1) for conditions observed during and between storms, and for a range of idealized conditions beyond those observed.

\section{c) Calibration of Model Sediment Transport}

The implementation of the model used in this chapter closely follows that described in Chapter 2. However, here Delft3D is run with morphological updating, which requires the calibration of a few free parameters in the sediment transport model. The two most commonly tuned parameters, the coefficients for wave- and current-induced transport [Lesser et al., 2004] were set to 0.125 and 0.200 , respectively, based on the morphological evolution and offshore waves observed over a two-month long period with several storms (Appendix 2).

\section{Results}

\section{a) Validation of Hydrodynamics}

The Delft3D wave and circulation model accurately simulates the observed wave heights, wave directions, and currents in 12, 7, and $2 \mathrm{~m}$ depth during calm conditions in 2013 and 2014 (see Chapter 1). Model skill also is high during much more energetic storm events. In these cases, offshore boundary wave conditions were given by observations of waves from the buoy in $50 \mathrm{~m}$ depth south of Martha's Vineyard. The results are similar if the offshore boundary conditions are 
given by output from the WaveWatch3 (WW3) model. During hurricanes, wind forcing becomes important for accurate simulations (see Appendix 2). Wind boundary data were acquired from WW3 (forced by the Global Data Assimilation Scheme [Tolman, 2002]).

Using these wind and wave boundary conditions, the model simulates accurately the observed wave heights (Figure 3a,e) and directions (Figure 3b,f) in 12-m depth water during both storms. The model also simulates the currents observed in the inlet channel in approximately $2-\mathrm{m}$ water depth (Figure $3 \mathbf{c , d}, \mathbf{d , g}, \mathbf{h}$ ). Some of the discrepancies in the simulated east current during Irene (Figure 3c) may be owing to spatially varying currents within the inlet that change on scales smaller than a model grid cell, especially near the observations in complex shallow bathymetry.
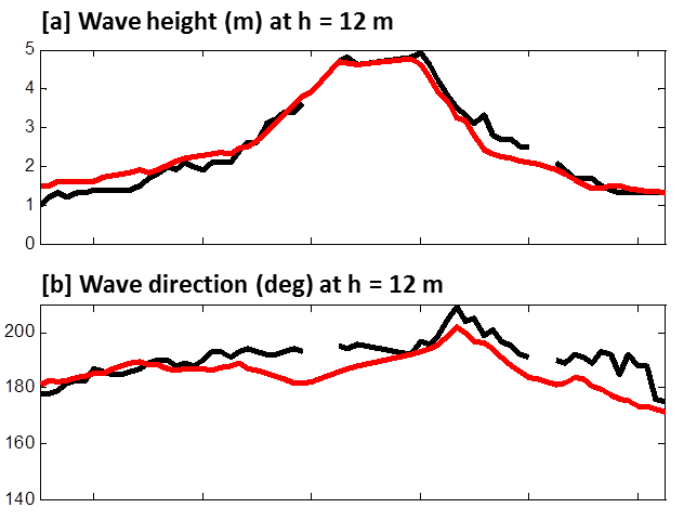

[c] East velocity $(\mathrm{m} / \mathrm{s})$ at $\mathrm{h}=\mathbf{2} \mathrm{m}$
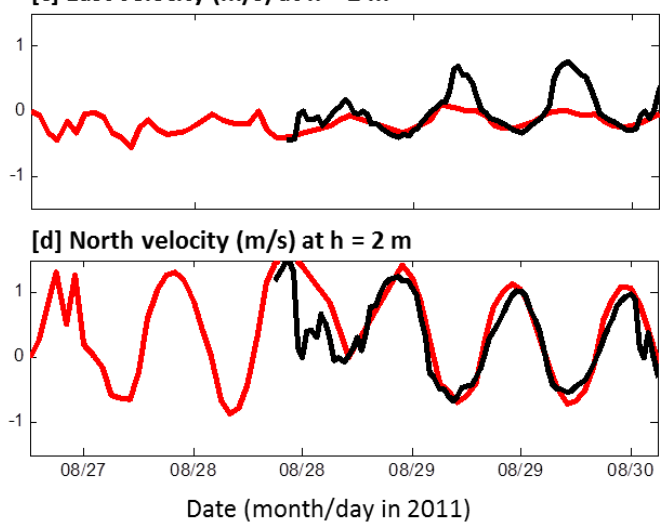

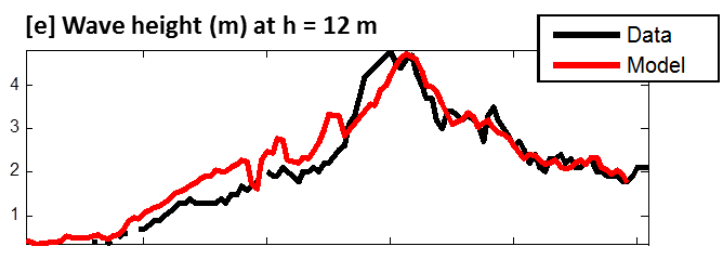

[f] Wave direction (deg) at $\mathrm{h}=12 \mathrm{~m}$

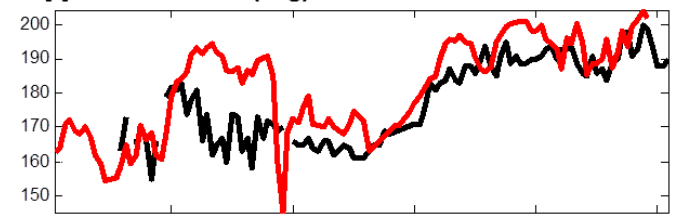

[g] East velocity $(\mathrm{m} / \mathrm{s})$ at $\mathrm{h}=\mathbf{2} \mathrm{m}$

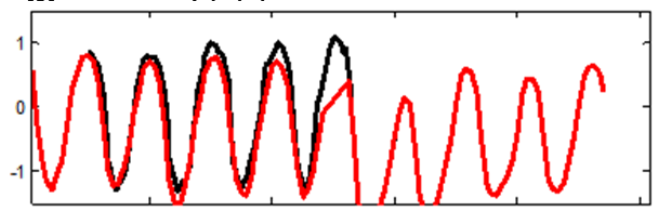

[h] North velocity $(\mathrm{m} / \mathrm{s})$ at $\mathrm{h}=\mathbf{2} \mathrm{m}$

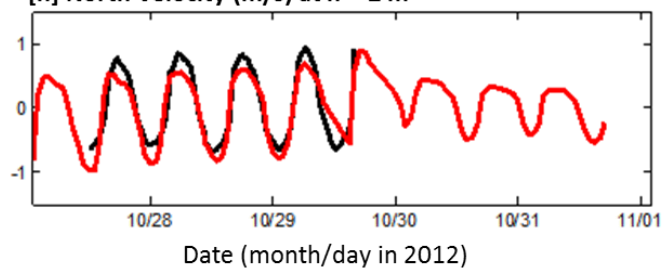

Figure 3: Observed (black curves) and modeled (red curves) (a,e) significant wave height and $(\mathrm{b}, \mathrm{f})$ wave direction at MVCO (12 m depth), and (c,g) east-west and (d,h) north-south velocity inside the inlet mouth ( $2 \mathrm{~m}$ depth) for (a-d) Hurricane Irene and (e-h) Hurricane Sandy. 


\section{b) Validation of Morphodynamics}

A wide range of metrics for model morphodynamic skill can be examined depending on the sediment transport quantities of interest, although interpreting these metrics often requires sitespecific knowledge ([Sutherland et al., 2004; Ganju et al., 2011; Daly et al., 2014; Luijendijk et al., 2017]; and many others). For example, quantitative metrics can be used to test if changing a model parameter produces a relatively more accurate simulation of observed morphological evolution. However, it is difficult to use these metrics to determine if the model skill is poor or good in an absolute sense. In contrast, qualitative metrics give a sense of absolute model skill on a case-by-case basis, and are used here to evaluate model performance during storms. An accompanying quantitative model validation is given in Appendix 2.
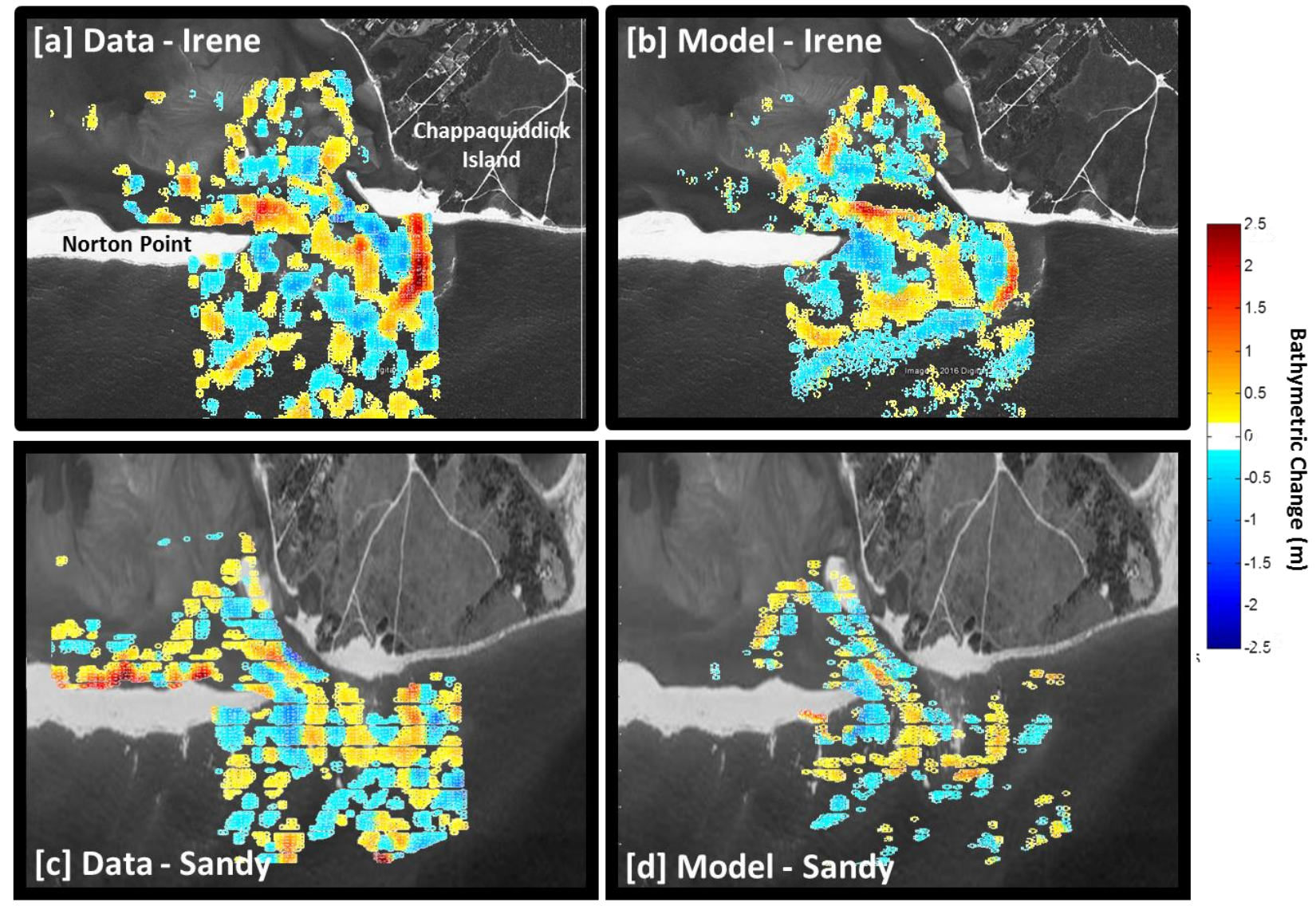

Figure 4: Bathymetric change (red is accretion, blue is erosion, scale on the right) between (a,c) observed and (b,d) simulated hurricane conditions for Hurricanes $(a, b)$ Irene in 2011 and $(c, d)$ 
Sandy in 2012. The observed pre- and post-storm bathymetries are interpolated onto the 13-m horizontal spacing model grid.

The calibrated Delft3D numerical model simulates accurately the observed bathymetric changes owing to Hurricanes Irene and Sandy. For example, the simulated spatial patterns and amplitudes of erosion and deposition (Figures 4b,d) are similar to those observed (Figure 4a,c). Further, the simulated bathymetric changes across and along the inlet, along the ebb shoal, and south of inlet are consistent with the change observed during both storms (Figure 5). Some of the simulated patterns in erosion and deposition are shifted spatially relative to the observed patterns (Figure 5). Spatial (wavenumber) spectra of the simulated and observed bathymetric change along transects (Figure 6) are similar, suggesting that other than a small spatial shift, modeled bathymetric changes are consistent with the observed changes. The spatial shift partially may be because observed bathymetry, with $0.1 \mathrm{~m}$ spatial resolution in N-S and $10 \mathrm{~m}$ spatial resolution in E-W, were stretched and compressed to fit onto the 13-m model grid and to seamlessly mesh with observed bathymetry outside of the inlet location. The hydrodynamic and morphologic simulation tests demonstrate that the field-calibrated model can be used to study morphological evolution near Katama Inlet.

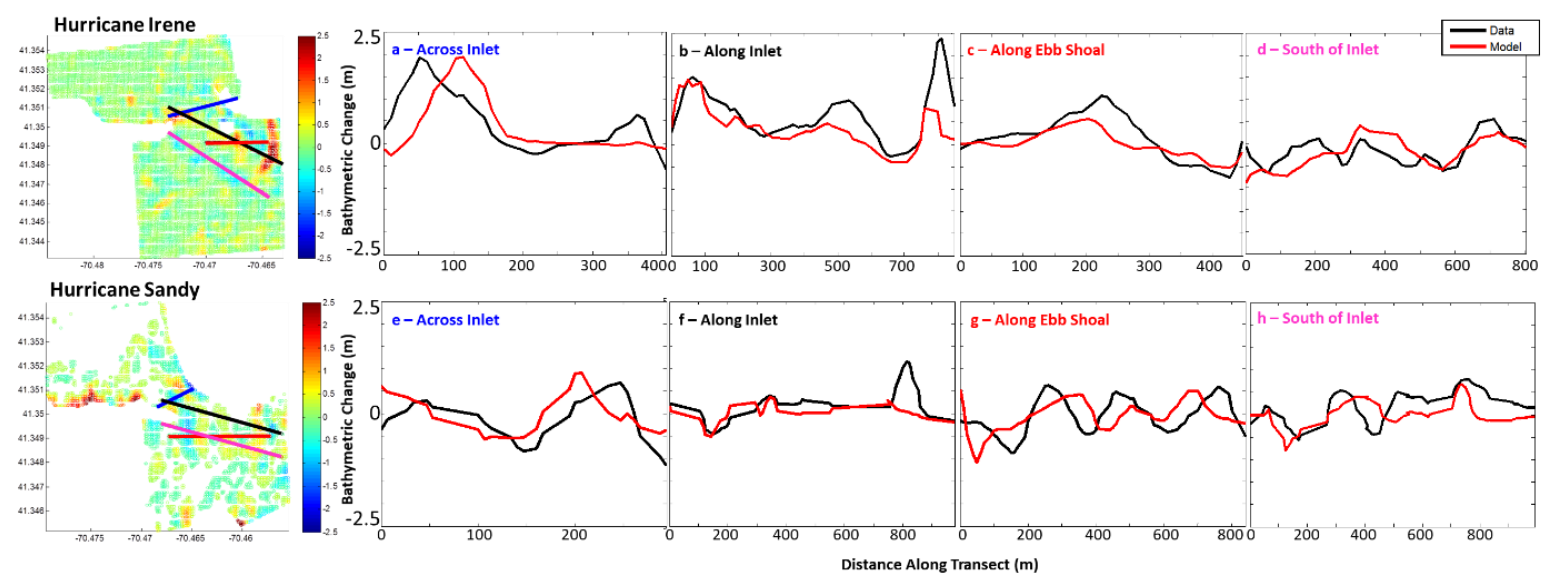

Figure 5: Observed (black curves) and simulated (red curves) changes in erosion and deposition versus distance along transects located across the inlet mouth (blue), along the inlet channel (black), across the ebb shoal (red), and on the southern shoreline of Norton Point. The location of 
each transect is shown in the color contour plots of bathymetric change on the left for (top) Hurricane Irene and (bottom) Hurricane Sandy.

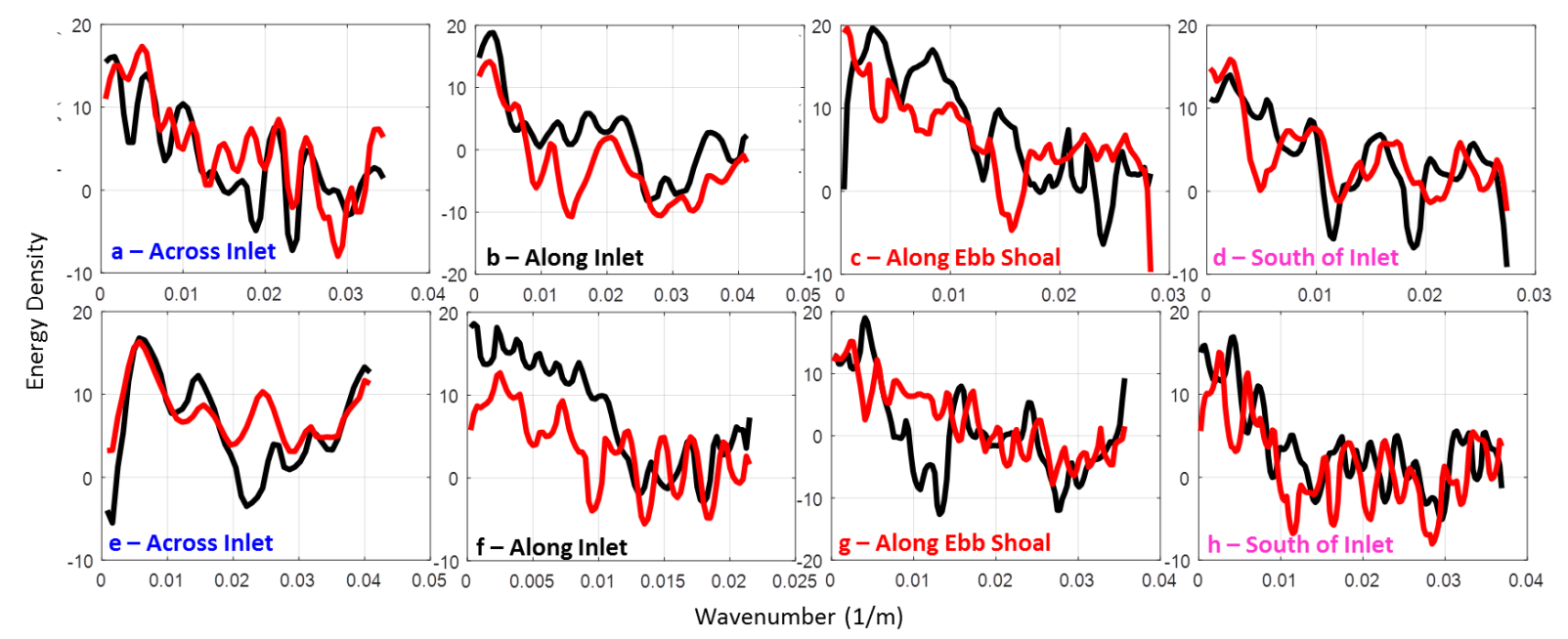

Figure 6: Observed (black curves) and simulated (red curves) power spectral density versus wavenumber of changes in erosion and deposition along the transects located (a,e) across the inlet mouth (blue), (b,f) along the inlet channel (black), (c,g) across the ebb shoal (red), and (d,h) on the southern shoreline of Norton Point. The location of each transect is shown in the color contour plots of bathymetric change on the left in Figure 5 for (top) Hurricane Irene and (bottom) Hurricane Sandy.

\section{c) Storm Impact on Morphology on Day to Week Timescales}

Alongshore sediment transport can be scaled roughly with the wave energy incident on a shoreline, and thus episodic, high-wave events such as hurricanes shape the morphological evolution of wave-energy dominated nearshore environments [Walstra et al., 2013; Herrling and Winter, 2014; Kaji et al., 2014]. The effect of episodic events on mixed wave-and-current energy systems is less well known, although recent studies at the Sand Engine in the Netherlands suggest storm energy has a similar relationship to sediment transport in the presence of tidal currents $<1 \mathrm{~m} / \mathrm{s}$ [Luijendijk et al., 2017] when wave-driven currents in the nearshore approach 1 $\mathrm{m} / \mathrm{s}$ [Radermacher et al., 2017]. Tidal currents near Katama $(\sim 3 \mathrm{~m} / \mathrm{s}$ around the corner of Chappaquiddick Island and $\sim 2 \mathrm{~m} / \mathrm{s}$ through the inlet) can be stronger than those observed at the Sand Engine $(0.8 \mathrm{~m} / \mathrm{s})$ and wave-driven currents tend to be weaker owing to less obliquely 
incident waves $(1 \mathrm{~m} / \mathrm{s}$ at the Sand Engine compared with 0.2 to $0.9 \mathrm{~m} / \mathrm{s}$ south of Katama Bay depending on offshore wave heights and angles). Here, the field-verified Delft3D wave-currentsediment transport model is used to determine the relative effects of short, energetic storms (e.g., hurricanes) and longer, less energetic storms (e.g., nor'easters) in the mixed wave-and-current energy Katama Inlet system.

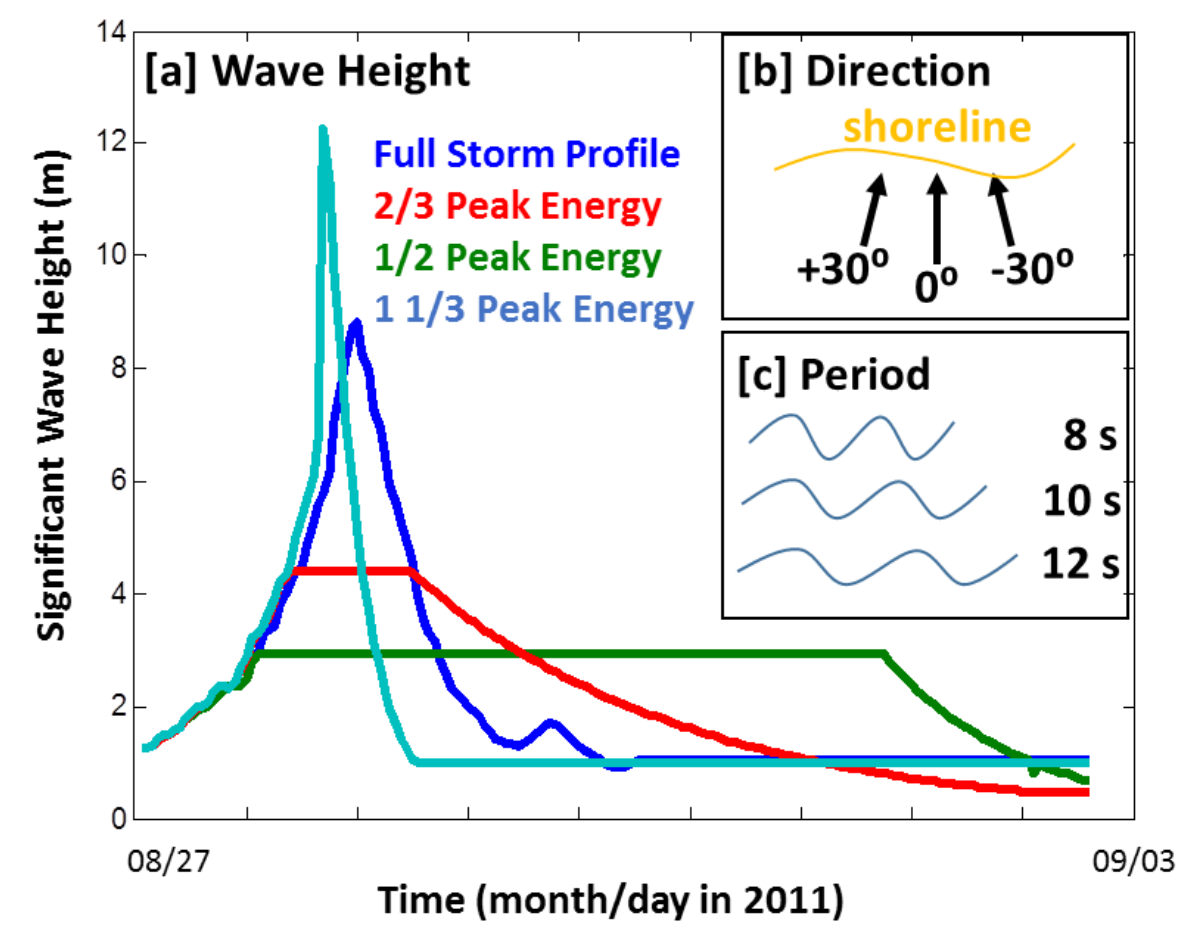

Figure 7: Boundary conditions for storm intensity simulations, including (a) significant wave height, (b) wave direction, and (c) wave period. The energy under each curve of significant wave height versus time (Figure 7a) is identical to that measured during Hurricane Irene (dark blue curve), but distributed differently over time either to enhance the maximum (peak) energy ( $11 / 3$ times, light blue curve) or to decrease peak energy either by $2 / 3$ (red) or $1 / 3$ (green). Offshore wave boundary conditions were a JONSWAP spectral shape with a $\cos ^{20} \theta$ directional distribution, with wave height given by the time series in Figure 7a, and coupled with a mean period and direction that was constant for each 6-day model simulation. Simulations were run for different wave periods (Figure 7b) and wave directions (Figure 7c) that are similar to those observed.

For these idealized model simulations of storm events, the wave boundary conditions were based on observations at the 50-m depth waverider buoy collected during Hurricane Irene. The offshore boundary significant wave height was modified to change the distribution of energy of Irene over 
time, while keeping the time-integrated storm energy constant (Figure 7a). JONSWAP spectra at the boundary were generated based on the temporal distribution of offshore wave energy and a range of peak periods and offshore wave directions (Figure 7b,c). To ensure identical numbers of tidal cycles and tidal-current transport, all model runs were six days long regardless of the length of the storm peak.

Storm intensity was calculated in $12 \mathrm{~m}$ depth (to account for wave transformation over shallow offshore bathymetry) by integrating the energy of the storm under its peak (defined as the highest $70 \%$ of wave energy in the time series), and dividing by the duration of the peak. The amount of sand eroded and accreted along the shoreline over the course of the storm is quantified by the variance in the bathymetric change over the six days. The area used for the variance calculation encompassed the most dynamic regions along the shoreline, between the beach and 6-m water depth near the inlet and along the corner of Chappaquiddick Island (Figure 1, pink box). 

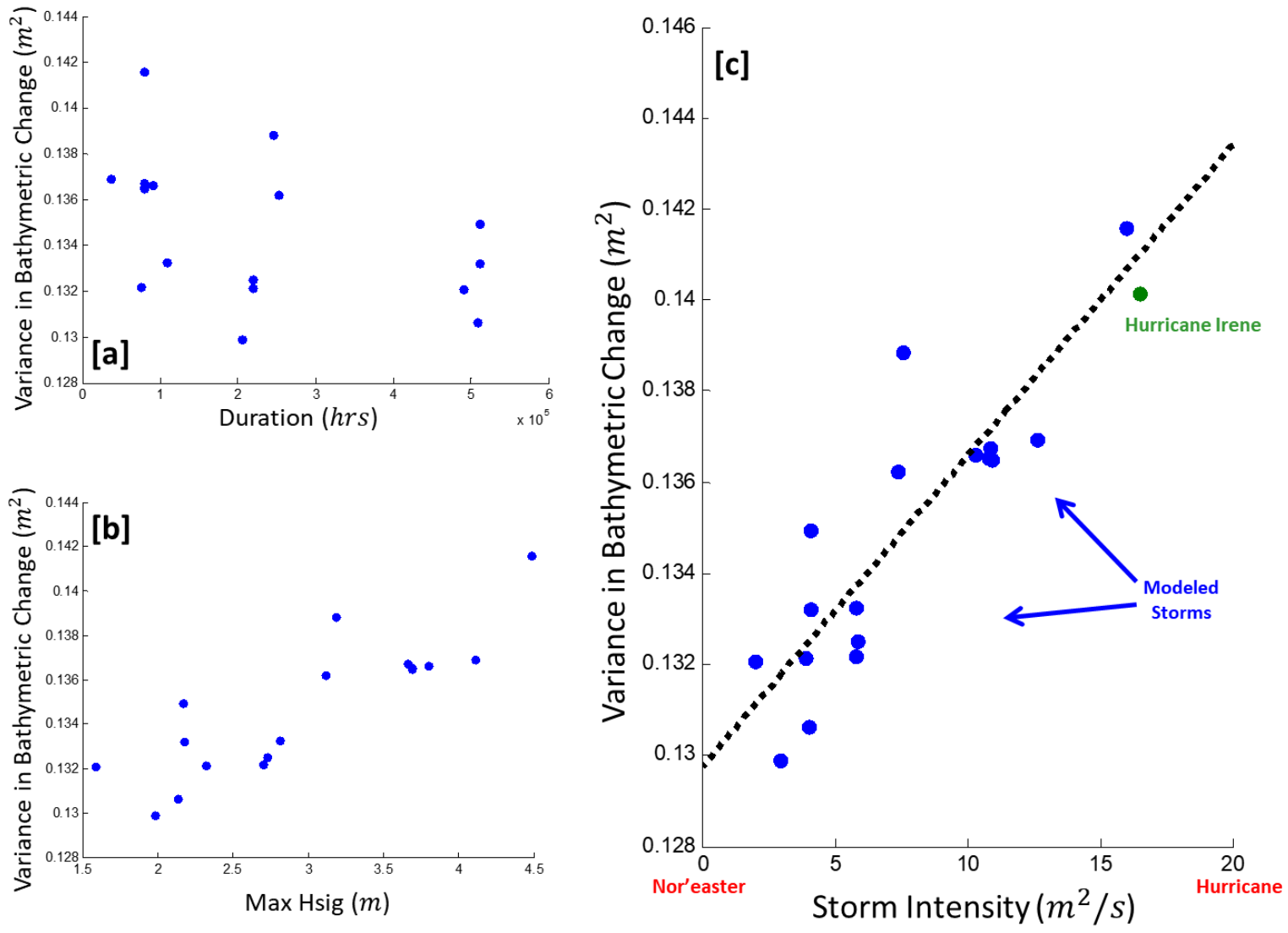

Figure 8: Spatial variance in bathymetric change versus (a) storm duration, (b) maximum storm significant wave height, and (c) storm intensity. The variance is calculated over the area shown in Figure 1, pink box. Intensity is defined as the integrated energy of the storm in 12-m water depth divided by the storm duration. The dotted line in (c) is the least squares fit between bathymetric change variance and storm intensity $\left(R^{2}=0.78\right)$.

The idealized simulations suggest that for a range of storm durations (Figure 8a) and maximum wave heights (Figure 8b) bathymetric change increases with higher storm intensity, even for identical amounts of wave energy entering the model domain (Figure 8c). Thus, hurricanes (shorter duration, higher maximum wave height storms) move more sand at Katama than nor'easters (longer duration, lower maximum wave height storms) with similar overall energy. Bathymetric change also increases with maximum significant wave height (Figure 8b), as expected in wave-dominated environments because sediment transport scales with wave energy. 
Katama is a mixed-wave-and-tidal-current energy environment, and thus these results suggest the influence of tidal currents is minimized during storm wave conditions.
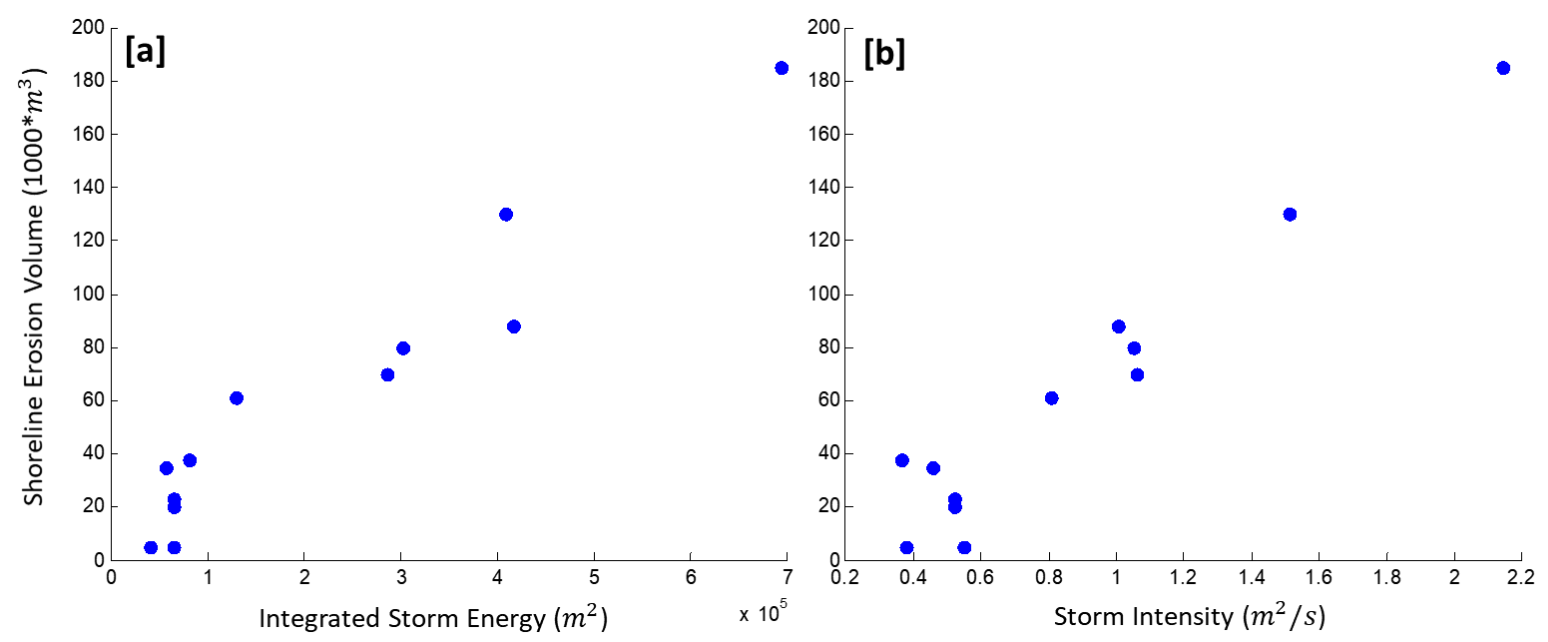

Figure 9: Shoreline erosion volume at the Sand Engine in the Netherlands versus (a) integrated wave energy and (b) storm intensity (integrated wave energy divided by storm duration). Figure 9a and data for Figure 9b are from [Luijendijk et al., 2017], with permission.

The trend of bathymetric change with storm intensity is consistent with observations at the Sand Engine in the Netherlands [Luijendijk et al., 2017]. Sand Engine observations included storms of varying offshore energy that eroded the nourishment in an environment where wave-driven nearshore currents usually are greater than the local tidal currents. The eroded volume is correlated with the integrated storm energy (Figure 9a, [Luijendijk et al., 2017]). When the integrated energy of the storms is transformed into intensity by dividing by the storm duration, observations at the Sand Engine also suggest that there is a linear relationship between storm intensity and sediment transport if there is sufficient sediment supply. Despite different relative roles of wave- and current-driven transport, the similarity of the relationship between bathymetric change and storm intensity at dissimilar nearshore environments (compare Figure 8c with Figure 9b) suggests that the temporal distribution of wave energy during storms can impact bathymetric change in a range of mixed wave-and-current energy environments. 


\section{d) Storm Impact on Morphology on Monthly Timescales}

Morphological evolution over months to years can be affected by the number and timing of storms. For example, a rapid sequence of storms ("clusters") may have a different impact than the same storms separated farther in time [Splinter et al., 2014a; Dissanayake et al., 2015; Angnuureng et al., 2017]. Here, model simulations are used to examine the effects of the number and timing of storms on the 2-month-long evolution of the sandy shoreline near Katama Inlet.

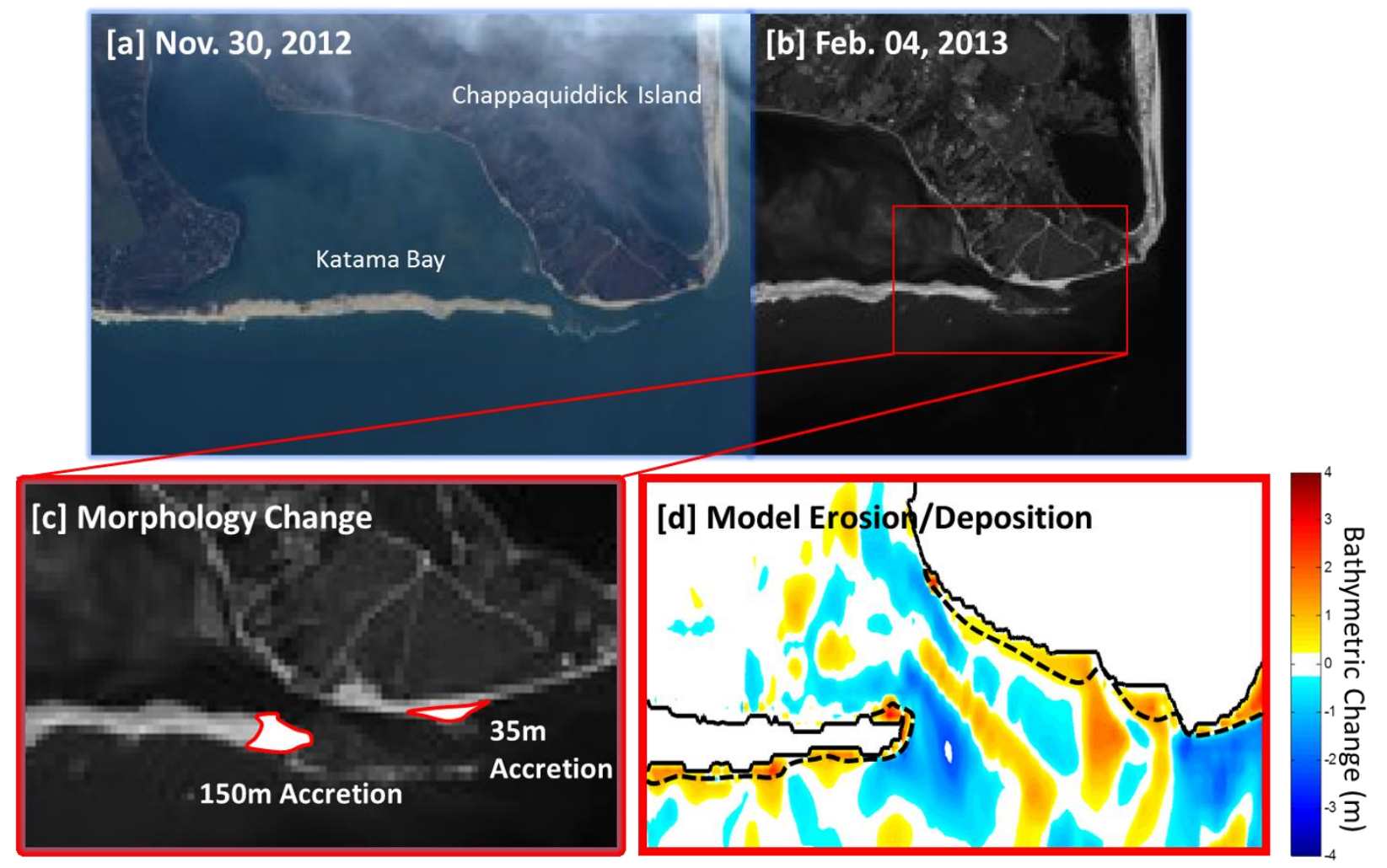

Figure 10: Georectified satellite images depicting shoreline position around Katama Inlet for (a) November 30, 2012 and (b) February 4, 2013, with (c) the corresponding approximate change in the shoreline near the inlet, including the $\sim 150 \mathrm{~m}$ accretion of the west side of the inlet (Norton Point) and the $\sim 35 \mathrm{~m}$ accretion of the south side of Chappaquiddick Island. Similar qualitative trends are seen in (d) model simulations of bathymetric change over this time (red = accretion, blue $=$ erosion, black curves are pre- (solid curves) and post- (dashed curves) simulation shorelines). 
Between November 30, 2012 and February 4, 2013 Norton Point accreted eastward about $150 \mathrm{~m}$ and the beach on the southern shore of Chappaquiddick Island accreted approximately $35 \mathrm{~m}$ (Figure 10). During this 2-month period there were four storms $(H s i g>3 \mathrm{~m})$, separated in time by as little as a few days and as much as a month. (Figure 11).

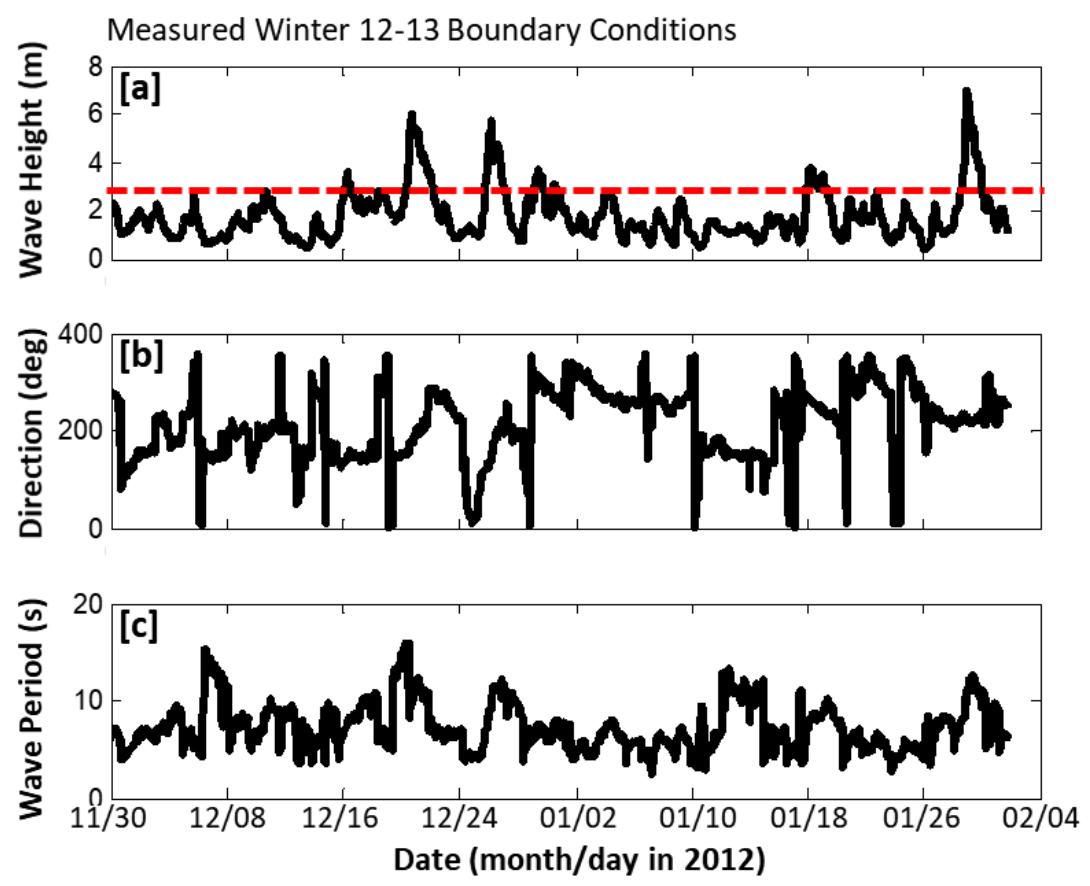

Figure 11: (a) Significant wave height, (b) mean wave direction, and (c) peak wave period at the NOAA buoy 44097 located in 50-m water depth versus time. The red dashed line in (a) marks the storm wave height threshold $(\mathrm{Hsig}=3 \mathrm{~m})$.

To test the impact of the timing of these storms on shoreline evolution, a series of simulations were performed to (1) validate the model skill simulating the observed evolution using the observed wave boundary conditions, (2) evaluate the model skill for simulations that use a reduced (shorter) boundary condition time series and multiply the associated morphological change by a scaling factor (MORFAC, [Lesser et al., 2004], see Appendix 3) and, (3) use the computationally less demanding model to evaluate the impact of storms, storm timing, and storm clustering on the migration rate of the inlet. 

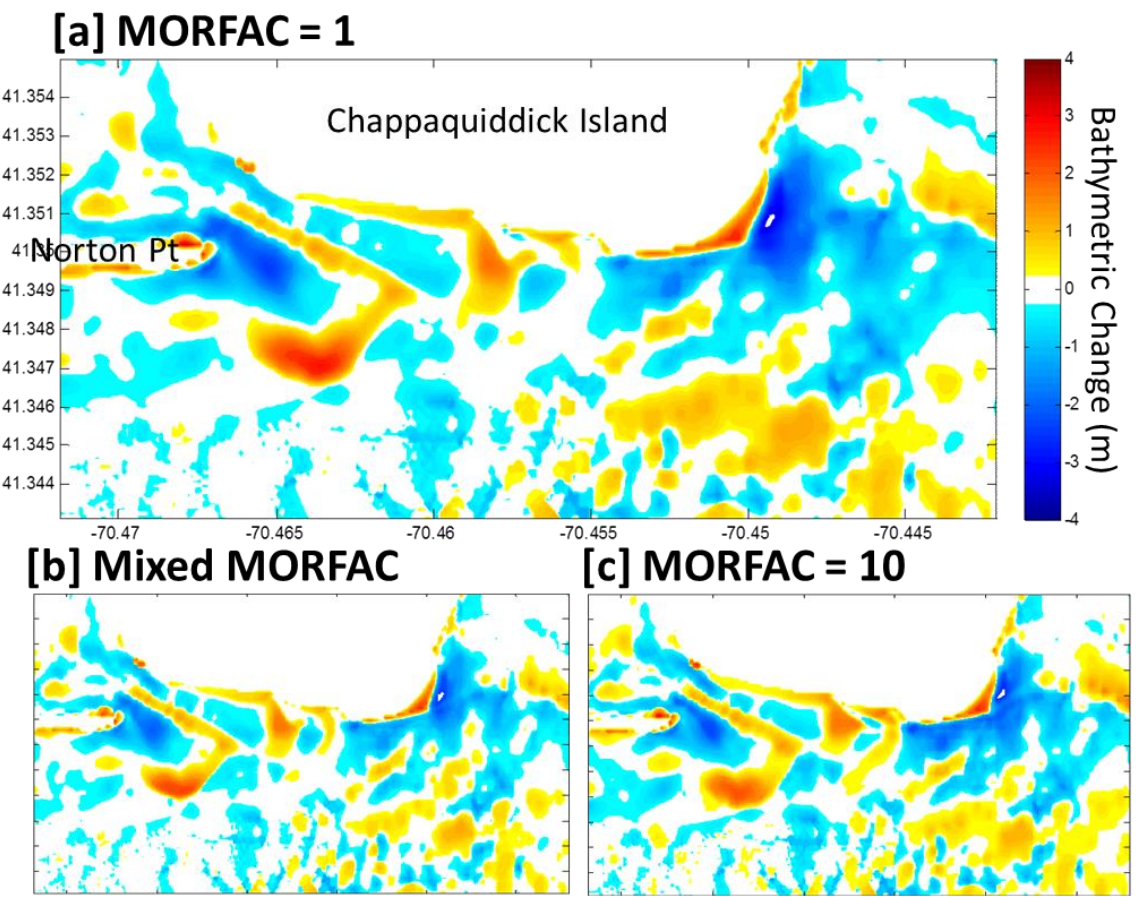

[c] MORFAC $=10$

BSS $=0.86$

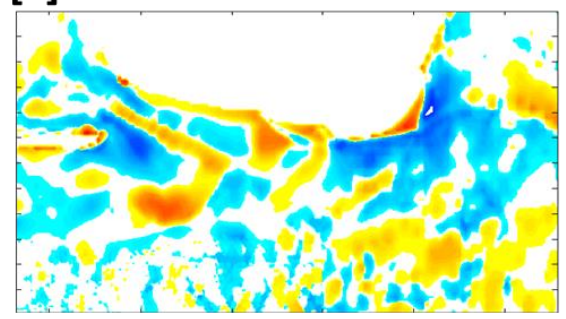

BSS $=0.89$

Figure 12: Contours of simulated bathymetric change (red $=$ accretion, blue $=$ erosion, scale on the right) for model runs with (a) no morphological acceleration (MORFAC $=1),(b)$ morphological acceleration applied only to non-storm conditions (MORFAC $=1$ during storms, MORFAC $=10$ otherwise), and (c) morphological acceleration applied at all times (MORFAC $=$ 10). Compared with the MORFAC $=1$ simulation, the Brier Skill Scores (see Appendix 2) of the mixed MORFAC and MORFAC $=10$ simulations are listed below each contour plot.

The growth of Norton Point and the Chappaquiddick beach simulated with the model using the full observed wave boundary conditions is qualitatively consistent with the observed accretion (compare Figure 10d with Figure 10c). The eastward extent of the simulated accretion around Norton Point is less than that estimated from the satellite images, possibly because wind, which could enhance storm waves and subsequent accretion of the inlet (Appendix 2), was not activated for this model run to save computation time.

Simulations with reduced wave boundary conditions (see Appendix 3) using MORFAC = 10 only for non-storm conditions and MORFAC $=1$ for storms (Figure 12b) and using MORFAC $=$ 10 for the full time series (Figure 12c) compare well with the full, MORFAC $=1$ model run 
(Figure 12a). Accelerated model runs reduce computation times six- to ten-fold relative to using the full boundary time series, while not affecting the simulated morphological evolution significantly (Figure 12).
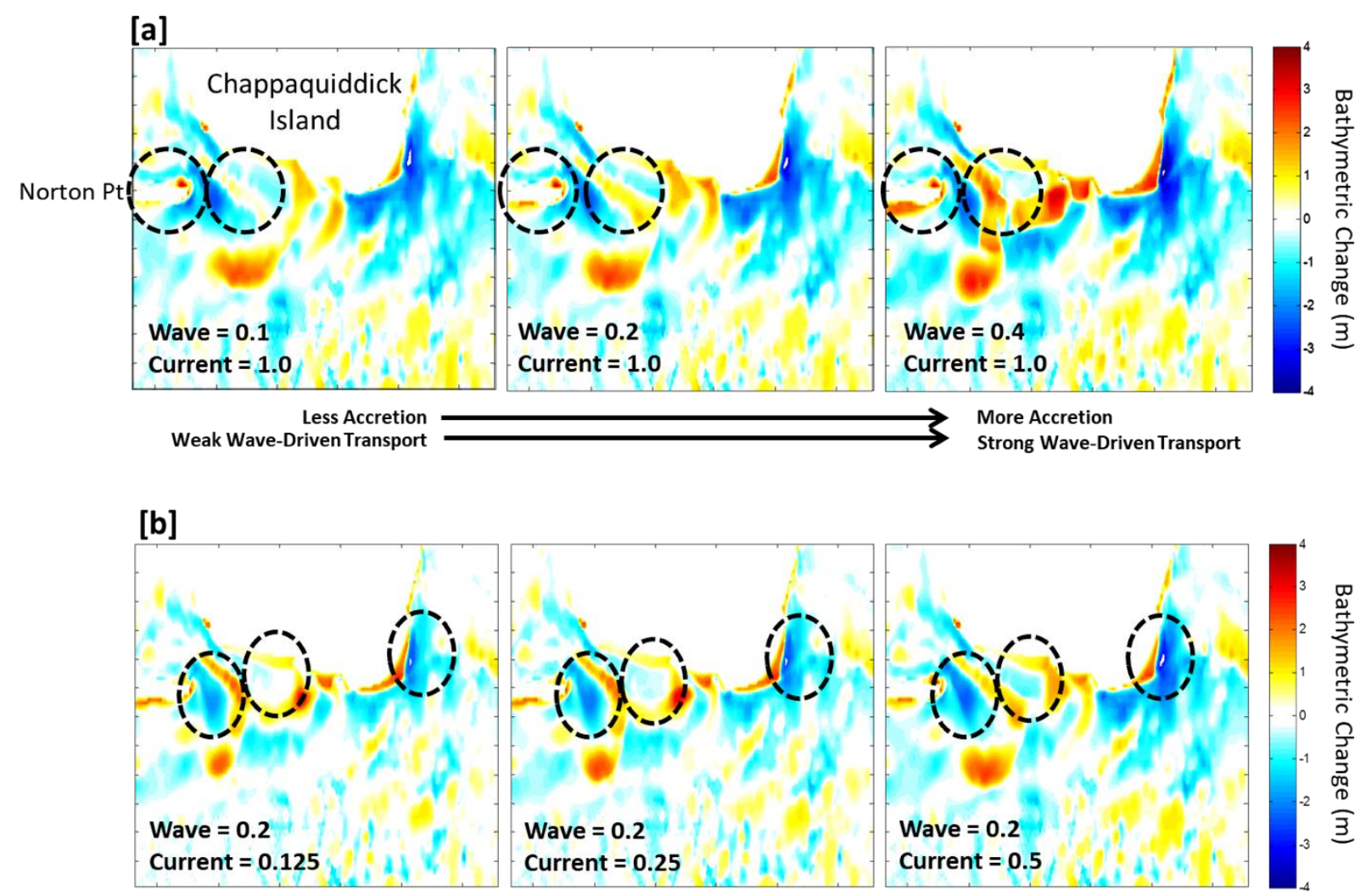

Less Erosion
Weak Tidal Current Transport

More Erosion

Strong Tidal Current Transport

Figure 13: Contours of simulated bathymetric change (red $=$ accretion, blue $=$ erosion, scale on the right) using MORFAC = 10 between Nov 2012 and Feb 2013 for different (a) wave and (b) tidal current transport coefficients. In Figure 13a, increasing the wave transport coefficient (values in bottom right of each panel, tidal current coefficient $=1$ ) enhances accretion around the west side of the inlet and in the inlet channel (dashed circles in top panels). In Figure 13b, increasing the tidal current transport coefficient (values in bottom right of each panel, wave coefficient $=0.2$ ) enhances erosion within the inlet channel and around the corner of Chappaquiddick Island (regions with high tidal current velocities, dashed circles in lower panels).

Accelerated model runs were used to isolate the effects of waves and tidal currents on inlet evolution by varying their respective transport parameters away from the tuned values used to simulate Hurricanes Irene and Sandy (Figure 4). Accretion around the inlet increases as wave 
energy increases, especially in the inlet channel and on the shoreline near Norton Point and Chappaquiddick Island (circled in Figure 13a). In contrast, erosion around the inlet increases as the tidal current transport coefficient increases, especially in the inlet channel and around the corner of Chappaquiddick Island (circled in Figure 13b).

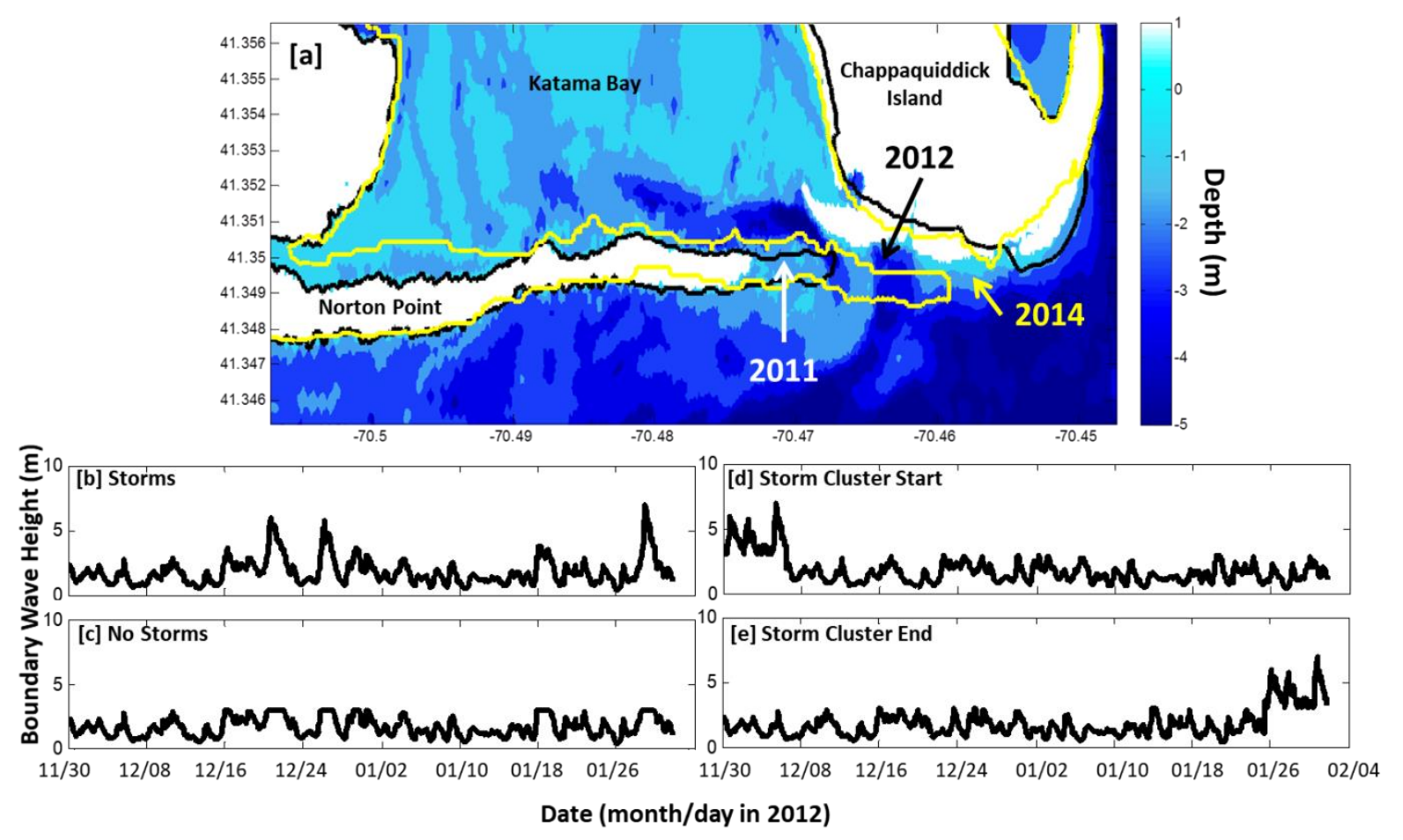

Figure 14: (a) Bathymetry (dark = deep water, light = shallow, scale on the right) measured in 2011 (white shaded area), 2012 (black curve), and 2014 (yellow curve) used in two-month-long model runs with boundary conditions given by the observed wave time series (b) unaltered, (c) with storms (Hsig $>3 \mathrm{~m}$ ) removed, (d) with all the storms clustered at the beginning of the time series and (e) with all the storms clustered at the end of the time series. The dated arrows point to the approximate location of the inlet channel in each year.

The simulations suggest that strong tidal currents erode the inlet and hinder its migration, whereas strong wave conditions accrete the inlet and enhance its migration. To test this hypothesis, morphological evolution was simulated for 3 observed bathymetries that had different inlet tidal currents. As Katama Inlet migrated eastward, it rotated from oriented N-S in 2011 to oriented E-W in 2014 (Figure 14), lengthened, narrowed, and shoaled, and the tidal currents in the inlet channel decreased [Orescanin et al., 2016, 2017]. To investigate the effects 
of different sequences of the observed storms for different balances of wave-driven and tidal currents, morphological evolution was simulated for 4 wave boundary time series applied to each of the 3 inlet orientations. The boundary wave time series were the (1) observed time series of waves (Figure 14b), (2) the same boundary conditions, but with storms (Hsig > $3 \mathrm{~m}$ ) removed (Figure 14c), (3) all the storms clustered at the beginning of the time series (Figure 14d), and (4) all the storms clustered at the end of the time series (Figure 14e). Morphological evolution also was simulated without waves by running Delft3D without SWAN.
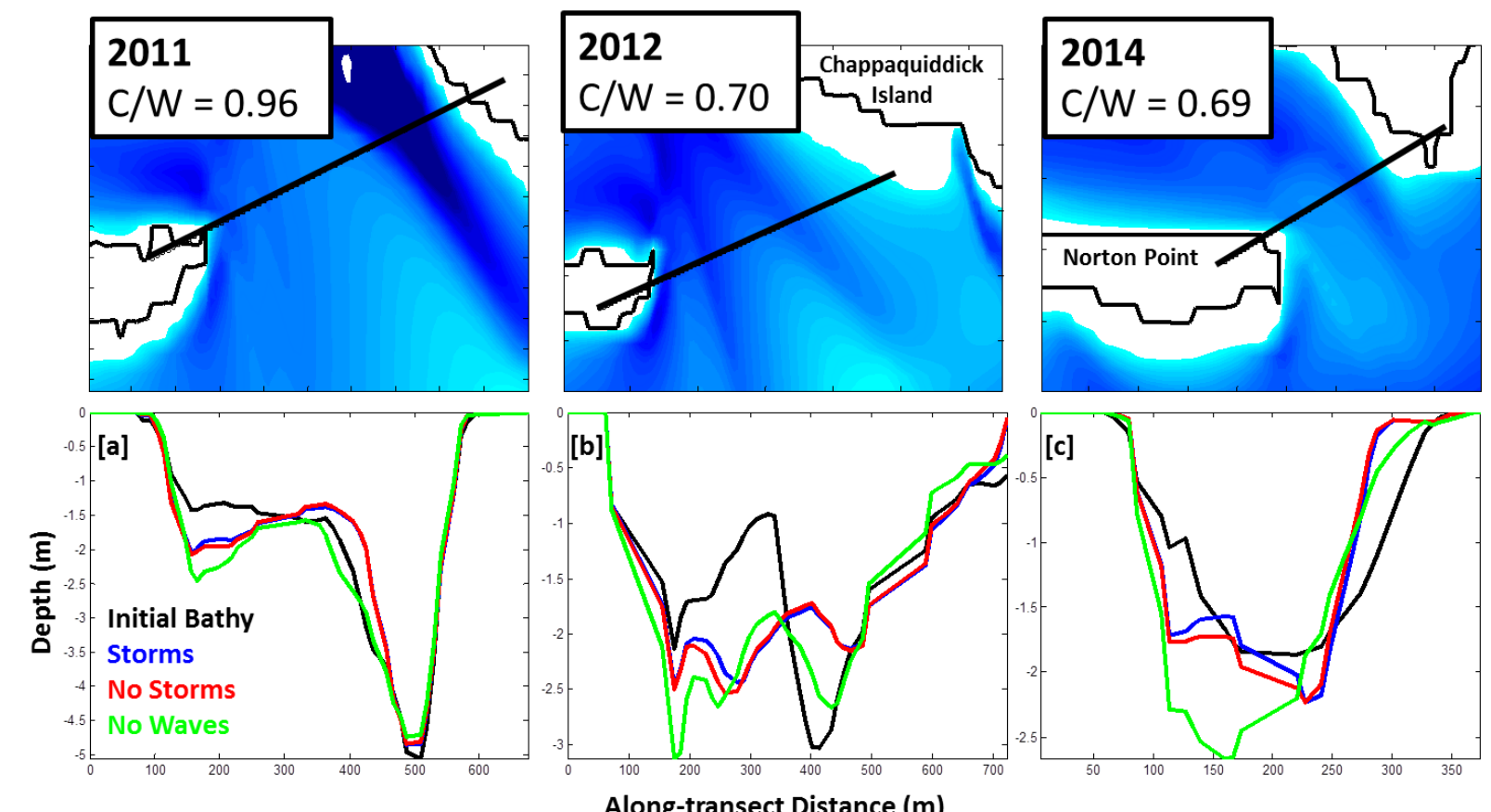

Figure 15: (top) Inlet bathymetric contours (dark blue = deep water, light blue = shallow) for the three years used in the two-month-long simulations. The ratio of tidal current to wave-driven transport $(\mathrm{C} / \mathrm{W})$ is given in the upper left. Black lines indicate the location of transects across the inlet along which (bottom) depth is plotted for (a) 2011, (b) 2012, and (c) 2014 for (black) initial model bathymetry, (blue) final bathymetry including storms (Figure 14b), (red) final bathymetry without storms (Figure 14c), and (green) final bathymetry without waves.

Inlet currents decrease and wave-driven transport becomes more important as the inlet migrates

(Figure 15, C/W decreases left to right), and the inlet channel moves farther with stronger wave conditions for all inlet orientations (Figure 15, compare the blue curves with the red 
and green curves). The simulated changes in the channel position suggest that both high wave conditions and lower tidal currents through the inlet enhance inlet migration rates.

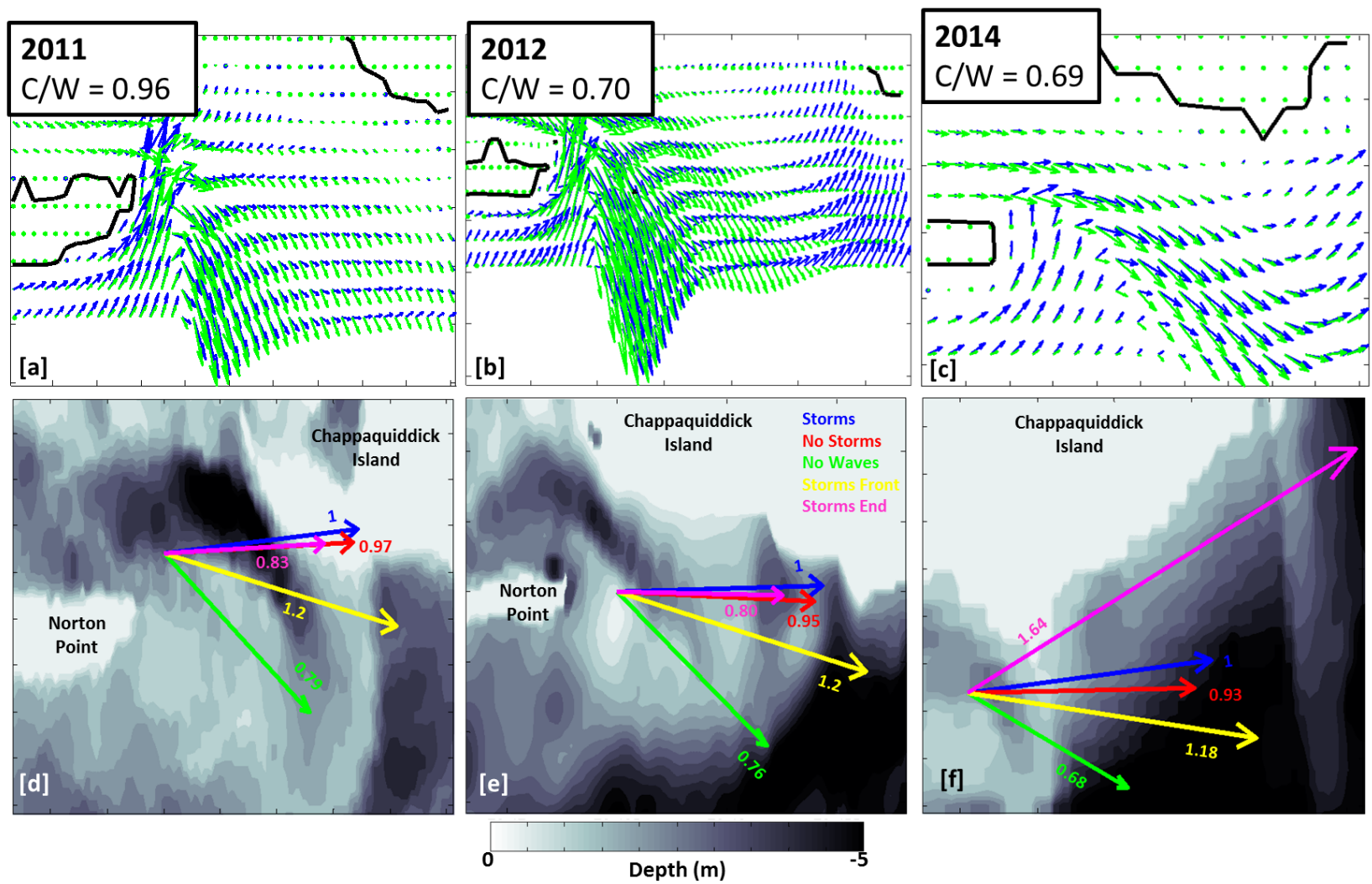

Figure 16: Mean sediment transport vectors using bathymetry measured in (a) 2011, (b) 2012, and (c) 2014 (ratios of tidal- to wave-driven transport, C/W given in the upper left) simulated with storms (blue arrows) and without waves (green arrows). Bathymetry of the inlet in (d) 2011, (e) 2012, and (f) 2014 (dark = deep water, light = land) with transport vectors averaged both over time and within the inlet for simulations with storms (blue), without storms (red), without waves (green), with storms clustered at the front of the model run (yellow), and with storms clustered at the end of the model run (pink). Averaged transport values are given for (blue) model runs with storms and all other values are given as percentages of the storm model simulation. The time series of waves used on the offshore boundaries are given in Figure 14.

For all bathymetric configurations, the sand to the west of the initial inlet channel is moved east

(Figure 16 a,b,c blue arrows), filling in the original channel, while strong currents around the corner of Norton Point scour a new channel on the western side of the inlet (Figure 16 a,b,c large, southward oriented arrows on west side of inlet). The eastward transport in the inlet is more pronounced with storm conditions (Figure 16, compare the direction of the blue (storm) 
with the green (no wave) arrows)). The total transport (the sum of the transport vectors) within the inlet area primarily is eastward for all cases (Figure 16d,e,f). Simulations with low or no waves have a stronger southward transport component than simulations with storms (Figure 16 d,e,f, compare the blue with the red and green vectors), consistent with the different channel migrations for different conditions (Figure 15 a,b,c). Similar to the MORFAC simulations (Figure 13), the erosion (accretion) of the inlet channel decreases (increases) as the influence of waves decreases (compare the blue and red curves with the green curves Figure 15). Thus, the simulations suggest that high wave conditions enhance inlet migration, whereas in the absence of waves, tidal currents erode the inlet channel and reduce eastward transport.

Shoreface and dune erosion increases with increased frequency and clustering of storms in wavedominated shorelines [Splinter et al., 2014a; Dissanayake et al., 2015]. Here, the model is used to investigate the effects of storm sequencing on morphological change in a mixed wave and tidal-current energy environment. The time series of offshore waves observed for 2 months (Figure 14) was rearranged to place the storms $(\mathrm{Hsig}>3 \mathrm{~m}$ ) at the start or the end of the record, or removed entirely. Relative to using the observed time series of offshore waves, simulations with storms clustered at the beginning cause more southward and less eastward transport (Figure 16, yellow vector), whereas storms clustered at the end cause more eastward transport with lower current-to-wave ratios, and no southward transport (Figure 16, pink vectors), suggesting that the sequence of storms affects the inlet migration rate in this two month period, consistent with previous results [Splinter et al., 2014b; Dissanayake et al., 2015]. When all of the storms are at the start of the simulation, the channel morphology evolves rapidly, creating a new channel on the western side of the inlet. During subsequent low-wave conditions, the tidal-current-driven 
erosion of the inlet channel is stronger than the wave-driven accretion, deepening the new channel (allowing for stronger currents) and hindering eastward sediment transport. Conversely, when all of the storms are at the end of the simulation, the initial channel fills in gradually and the new channel forms more slowly, reducing current-related transport relative to the front-end storm cluster scenario. The final cluster of high waves drives more transport eastward, resulting in net eastward transport, an effect that is more pronounced as the inlet migrates east and waves become more important (Figure 16, d-f).

Although during the 2-month period simulations with storms (Hsig > $3 \mathrm{~m}$, blue vectors in Figure 16) led to more eastward transport than simulations without storms (red vectors in Figure 16), the simulations without waves have similar eastward transport components (green vectors in Figure 16), but more southward transport, likely leading to increased erosion of the inlet channel and slower inlet migration. Depending on the inlet configuration, this enhanced southward transport could erode the inlet enough to prevent migration in the absence of waves.

\section{Conclusion}

Numerical simulations of morphological evolution on the southern shoreline of Martha's Vineyard, MA near the migrating Katama Inlet were validated with measured bathymetric change owing to Hurricanes Irene and Sandy, as well as with shoreline change estimated with satellite images spanning two months in winter 2012-13. Model results show that on timescales of days to weeks, storm intensity influences bathymetric change in a sandy nearshore environment, with higher storm intensity (e.g., hurricane conditions) correlated with more bathymetric change. On timescales of months, simulations suggest that higher wave energy 
relative to tidal current energy causes faster inlet migration, whether owing to storm conditions (large waves) or inlet orientation (inlet currents decrease). Model simulations further suggest that even without storms, but with moderate waves, the inlet migration rate increases as the inlet approaches Chappaquiddick Island, because tidal currents through the inlet decrease as it migrates, rotates, narrows, lengthens, and shoals. The presence of storms, whether clustered or spaced over time, enhances eastward transport and the migration rate of the inlet. Thus, the observations and simulations suggest that storm conditions influence the morphological evolution of a sandy beach system (in this case, the migration of an inlet), with the bathymetric change increasing with increasing storm energy, intensity, and frequency. However, for a mixed wave-and-tidal energy system, such as investigated here where tidal currents usually are stronger than breaking-wave driven currents, shoreline evolution can continue without storms, with the system bathymetry reworked by storms, producing different bathymetric patterns depending on the sequences of storms.

\section{Acknowledgements}

The data used in this study are available by contacting the authors, hychenj@mit.edu or elgar@whoi.edu. Support was provided by ONR, NSF, Sea Grant, NDSEG, and the Office of the Assistant Secretary of Defense (Research and Engineering) via National Security Science and Engineering and Vannevar Bush Faculty Fellowships. Mumen Alzubi, Eeshan Bhaat, Kohl Brinkman, Danik Forsman, Janet Fredericks, Levi Gorrell, Liliana Montoya, Mara Orescanin, Maddie Smith, Anna Wargula, and Billy Wells helped obtain the observations,. 


\section{References}

van der A, D. a., T. O’Donoghue, A. G. Davies, and J. S. Ribberink (2011), Experimental study of the turbulent boundary layer in acceleration-skewed oscillatory flow, J. Fluid Mech., 684, 251-283, doi:10.1017/jfm.2011.300.

Amoudry, L., T.-J. Hsu, and P. L.-F. Liu (2008), Two-phase model for sand transport in sheet flow regime, J. Geophys. Res., 113(C3), C03011, doi:10.1029/2007JC004179.

Amoudry, L. O., and A. J. Souza (2011), Deterministic Coastal Morphological and Sediment Transport Modeling: a Review and Discussion, Rev. Geophys., 49, 1-21, doi:10.1029/2010RG000341.1.INTRODUCTION.

Angnuureng, D. B., R. Almar, N. Senechal, B. Castelle, K. A. Addo, V. Marieu, and R. Ranasinghe (2017), Shoreline resilience to individual storms and storm clusters on a mesomacrotidal barred beach, Geomorphology, 290, 265-276, doi:10.1016/j.geomorph.2017.04.007.

Avila, L. A., and J. Cangialosi (2011), Tropical Cyclone Report: Hurricane Irene.

Bagnold, R. A. (1966), An Approach to the Sediment Transport Problem from General Physics.

Bailard, J. A. (1981), An Energetics Total Load Sediment Transport Model For a Plane Sloping Beach, J. Geophys. Res., 86(Cll), 10938-10954.

Blake, E. S., T. B. Kimberlain, J. P. Cangialosi, and J. L. Beven II (2013), Tropical Cyclone Report: Hurricane Sandy.

Bowen, A. J. (1980), Simple models of nearshore sedimentation; beach profiles and longshore bars, in The Coastlines of Canada, edited by S. B. Mccann, pp. 1-11, Geological Survey of Canada.

Calantoni, J., K. T. Holland, and T. G. Drake (2004), Modelling sheet-flow sediment transport in wave-bottom boundary layers using discrete-element modelling., Philos. Trans. A. Math. Phys. Eng. Sci., 362(1822), 1987-2001, doi:10.1098/rsta.2004.1427.

Daly, C. J., K. R. Bryan, M. R. Gonzalez, A. H. F. Klein, and C. Winter (2014), Effect of selection and sequencing of representative wave conditions on process-based predictions of equilibrium embayed beach morphology, Ocean Dyn., 64(6), 863-877, doi:10.1007/s10236014-0730-9.

Dietrich, J. C., S. Tanaka, J. J. Westerink, C. N. Dawson, R. a. Luettich, M. Zijlema, L. H. Holthuijsen, J. M. Smith, L. G. Westerink, and H. J. Westerink (2011), Performance of the Unstructured-Mesh, SWAN+ADCIRC Model in Computing Hurricane Waves and Surge, $J$. Sci. Comput., 52(2), 468-497, doi:10.1007/s10915-011-9555-6.

Dissanayake, P., J. Brown, P. Wisse, and H. Karunarathna (2015), Comparison of storm cluster vs isolated event impacts on beach/dune morphodynamics, Estuar. Coast. Shelf Sci., 164, 
301-312, doi:10.1016/j.ecss.2015.07.040.

Drake, T. G., and J. Calantoni (2001a), Discrete particle model for sheet flow sediment transport in the nearshore, J. Geophys. Res., 106(C9), 19859-19868.

Drake, T. G., and J. Calantoni (2001b), Discrete particle model for sheet flow sediment transport in the nearshore, J. Geop, 106(C9), 19859-19868.

Fredsoe, J. (1984), Turbulent boundary layer in wave-current motion, J. Hydraul. Eng., 110(8), $1103-1120$.

Fredsoe, J., and R. Deigaard (1992), Mechanics of Coastal Sediment Transport, World Scientific Publishing, Singapore.

Gallagher, E. L., S. Elgar, and R. T. Guza (1998), Observations of sand bar evolution on a natural beach, J. Geophys. Res., 103(C2), 3202-3215.

Ganju, N. K., B. E. Jaffe, and D. H. Schoellhamer (2011), Discontinuous hindcast simulations of estuarine bathymetric change: A case study from Suisun Bay, California, Estuar. Coast. Shelf Sci., 93(2), 142-150, doi:10.1016/j.ecss.2011.04.004.

Grant, W. D., and O. S. Madsen (1979), Combined Wave and Current Interaction With a Rough Bottom, J. Geophys. Res., 84(C4), 1797-1808.

Grant, W. D., and O. S. Madsen (1982), Movable bed roughness in unsteady oscillatory flow, $J$. Geophys. Res., 87(C1), 469, doi:10.1029/JC087iC01p00469.

Harris, C. K., and P. L. Wiberg (2001), A two-dimensional, time-dependent model of suspended sediment transport and bed reworking for continental shelves, Comput. Geosci., 27(6), 675690, doi:10.1016/S0098-3004(00)00122-9.

Herrling, G., and C. Winter (2014), Morphological and sedimentological response of a mixedenergy barrier island tidal inlet to storm and fair-weather conditions, Earth Surf. Dyn., 2(1), 363-382, doi:10.5194/esurf-2-363-2014.

Hoefel, F., and S. Elgar (2003), Wave-induced sediment transport and sandbar migration., Science, 299(5614), 1885-7, doi:10.1126/science.1081448.

Hopkins, J., S. Elgar, and B. Raubenheimer (2017), Flow separation effects on shoreline sediment transport, Coast. Eng., 125, doi:10.1016/j.coastaleng.2017.04.007.

Hsu, T.-J., and P. L.-F. Liu (2004), Toward modeling turbulent suspension of sand in the nearshore, J. Geophys. Res., 109(C6), C06018, doi:10.1029/2003JC002240.

Hsu, T.-J., and B. Raubenheimer (2006), A numerical and field study on inner-surf and swash sediment transport, Cont. Shelf Res., 26(5), 589-598, doi:10.1016/j.csr.2006.02.004.

Hsu, T.-J., S. Elgar, and R. T. Guza (2006), Wave-induced sediment transport and onshore 
sandbar migration, Coast. Eng., 53(10), 817-824, doi:10.1016/j.coastaleng.2006.04.003.

Kaji, A., A. P. Luijendijk, J. S. M. van Thiel de Vries, M. A. de Schipper, and M. J. F. Stive (2014), Effect of different forcing processes on the longshore sediment transport at the sand motor, the Netherlands, Coast. Eng. Proc., 1 BT-Pr, 1-11, doi:10.9753/icce.v34.sediment.71.

Lesser, G. R., J. A. Roelvink, J. a. T. M. van Kester, and G. S. Stelling (2004), Development and validation of a three-dimensional morphological model, Coast. Eng., 51, 883-915, doi:10.1016/j.coastaleng.2004.07.014.

Lindemer, C. A., N. G. Plant, J. A. Puleo, D. M. Thompson, and T. V. Wamsley (2010), Numerical simulation of a low-lying barrier island's morphological response to Hurricane Katrina, Coast. Eng., 57(11-12), 985-995, doi:10.1016/j.coastaleng.2010.06.004.

Luijendijk, A. P., R. Ranasinghe, M. A. de Schipper, B. A. Huisman, C. M. Swinkels, D. J. R. Walstra, and M. J. F. Stive (2017), The initial morphological response of the Sand Engine: A process-based modelling study, Coast. Eng., 119(July 2016), 1-14, doi:10.1016/j.coastaleng.2016.09.005.

Madsen, O. S. (1994), Spectral Wave-Current Bottom Boundary Layer Flows, in Coastal Engineering Proceedings, vol. 1, pp. 384-398.

Masselink, G., B. Castelle, T. Scott, G. Dodet, S. Suanez, D. Jackson, and F. Floc'h (2016), Extreme wave activity during 2013/2014 winter and morphological impacts along the Atlantic coast of Europe, Geophys. Res. Lett., 43(5), 2135-2143, doi:10.1002/2015GL067492.

Meyer-Peter, E., and R. Muller (1948), Formulas for Bed-Load Transport, in Rep. 2nd Meeting Int. Assoc. Hydraul. Struct. Res., pp. 39-64, Stockholm, Sweden.

Miller, H. C. (1999), Field measurements of longshore sediment transport during storms, Coast. Eng., 36(4), 301-321, doi:10.1016/S0378-3839(99)00010-1.

Moore, L. J., D. E. McNamara, A. B. Murray, and O. Brenner (2013), Observed changes in hurricane-driven waves explain the dynamics of modern cuspate shorelines, Geophys. Res. Lett., 40(22), 5867-5871, doi:10.1002/2013GL057311.

Morton, R. A., J. C. Gibeaut, and J. G. Paine (1995), Meso-scale transfer of sand during and after storms: implications for prediction of shoreline movement, Mar. Geol., 126(1-4), 161-179, doi:10.1016/0025-3227(95)00071-6.

Mulligan, R. P., J. P. Walsh, and H. M. Wadman (2015), Storm Surge and Surface Waves in a Shallow Lagoonal Estuary during the Crossing of a Hurricane, J. Waterw. Port, Coastal, Ocean Eng., 141(4), A5014001, doi:10.1061/(ASCE)WW.1943-5460.0000260.

Orescanin, M. M., S. Elgar, and B. Raubenheimer (2016), Changes in bay circulation in an evolving multiple inlet system, Cont. Shelf Res., 124, 13-22, doi:10.1016/j.csr.2016.05.005. 
Orescanin, M. M., S. Elgar, B. Raubenheimer, and L. Gorrell (2017), Effects of a shallow flood shoal and friction on hydrodynamics of a multiple-inlet system, J. Geophys. Res. Ocean., doi:10.1002/2016JC012502.

Radermacher, M., M. A. de Schipper, C. Swinkels, J. H. MacMahan, and A. J. H. M. Reniers (2017), Tidal flow separation at protruding beach nourishments, J. Geophys. Res. Ocean., 122(1), 63-79, doi:10.1002/2016JC011942.

Van Rijn, L. (1985), Sediment Transport, Part I: Bed Load Transport, J. Hydraul. Eng., 110(10), 1431-1456.

Van Rijn, L. (1993), Principles of Sediment Transport in Rivers, Estuaries and Coastal Seas, Aqua Publishing, Blokzijl, Netherlands.

Van Rijn, L. (2002), Longshore Sediment Transport, Coast. Eng., 10, 2439-2451.

Soulsby, R. L., and S. Clarke (2005), Bed Shear-stresses Under Combined Waves and Currents on Smooth and Rough Beds.

Soulsby, R. L., and J. S. Damgaard (2005), Bedload sediment transport in coastal waters, Coast. Eng., 52(8), 673-689, doi:10.1016/j.coastaleng.2005.04.003.

Splinter, K. D., J. T. Carley, A. Golshani, and R. Tomlinson (2014a), A relationship to describe the cumulative impact of storm clusters on beach erosion, Coast. Eng., 83, 49-55, doi:10.1016/j.coastaleng.2013.10.001.

Splinter, K. D., J. T. Carley, A. Golshani, and R. Tomlinson (2014b), A relationship to describe the cumulative impact of storm clusters on beach erosion, Coast. Eng., 83, 49-55, doi:10.1016/j.coastaleng.2013.10.001.

Sutherland, J., a. H. Peet, and R. L. Soulsby (2004), Evaluating the performance of morphological models, Coast. Eng., 51(8-9), 917-939, doi:10.1016/j.coastaleng.2004.07.015.

Thornton, E. B., R. T. Humiston, and W. Birkemeier (1996), Bar / trough generation on a natural beach, J. Geophys. Res., 101(C5), 12097-12110.

Tolman, H. L. (2002), User manual and system documentation of WAVEWATCH-III version 2.22, NOAA / NWS / NCEP / MMAB Tech. Note, 222, 133.

Wahl, T., and N. G. Plant (2015), Changes in erosion and flooding risk due to long-term and cyclic oceanographic trends, Geophys. Res. Lett., 42(8), 2943-2950, doi:10.1002/2015GL063876.

Walstra, D. J. R., R. Hoekstra, P. K. Tonnon, and B. G. Ruessink (2013), Input reduction for long-term morphodynamic simulations in wave-dominated coastal settings, Coast. Eng., 77, 57-70, doi:10.1016/j.coastaleng.2013.02.001. 
Van Wellen, E., a. . Chadwick, and T. Mason (2000), A review and assessment of longshore sediment transport equations for coarse-grained beaches, Coast. Eng., 40(3), 243-275, doi:10.1016/S0378-3839(00)00031-4.

Yeganeh-Bakhtiary, A., B. Shabani, H. Gotoh, and S. S. Y. Wang (2009), A three-dimensional distinct element model for bed-load transport, J. Hydraul. Res., 47(2), 203-212, doi:10.3826/jhr.2009.3168.

Yuan, J., and O. S. Madsen (2014), Experimental study of turbulent oscillatory boundary layers in an oscillating water tunnel, Coast. Eng., 89, 63-84, doi:10.1016/j.coastaleng.2014.03.007. 


\section{Conclusions and Future Work}

The work presented here focuses on nearshore observations at a field site in Martha's Vineyard, MA that exhibits measurable morphological change over timescales ranging from weeks to years. The most prominent feature at this site is the migrating Katama Inlet, which has a history of breaching, moving east, and closing over the course of a decade. Measurements and numerical simulations of waves, currents, and bathymetry from 2011 to 2016 at this sandy inlet site are used to explore nearshore processes, including wave-current interaction and bathymetric change on a range of spatial and timescales, that could inform studies at other dynamic mixed energy wave and current coastal systems.

Katama Bay and Inlet can be viewed as a channel for flow between Vineyard Sound to the north of the Bay (open via Edgartown Channel) and the Atlantic Ocean to the south (open via Katama Inlet). As such, this thesis focuses on the impacts of waves and currents on sandy coastal environments, rather than specific features of a single-inlet system. The first chapter centers on waves and currents, with field-verified Delft3D simulations used to demonstrate that the observed tidal modulation of wave direction is owing to interaction with tidal currents. The simulations also show that, in a tidally averaged sense, in shallow water near and within the surfzone the changes to wave direction from depth-induced refraction over complex nearshore bathymetry override the changes in wave direction owing to wave-current interaction on the inner shelf.

The second chapter further explores this complex bathymetry, focusing on the curved shoreline at the southeast corner of Martha's Vineyard, which eroded hundreds of meters coincident with 
the inlet opening. Observations of flow fields around this corner reveal a region of flow separation where the strong ebb tide jet to the east of the island separates from the shoreline as it rounds the corner, creating a quiescent zone. The Delft3D model, further validated with these observations, is used to determine the effect of the inlet and the region of flow separation on the sediment transport near the shoreline at the corner. Model results show that the intensity of the flow separation region, controlled by the curvature of the corner, correlates with the amount of erosion and deposition around the corner, with sharper corners producing more intense separation and sediment transport. These results suggest a feedback between corner shape and flow separation. The feedback may end once the inlet wraps around the corner of the island and closes, creating a smoother corner with correspondingly less intense separation.

The third chapter combines observations of waves, currents, and bathymetric change during storm events, as well as observations of shoreline change over timescales of months to understand the impact of storms on inlet evolution. Delft3D simulations of storms with a range of intensities reveal that higher intensity wave events (e.g., hurricanes) cause more bathymetric change than lower intensity wave events (e.g., nor'easters) in this mixed wave-and-tidal current energy system. Further simulations of month-long shoreline change reveal that the presence of storms can enhance inlet migration, and that the sequencing and frequency of these storms may also have an impact on the rate of inlet migration.

\section{Future Work}

The observational data collected in the five years the PVLAB monitored this field site will be instrumental in ongoing studies to refine the characterization of sediment transport in the 
nearshore. With more time and higher computational power, model simulations spanning bathymetric surveys from year to year can be used to test broader ranges of storm frequency and energy to refine the understanding of how these influence nearshore sediment transport. Additionally, long model simulations without waves could be run to test for the existence of a "steady state" for the inlet when only tidal currents drive sediment transport. Results from Chapter 3 suggest that tidal currents alone scour the inlet, potentially keeping it open if waves are not present to accrete the inlet. Whether or not this results in a steady state depends on the currents through the inlet, the asymmetric tidal alongshore currents owing to flow separation (possibly driving net transport east), and the feedback between tidal currents and shoreline erosion at the corner of Chappaquiddick Island.

Year-long simulations also may be useful for exploring seasonal patterns in waves, currents, and bathymetric change at this site, and for simulating the closure of the inlet, which occurred most recently in April 2015. A model able to simulate the inlet closing will require accurate parameterizations of overwash and cross-shore transport, so future work focusing on improving numerical models for these processes could benefit from Katama observations.

Future methodology work also includes determining better wind boundary conditions in the model. Large-scale atmospheric models other than WW3 could supply wind data to the Katamaverified Delft3D model to improve wind and wave simulations before and after Hurricanes Irene and Sandy. These tests could determine the wave and current conditions for which accurate wind boundary conditions are important and for which wind can be neglected. 
The observations and simulations presented here demonstrate the importance of wave-current interactions, inner shelf currents, nearshore and inlet tidal flows, and complex bathymetry to sediment transport and morphological evolution on a sandy shoreline. 


\section{Appendix 1:}

\section{Sediment Transport Implementation in Delft3D}

Sediment transport calculations used to simulate morphodynamics at Katama are based on formulas developed by Van Rijn (1993) and implemented in Delft3D [Lesser et al., 2004]. Here, a brief description of the processes used in the Delft3D sediment module, specific to noncohesive sediment and a $2 \mathrm{DH}$ implementation, is given to inform the results of simulated morphological change discussed in Chapter 3. All constant, user-specified values applied in this study are provided where appropriate.

Sediment motion is treated separately as suspended load (sand moving as a tracer in the water column) or bedload (sand moving in a boundary layer above the bed). A reference level above the bed is used to distinguish between the two types of motion, where sand above this level is considered suspended load and below this level is considered bed load. The reference bed level is given by

$$
a=\min \left[\max \left(c_{1} k_{s}, \frac{\Delta r}{2}, 0.01 h\right), 0.20 h\right]
$$

where

$c_{1}=$ user defined proportionality factor $=1$

$k_{s}=$ user defined current related roughness height $=0.01 \mathrm{~m}$

$\Delta r=$ wave induced ripple height $=0.025 \mathrm{~m}$

$h=$ water depth

The reference bed level is bounded below and above by fractions of the water depth $h$ to ensure a distinction between submerged seafloor and the ambient water column. Above this level, the suspended load formula is a standard advection-diffusion equation tracking sediment 
concentration, with source and sink terms specific to the processes of sand transport. In particular, sources include sand kicked up into the water column from the bed, and sinks include the settling velocity of sediment. Here, settling velocity is given as

$$
w_{s}=\frac{10 v}{D_{50}}\left(\sqrt{1+\frac{0.01(s-1) g D_{50}^{3}}{v^{2}}}-1\right)
$$

where

$v=$ kinematic viscosity coefficient of water

$D_{50}=$ representative diameter of sediment fraction

$s=$ ratio of sediment density $\rho_{s}$ to water density $\rho_{w}$

This sediment sink formulation considers only properties of the ambient water and sand grain to describe a downward flux owing to gravitational forces.

The source term of sand is modeled as a diffusion process, with a vertical diffusive flux calculated using the turbulence closure formula specified by the user. Here, with the model in 2DH mode, the vertical eddy diffusivity is a constant supplied by the user. The vertical diffusive flux $E$, with this constant set as default $\epsilon_{s}=10 \mathrm{~m}^{2} / \mathrm{s}$, is determined by

$$
E=\epsilon_{s}\left(\frac{\partial c}{\partial z}\right)
$$

The implementation of this partial differential equation requires a vertical profile of sediment concentration near the bed. In 2D mode, this cannot be explicitly calculated. Instead, it is assumed to be a standard parabolic profile given as

$$
c(z)=c_{a}\left[\frac{a(h-z)}{z(h-a)}\right]^{A}
$$

where

$c(z)=$ concentration of sediment fraction 
$c_{a}=$ user - defined reference concentration of sediment fraction (see below)

$z=$ elevation above bed

$A=\frac{\mathrm{w}_{\mathrm{s}} u_{*}}{\kappa}$

$\kappa=$ von - Karman constant $=0.4$

$u_{*}=$ bed shear velocity

The reference concentration $c_{a}$ of sand at the reference height $a$ sets the bounds of the vertical sediment profile, and is determined by

$$
c_{a}=0.015 \rho_{s} \frac{D_{50} T_{a}^{1.5}}{a D_{*}^{0.3}}
$$

where

$D_{*}=D_{50}\left[\frac{(s-1) g}{v^{2}}\right]^{\frac{1}{3}}=$ non-dimensional particle diameter

$T_{a}=\frac{\left(\mu_{c} \tau_{b, c w}+\mu_{w} \tau_{b, w}\right)-\tau_{c r}}{\tau_{c r}}=$ non-dimensional bed shear stress

The components of the non-dimensional bed stress incorporate the effects of both waves

(subscript $w$ ) and currents (subscript $c w$ ) on the bed, characterized as efficiency factors $(\mu$ ) and shear stress values $(\tau)$. These are given by Van Rijn (1993) for currents, which rely on a "current-related" friction factor $\left(f_{c}\right)$ as follows

$$
\begin{gathered}
\tau_{b, c w}=\rho_{w} u_{*}^{2} \\
\mu_{c}=\frac{f_{c}{ }^{\prime}}{f_{c}}
\end{gathered}
$$

where

$$
\begin{aligned}
& f_{c}^{\prime}=0.24\left[\log _{10}\left(\frac{12 h}{3 D_{90}}\right)\right]^{-2} \\
& f_{c}=0.24\left[\log _{10}\left(\frac{12 h}{k_{s}}\right)\right]^{-2}
\end{aligned}
$$


and

$D_{90}=1.5 D_{50}$

The shear stress owing to currents depends primarily on simulated bed shear velocities (from Delft3D -FLOW) and on an approximated bed roughness (comparing $D_{90}$, which characterizes the largest sediment grain sizes in a bed, to $k_{s}$, which characterizes a user-defined roughness height, in the friction factor above). This approximation of bed roughness is one of many aspects of the sediment transport module which could be improved with more detailed formula (as opposed to a simple coefficient), though for the purposes of this study the default method and value of $k_{s}$ works well (see Chapter 3).

For waves, the expressions are similar, using a "wave-specific" friction factor $\left(f_{w}\right)$ which depends on the characteristics of the wave field calculated in Delft3D-WAVE

$$
\begin{gathered}
\tau_{b, w}=\frac{1}{2} \rho_{w} f_{w}\left(U_{\delta}\right)^{2} \\
\mu_{w}=\max \left(0.063, \frac{1}{8}\left(1.5-\frac{H_{s}}{h}\right)^{2}\right)
\end{gathered}
$$

where

$U_{\delta}=$ peak orbital velocity at the bed

$f_{w}=\exp \left(-6+5.2\left(\frac{A_{\delta}}{k_{s, w}}\right)^{-0.19}\right)$

$H_{s}=$ significant wave height

$k_{s, w}=$ user - defined wave roughness $=0.05$

$A_{\delta}=\frac{T_{p} U_{\delta}}{2 \pi}=$ peak orbital excursion at bed

$T_{p}=$ wave period 
To produce the non-dimensional shear stress $T_{a}$, the formulas for shear stress produced by waves and currents are compared to the critical shear stress for sediment motion

$$
\tau_{c r}=\left(\rho_{s}-\rho_{w}\right) g D_{50} \theta_{c r}
$$

where $\theta_{c r}$ is the threshold Shield's parameter approximated for different non-dimensional sediment diameters $D_{*}$. The Shield's parameter is an empirical relationship between sediment properties and a threshold of shear stress needed for bed motion. This relationship is often shown in graphical form, but for the purposes of a numerical model it must be distilled into approximate equations. The constants used in general form of this equation change between given ranges of values for $D_{*}$, with the general expression given as

$$
\theta_{c r}=C_{1} D_{*}^{C_{2}}
$$

The constants $C_{1}$ and $C_{2}$ are different for a given range of sediment diameters, highlighting the empirical nature of this relationship.

Though the calculation of suspended sediment transport is divided into several different components seen above, thse describe a straightforward process by which sand is being kicked up into the water column (a balance of shear stress owing to waves and currents vs. critical shear stress of motion), moved as a passive tracer once it is in the water column, and pulled back to the bed via gravitational forces (settling velocity).

Bedload transport is given as a more condensed formula, though with similar dependence on critical shear stress values. In this case, calculating the bedload transport magnitude requires a comparison of near-bed shear velocities and the critical shear velocity which matches to the 
Shield's parameter for the type of sand grain at the bed. The general formula for bedload magnitude is given as [Van Rijn, 1993]

$$
S_{b}=0.006 \rho_{s} w_{s} D_{50} M^{0.5} M_{e}^{0.7}
$$

where

$M=\frac{v_{e f f}^{2}}{(s-1) g D_{50}}=$ sediment mobility number owing to waves and currents

$M_{e}=\frac{\left(v_{e f f}-v_{c r}\right)^{2}}{(s-1) g D_{50}}=$ excess mobility number

$v_{e f f}=\sqrt{\left(v_{R}^{2}+U_{o n}^{2}\right.}$

and

$v_{c r}=$ critical depth - averaged velocity based on the Shield's curve [Van Rijn, 1985]

$v_{R}=$ depth - averaged velocity

$U_{\text {on }}=$ near - bed orbital velocity based on significant wave height

The values for velocities owing to waves and currents are supplied to the sediment transport module by Delft3D (FLOW and WAVE). Since $S_{b}$ only describes the amount of sand being moved, it is further split into wave and current components to calculate the direction of the transport owing to each of these factors (one component acting in the direction of near-bed currents, the other in the direction of wave propagation). Similarly, suspended sediment is also split into two components, one corresponding to the direction of waves and the other to the direction of currents.

The expression for the total sediment transport is therefore a sum of four components: suspended load in the direction of waves $\left(S_{s, w}\right)$, suspended load in the direction of currents $\left(S_{S, c}\right)$, bedload in 
the direction of waves $\left(S_{b, w}\right)$, and bedload in the direction of currents $\left(S_{b, c}\right)$. These final sediment transport values are multiplied by tuning constants before being re-combined into the final transport sum, as seen below

$$
S_{\text {total }}=c_{u 1} S_{s, w}+c_{u 2} S_{s, c}+c_{u 3} S_{b, w}+c_{u 4} S_{(b, s)}
$$

The tuning parameters $c_{u}$ allow the user to calibrate the final transport calculations to better resemble any data at hand. These coefficients are the calibration parameters mentioned most often in Chapter 3 and associated appendices, as they help account for processes not explicitly mentioned in the sediment transport formula (such as detailed asymmetry/skewness and wave streaming).

The model accounts for the effects of bed slope. A user can choose one of several different formulations to calculate a coefficient which, when multiplied with bedload transport, either enhances or reduces transport in a particular direction.

The convergence and divergence of the resulting sediment transport vectors indicates the locations of erosion and deposition in the domain. Delft3D performs a series of extra checks to ensure the stability of these calculations, including setting cells with accretion above the water level to be "dry" (i.e. land) and that all sediment calculations are performed in depths greater than a user-defined threshold depth (in this case, $0.1 \mathrm{~m}$ ). 


\section{References}

Lesser, G. R., J. A. Roelvink, J. a. T. M. van Kester, and G. S. Stelling (2004), Development and validation of a three-dimensional morphological model, Coast. Eng., 51, 883-915, doi:10.1016/j.coastaleng.2004.07.014.

Van Rijn, L. (1985), Sediment Transport, Part I: Bed Load Transport, J. Hydraul. Eng., 110(10), 1431-1456.

Van Rijn, L. (1993), Principles of Sediment Transport in Rivers, Estuaries and Coastal Seas, Aqua Publishing, Blokzijl, Netherlands. 


\section{Appendix 2:}

\section{Delft3D Morphodynamic Validation}

\section{1) Delft3D Morphological Models}

Observations of waves, currents, and bathymetry acquired at Katama Inlet during Hurricanes Irene and Sandy were used to evaluate sediment transport and morphological updating in Delft3D. The default sediment transport formulation, TRANSPOR2000 ([van Rijn, 2000]), was used in all model tests. TR2000 calculates separately bed load and suspended load owing to waves and currents. For bedload, it uses wave-orbital velocities and near-bed mean currents to determine a critical bed stress for sediment motion. For suspended load, an advection-diffusion equation is used to move sediment in the water column. As applied here in 2DH mode, the turbulence closure options are limited to a user-prescribed constant eddy viscosity and diffusivity (default values used). All model parameters were set to default values except the sediment grain size (D50 $=500 \mu \mathrm{m}$ ), the inclusion of a stationary wave roller model, and the tuning of waveand current-related transport coefficients (the default coefficients of 1 produced unrealistic transport patterns).

More recently, TRANSPOR2004 was released in updated open source versions of Delft3D. Unlike TR2000, TR2004 includes parameterizations of the effects of bed roughness owing to megaripples and dunes on bed shear stress owing to wave-orbital velocities. Thus, TR2004 is more appropriate in deeper waters with dunes and larger bedforms than occur in the shallow depths of interest around Katama. Moreover, previous work shows relatively small differences in simulated sediment transport between the two approaches ([Van Rijn et al., 2004]). 


\section{2) Metrics for Validation}

The Brier Skill Score is used to compare the relative skill of different simulations, similar to other 2DH numerical morphological studies ([Ganju and Schoellhamer, 2009; Ganju et al., 2011; Ranasinghe et al., 2011; Daly et al., 2014; Luijendijk et al., 2017]). The skill score is defined in discrete form as

$$
B S S=1-\frac{\sum\left(\Delta z_{o}-\Delta z_{m}\right)}{\sum\left(\Delta z_{o}\right)}
$$

where $\Delta z_{o}$ is the observed and $\Delta z_{m}$ is the modeled bathymetric change. A BSS $=1$ indicates perfect model skill. A BSS $<1$ indicates the simulated morphological evolution diverges from the observations. The score can be used to examine in more detail how model and data disagree (or not) as follows ([Sutherland et al., 2004])

$$
\begin{gathered}
B S S=\frac{\alpha-\beta-\gamma+\epsilon}{1+\epsilon} \\
\alpha=\left(\frac{\operatorname{cov}\left(\Delta z_{o}, \Delta z_{m}\right)}{\sigma_{\Delta z_{o}} \sigma_{\Delta z_{m}}}\right)^{2} \\
\beta=\left(\sqrt{\alpha}-\frac{\sigma_{\Delta z_{m}}}{\sigma_{\Delta z_{o}}}\right)^{2} \\
\gamma=\left(\frac{\left\langle\Delta z_{m}\right\rangle-\left\langle\Delta z_{o}\right\rangle}{\sigma_{\Delta z_{o}}}\right)^{2} \\
\epsilon=\left(\frac{\left\langle\Delta z_{o}\right\rangle}{\sigma_{\Delta z_{o}}}\right)^{2}
\end{gathered}
$$


where $\sigma$ is the standard deviation, $\alpha$ shows how well the model simulates sand location ( $\alpha=1$ is considered good), $\beta$ shows how well the model simulates the volume of sand moved ( $\beta=0$ is considered good), $\gamma$ shows how well the model simulates the average bed level ( $\gamma=0$ is good), and $\epsilon$ is a normalization term. Both forms of the BSS are used here to compare numerical simulations with observations of bathymetric change during Hurricanes Irene and Sandy

\section{(Chapter 3).}
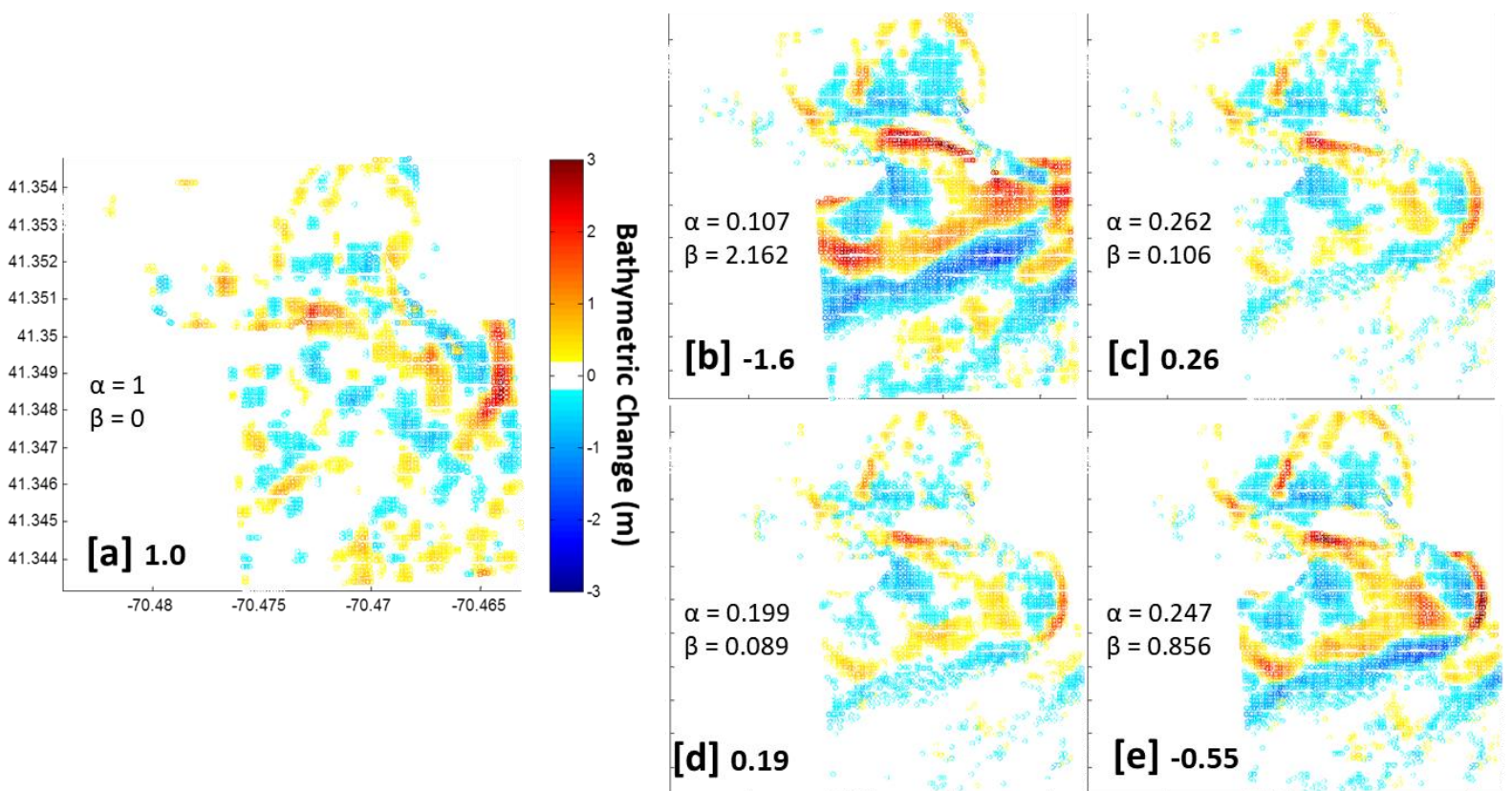

Figure 1: Bathymetric change contours (red = accretion, blue = erosion, scale on the right) owing to Hurricane Irene for (a) observations, (b) model simulations without wind, (c) model simulations with wind, (d) model simulations with wind and new transport coefficients, and (e) model simulations with wind and including the week of bathymetric change before Irene. The Brier Skill Score is indicated in bold (lower left) with the components of the skill score above ( $\alpha$ $=$ location error and $\beta=$ magnitude error). 


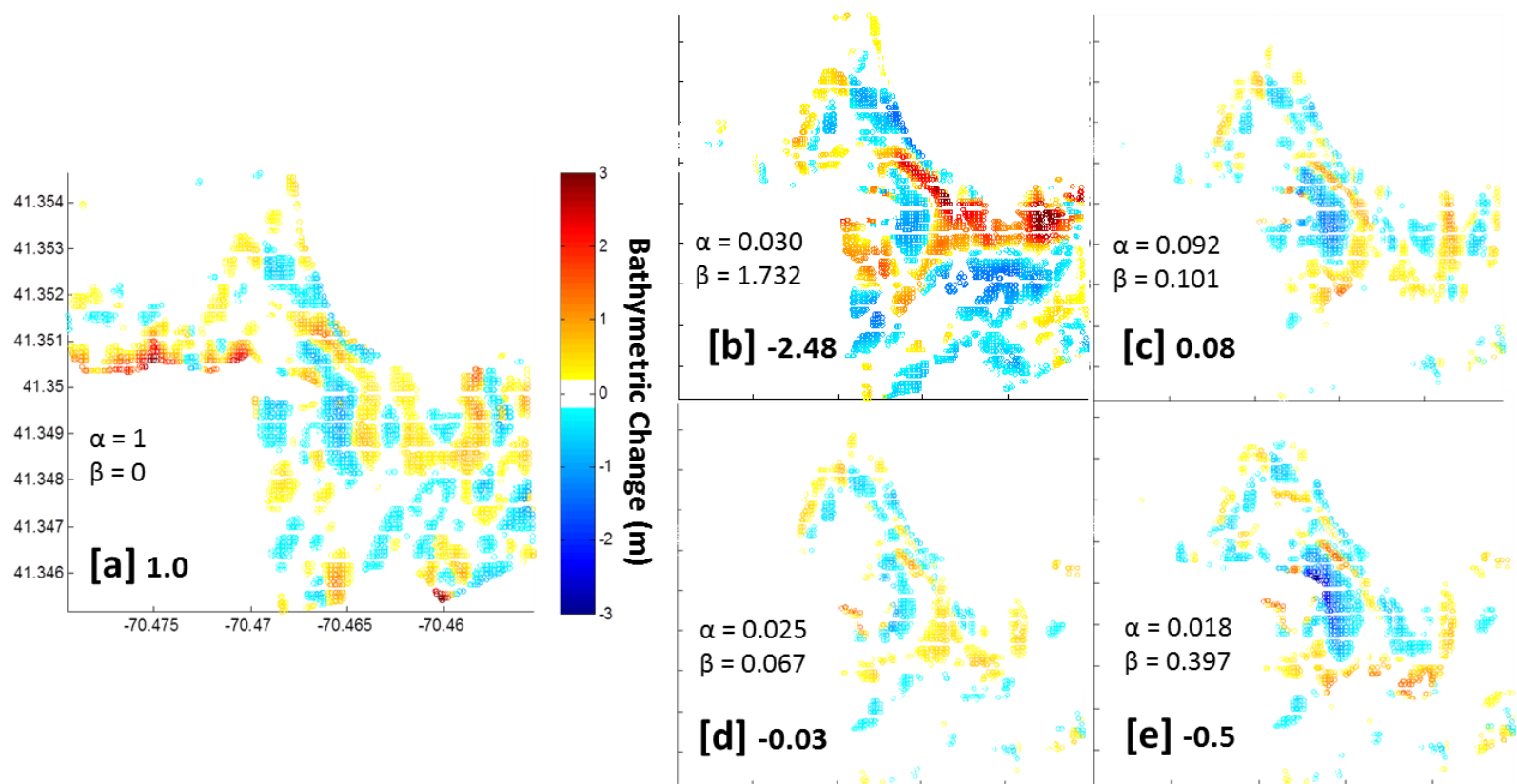

Figure 2: Bathymetric change contours (red = accretion, blue = erosion, scale on the right) owing to Hurricane Sandy for (a) observations, (b) model simulations without wind, (c) model simulations with wind, (d) model simulations with wind and new transport coefficients, and (e) model simulations with wind and including the nor'easter which occurred after the hurricane. The Brier Skill Score is indicated in bold (lower left) with the components of the skill score above ( $\alpha=$ location error and $\beta=$ magnitude error).

\section{3) Irene and Sandy}

Model skill, according to the BSS, is higher for Hurricane Irene than Sandy, but relatively low for each compared with an ideal BSS ("excellent" is classified as a BSS $>0.5$, "good" is a BSS > 0.2, and "fair" BSS > 0.1 [Luijendijk et al., 2017]). Although the simulated bathymetric change is qualitatively consistent with the observed changes (Figures 3-5 in Chapter 3), the best BSS for these runs fall into either the "good" or "fair" category. Some of the error could be owing to the (not modeled) morphological evolution that occurred during the times between the bathymetric surveys and the 6-day periods around the storms that were simulated.

Breaking the BSS into its components for each model run reveals that most of the error is in the $\alpha$ term, or the spatial discrepancies between model and data (Figures 1 and 2). This is likely a 
consequence of transforming the observed pre-storm bathymetry (surveyed in a relatively small area near the inlet) to both fit on the model 13 -m grid and mesh smoothly with previously observed bathymetry outside of the pre-storm survey area. As a result, the pre-storm bathymetry used in the model was distorted slightly in space relative to surveyed pre-storm bathymetry, and likewise the change in bathymetry from pre- to post-storm had the same distortion, leading to errors in the location of bathymetric features between model and data.

The model skill is higher for Hurricane Irene than Hurricane Sandy, possibly because the spatial shift arising from putting the observed bathymetry on the model grid was reduced by the $60 \%$ larger spatial extent of the pre- and post- Hurricane Irene bathymetric surveys.

Additionally, the peak of each storm occurred at different phases of the tidal cycle, which could impact the response to the storm-force waves. However, overall bathymetric evolution during the storms did not change significantly if the time series of waves on the boundary was shifted 6 hours, suggesting that storm timing did not have a significant impact.

\section{4) Coefficient Calibration}

The sediment transport model in Delft3D is a parameterized equation based on the initiation of motion of sand owing to shear stress, and relies on bulk parameters averaged over several sand grains to describe the motion of sediment in a large area. As such, the transport equations must be "tuned" to specific field sites to account for the physics not captured by the parameterizations. The four parameters that describe the relative importance of bed or suspended loads owing to either waves or currents were adjusted in TR2000 to match observations at the Katama site. All 
coefficients have default values of 1.0, but previous studies ([Daly et al., 2014]; among others) have suggested reducing the coefficients of wave-driven transport by a factor of 10 .

Simulations of the bathymetric change during the hurricanes using 1.0 for current-related coefficients and 0.1 for wave-related coefficients were similar to observations. However, using these coefficients for simulations of the morphological evolution between December 2012 and February 2013 (see Chapter 3) resulted in less accretion near the inlet and southern shoreline of Chappaquiddick Island than was observed. Reducing the current coefficients reduced the erosion around the inlet, whereas increasing the wave coefficients enhanced accretion around the inlet and the eastern side of Norton Point (Chapter 3, Figure 11). The coefficients (wave $=0.200$, current $=0.125)$ that best reproduced the observed accretion were determined with an iterative process that began with doubling the wave coefficient, comparing two months of change between model and data, and adjusting the current coefficient in response. Bathymetric change during the hurricanes simulated with the original values for the coefficients is similar to the change simulated with coefficients tuned to the evolution observed over 2 winter months (compare Figure 1c with 1d and Figure 2c with 2d).

\section{5) Boundary Condition Calibration}

Standard boundary conditions for model runs included observed waves (from a buoy in 50-m water depth or from WW3 model output, see Chapter 1) and satellite-derived tidal constituents [Egbert and Erofeeva, 2002]. Optional boundary conditions include wind and atmospheric pressure during storms. Observed winds were spatially sparse (with only one station on Martha's Vineyard and one station on Nantucket for the entire model domain), so WW3 winds were used 
in the model where possible and when they could be verified with observations. Wind coefficients in the model were left at default values. Similarly, WW3 pressure fields were used in model simulations. Neither wind nor pressure were included in idealized model runs which did not simulate a specific observed morphological change.

Comparisons between runs of Hurricanes Irene and Sandy with and without wind show significantly greater skill with the inclusion of wind (Figures 1b with 1c and Figure 2b with 2c). Including spatially varying atmospheric pressure did not result in significant improvement in model skill (not shown).

\section{6) Calibration to Full Observation Period}

The effects of including the full time series (big and small waves) between the surveys were evaluated when computationally reasonable. Bathymetry was measured 3 weeks before and 2 days after Hurricane Irene, as well as immediately before Hurricane Sandy and then 7 days later after the passage of a small nor'easter. The weeks before Irene and the nor'easter after Sandy were included in hurricane simulations with available boundary conditions and compared to simulations of each hurricane alone.

Increasing the duration of the pre-Irene waves, winds, and currents to include the 3 weeks before the storm and the 6 days during the storm was computationally prohibitive. A complete simulation was run starting 1 week immediately prior to Irene and continuing through the 6-day storm simulation to determine the change in model skill with a reduced amount of pre-storm conditions. 

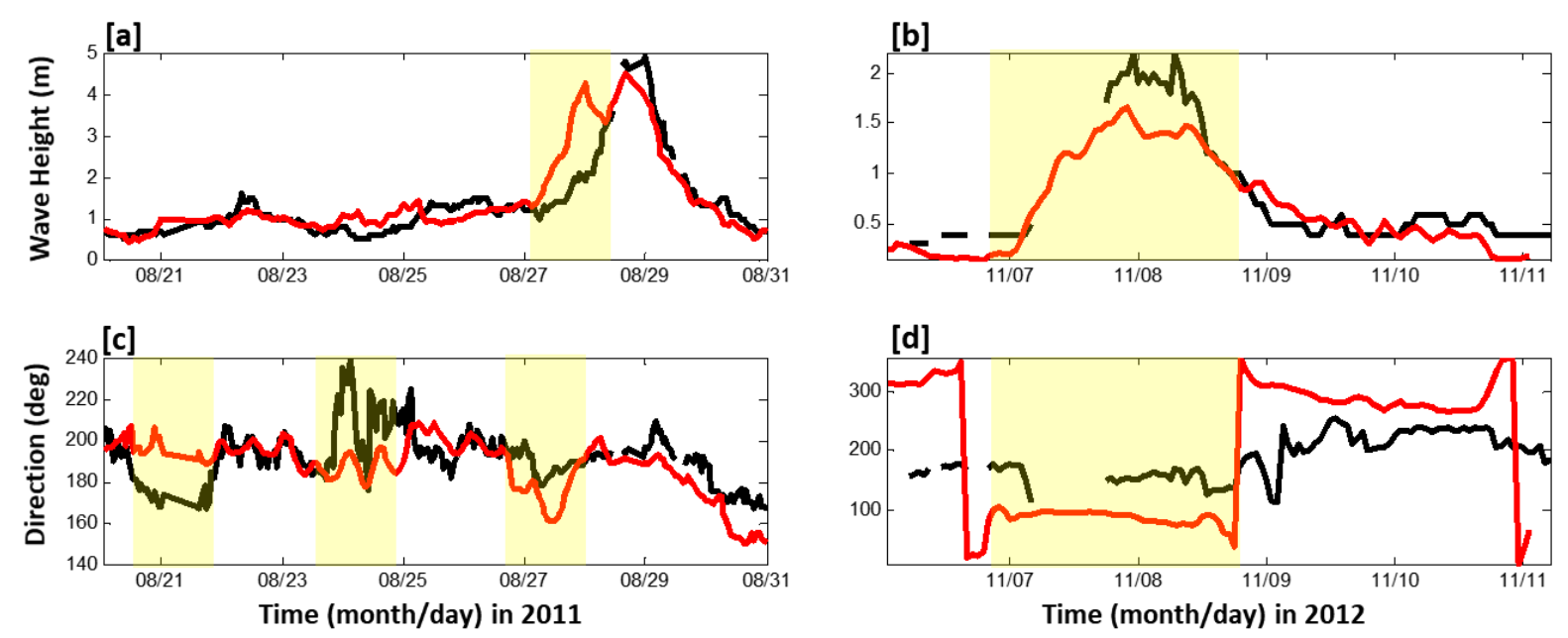

Figure 3 Observed (black) and simulated (red) (a,b) significant wave height and (c,d) wave direction versus time in 12-m water depth at MVCO during $(a, c)$ Hurricane Irene and (b,d) a nor' easter after Hurricane Sandy.

WW3 predictions of winds and wave directions can be inaccurate at some locations along the boundaries of the model domain, and thus the waves simulated with and without wind before Hurricane Irene (Figure 3 a,c) and during the nor'easter after Hurricane Sandy (Figure 3b,d) are not accurate in $12 \mathrm{~m}$ depth. Consequently, the model skill for simulating morphological change between the surveys did not increase (and occasionally decreased) with these longer time series (compare Figure 1c with 1e and Figure 2c with 2e). As with hurricanes, wind is likely important to simulate observed morphological change owing to nor'easters (post-Sandy) and leading into hurricanes (pre-Irene). The effect of wind on waves, as seen at MVCO, was inaccurate during the nor' easter when the model was forced with wind conditions from WW3

(Figure 3a,b). Model simulations without wind and waves (pre-Irene) and without wind (postSandy) (not shown) did not perform better.

The skill of simulations that included a few-day period around a hurricane, but not the sediment transport that may have occurred in the several weeks before or after the hurricane (when 
bathymetric surveys were obtained) suggests that wave and current conditions during a storm are the primary driver of sediment transport (Figures 1 and 2, compare (a) and (c-d)). Simulations that include accurate boundary conditions for all the time between surveys (before and after the hurricanes) would increase model skill compared with the surveys, but the bulk of the transport occurs during the storm events. 


\section{References}

Daly, C. J., K. R. Bryan, M. R. Gonzalez, A. H. F. Klein, and C. Winter (2014), Effect of selection and sequencing of representative wave conditions on process-based predictions of equilibrium embayed beach morphology, Ocean Dyn., 64(6), 863-877, doi:10.1007/s10236014-0730-9.

Egbert, G. D., and S. Y. Erofeeva (2002), Efficient Inverse Modeling of Barotropic Ocean Tides, J. Atmos. Ocean. Technol., 19, 183-204.

Ganju, N. K., and D. H. Schoellhamer (2009), Calibration of an estuarine sediment transport model to sediment fluxes as an intermediate step for simulation of geomorphic evolution, Cont. Shelf Res., 29(1), 148-158, doi:10.1016/j.csr.2007.09.005.

Ganju, N. K., S. J. Lentz, A. R. Kirincich, and J. T. Farrar (2011), Complex mean circulation over the inner shelf south of Martha's Vineyard revealed by observations and a highresolution model, J. Geophys. Res., 116(C10), C10036, doi:10.1029/2011JC007035.

Luijendijk, A. P., R. Ranasinghe, M. A. de Schipper, B. A. Huisman, C. M. Swinkels, D. J. R. Walstra, and M. J. F. Stive (2017), The initial morphological response of the Sand Engine: A process-based modelling study, Coast. Eng., 119(July 2016), 1-14, doi:10.1016/j.coastaleng.2016.09.005.

Ranasinghe, R., C. Swinkels, A. Luijendijk, D. Roelvink, J. Bosboom, M. Stive, and D. Walstra (2011), Morphodynamic upscaling with the MORFAC approach: Dependencies and sensitivities, Coast. Eng., 58(8), 806-811, doi:10.1016/j.coastaleng.2011.03.010.

van Rijn, L. C. (2000), General view on sand transport by currents and waves: data analysis and engineering modelling for uniform and graded sand (TRANSPOR 2000 and CROSMOR 2000 models).

Van Rijn, L. C., D. J. R. Walstra, and M. Van Ormondt (2004), Description of TRANSPOR2004 and Implementation in Delft3D-ONLINE.

Sutherland, J., a. H. Peet, and R. L. Soulsby (2004), Evaluating the performance of morphological models, Coast. Eng., 51(8-9), 917-939, doi:10.1016/j.coastaleng.2004.07.015. 


\section{Appendix 3:}

\section{Wave Reduction Method}

Morphological acceleration factors (MORFACs) are used to reduce the computational cost of numerical simulations of morphological evolution ([Lesser et al., 2004]). The procedure assumes the sediment transported by a specific set of hydrodynamic conditions can be multiplied by a factor MORFAC $=n$ to estimate the sediment transported by $n$ realizations of these conditions. Thus MORFAC $=1$ is the model simulation run in full, whereas MORFAC $=10$ is the model run with the sediment transport accelerated 10-times. The use of a MORFAC must be validated against a full model run for any given environment because it applies a linear acceleration to a nonlinear process.

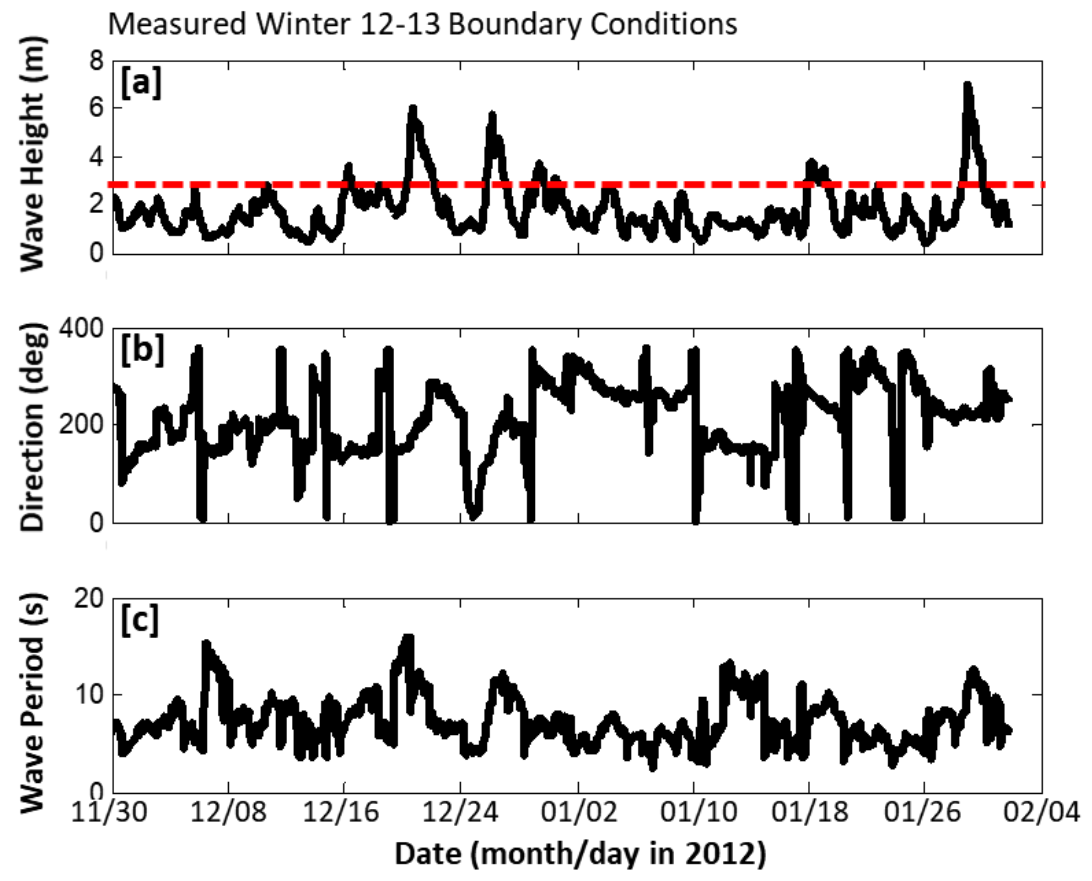

Figure 1: (a) Significant wave height, (b) mean wave direction, and (c) peak wave period at the NOAA buoy 44097 located in 50-m water depth versus time. The red dashed line in (a) marks the storm wave height threshold $(\mathrm{Hsig}=3 \mathrm{~m})$.

Here, boundary conditions (the 3 parameters: wave height, direction, and period, Figure 1) for the winter of 2012-13 were estimated every hour from observations from a NOAA buoy (44097) 
located in $50 \mathrm{~m}$ depth offshore of Katama Bay. There are many methods to condense these conditions for different values of MORFAC ([Yeganeh-Bakhtiary et al., 2009; Ganju et al., 2011; Ranasinghe et al., 2011; Hansen et al., 2013; Daly et al., 2014]). Here, with MORFAC = 10, the significant wave height was divided into a histogram of 10 equally sized bins spanning the range of observed wave heights. The most commonly occurring period and direction in each wave height bin were selected as the representative period and direction for that wave height. The boundary conditions consist of a reduced (by MORFAC) set of wave heights, periods, and directions from each bin, with the number of hours comprising wave conditions from each bin occurring in proportion to the number of wave conditions of that size in the full time series.

The end result is a time series that is a fraction of the length of the original, in this case one-tenth as long, with wave heights chosen from the ten bins based on frequency, and wave direction and period chosen within each of these ten bins to match the wave heights. The time series can then be randomly distributed (keeping triples of height, direction, and period together) or clustered to distribute storm conditions as desired. Significant wave heights greater than $3 \mathrm{~m}$ on the boundary are considered to be storm conditions.

The boundary condition can consist also of a mixed MORFAC. For example, for some model runs here, MORFAC $=10$ is applied to the non-storm waves and MORFAC $=1$ is applied during storms $(H s i g>3 \mathrm{~m})$. The simulated morphological evolution is similar with MORFAC=1, a mixed MORFAC, and MORFAC $=10$ (Figure 10, Chapter 3). The effects of the sequence and spacing of storms can be investigated by shifting the timing of the storms to be closer together or farther apart in the simulation run. 


\section{References}

Daly, C. J., K. R. Bryan, M. R. Gonzalez, A. H. F. Klein, and C. Winter (2014), Effect of selection and sequencing of representative wave conditions on process-based predictions of equilibrium embayed beach morphology, Ocean Dyn., 64(6), 863-877, doi:10.1007/s10236014-0730-9.

Ganju, N. K., B. E. Jaffe, and D. H. Schoellhamer (2011), Discontinuous hindcast simulations of estuarine bathymetric change: A case study from Suisun Bay, California, Estuar. Coast. Shelf Sci., 93(2), 142-150, doi:10.1016/j.ecss.2011.04.004.

Hansen, J. E., E. Elias, J. H. List, L. H. Erikson, and P. L. Barnard (2013), Tidally influenced alongshore circulation at an inlet-adjacent shoreline, Cont. Shelf Res., 56, 26-38, doi:10.1016/j.csr.2013.01.017.

Lesser, G. R., J. A. Roelvink, J. a. T. M. van Kester, and G. S. Stelling (2004), Development and validation of a three-dimensional morphological model, Coast. Eng., 51, 883-915, doi:10.1016/j.coastaleng.2004.07.014.

Ranasinghe, R., C. Swinkels, A. Luijendijk, D. Roelvink, J. Bosboom, M. Stive, and D. Walstra (2011), Morphodynamic upscaling with the MORFAC approach: Dependencies and sensitivities, Coast. Eng., 58(8), 806-811, doi:10.1016/j.coastaleng.2011.03.010.

Yeganeh-Bakhtiary, A., B. Shabani, H. Gotoh, and S. S. Y. Wang (2009), A three-dimensional distinct element model for bed-load transport, J. Hydraul. Res., 47(2), 203-212, doi:10.3826/jhr.2009.3168. 